\title{
Structural and functional characterisation of
}

\author{
$\mathrm{M} / \mathrm{T}$ cells using $\mathrm{Ca}^{2+}$ Imaging \\ and Activity Correlation Imaging \\ in dendritic networks \\ of the developing Xenopus brain
}

\author{
Dissertation \\ for the award of the degree \\ "Doctor rerum naturalium" (Dr. rer. nat.) \\ of the Georg-August-Universität Göttingen \\ within the GGNB doctoral program \\ "Molecular Physiology of the Brain" \\ submitted by \\ Camille Inès Alexandra Okom \\ born in \\ Strasbourg, France
}

Göttingen

2016 


\section{Thesis Committee}

\section{Prof. Dr. Dr. Detlev Schild}

Institute of Neurophysiology and Cellular Biophysics, University Medical Center, Göttingen

Prof. Dr. André Fiala

Department of Molecular Neurobiology of Behavior,

Johann-Friedrich-Blumenbach-Institute for Zoology and Anthropology, Göttingen

Prof. Dr. Nils Brose

Department of Molecular Neurobiology, Max Planck Institute of Experimental Medicine, Göttingen

Members of the Examination Board

Prof. Dr. Michael Hörner

European Neuroscience Institute Göttingen, Göttingen

Prof. Dr. Swen Hülsmann

Clinic for Anesthesiology, University Medical Center, Göttingen

Prof. Dr. Stefan Schütz

Dept. of Forest Zoology and Forest Conservation, Büsgen-Institute, Göttingen

\section{Date of thesis submission:}

Friday, October 28, 2016

Date of oral examination:

Friday, December 9, 2016 
I hereby declare that the $\mathrm{PhD}$ dissertation entitled "Structural and functional characterisation of $\mathrm{M} / \mathrm{T}$ cells using $\mathrm{Ca}^{2+}$ Imaging and Activity Correlation Imaging in dendritic networks of the developing Xenopus brain" was written independently and with no other sources and aids than quoted.

Göttingen, October 28, 2016

Parts of the results reported in this thesis have been published in the formats below:

Brinkmann, A.*, Okom, C.*, Kludt, E. and Schild, D. (2016). Recording Temperatureinduced Neuronal Activity through Monitoring Calcium Changes in the Olfactory Bulb of Xenopus laevis. JoVE (Journal of Visualized Experiments), (112), e54108-e54108.

Kludt, E., Okom, C*., Brinkmann, A.* and Schild, D. (2015). Integrating temperature with odor processing in the olfactory bulb. Journal of Neuroscience, 35(20): 7892-7902.

*The authors contributed equally to these studies. 
To the only GOD, our Saviour, through Jesus Christ our Lord, be glory, majesty, dominion and authority, before all time and now and forever. Amen. 


\section{Contents}

$\begin{array}{lr}\text { List of Figures and Tables } & 6\end{array}$

$\begin{array}{lr}\text { List of abbreviations } & 8\end{array}$

$\begin{array}{lr}\text { Summary } & 9\end{array}$

1 Introduction $\quad 11$

1.1 The sense of smell . . . . . . . . . . . . . . . . 11

1.2 The olfactory system of Xenopus laevis . . . . . . . . . . . . . . 12

1.2 .1 Olfactory epithelium . . . . . . . . . . . . 12

1.2 .2 Glomerular layer . . . . . . . . . . . . . . . 14

1.2.3 Mitral/tufted and granule cell layers . . . . . . . . . . . . 16

1.3 Non-chemical olfaction . . . . . . . . . . . . . . . . 18

1.3.1 Mechanosensitivity ..................... 18

1.3.2 Thermosensitivity . . . . . . . . . . . . . 19

1.4 Inhibition in the olfactory bulb . . . . . . . . . . . . 21

1.4.1 The role of periglomerular cells . . . . . . . . . . . 23

1.4.2 The role of granule cells . . . . . . . . . . . . 25

1.5 Scope of the thesis . . . . . . . . . . . . . . 28

2 Materials and Methods $\quad 29$

2.1 Nose-brain acute slices . . . . . . . . . . . . . . . . . 29

2.2 Calcium imaging and pharmacological treatment in acute slices . . . . . . . 29

2.3 Stimulus application . . . . . . . . . . . . . . 30

2.4 Single-cell filling and morphological reconstruction . . . . . . . . . . . . 31

2.5 Data analysis and processing . . . . . . . . . . . . . 31

$2.5 .1 \Delta \mathrm{F} / \mathrm{F}$ and response criterion $\ldots \ldots \ldots \ldots \ldots \ldots$

2.5 .2 Fourier analysis . . . . . . . . . . . . . . 32

2.5.3 Activity Correlation Imaging . . . . . . . . . . . . . . 32

2.6 Cell electroporation of ORNs . . . . . . . . . . . . . . . . 34

2.7 Nose-brain explant (whole-mount preparation) $\ldots \ldots$. . . . . . . 34 
2.8 Anti-GABA immunohistochemistry . . . . . . . . . . . . 35

2.9 Combined electrophysiological and calcium imaging recordings . . . . . . . 37

2.9.1 Depolarising pulses and fitting of $\mathrm{Ca}^{2+}$ spikes . . . . . . . . 38

3 Results $\quad 39$

3.1 Dual sensitivity and structure-function relationship of $\mathrm{M} / \mathrm{T}$ cells . . . . . . 39

3.1.1 Glomerular innervation patterns of $\mathrm{M} / \mathrm{T}$ cells $\ldots . . . . . .39$

3.1 .2 Chemosensitivity in the $\mathrm{OB} \ldots \ldots \ldots$. . . . . . . . 41

3.1.3 Temperature sensitivity in the OB . . . . . . . . . . . 41

3.1.4 Integration of temperature and odour signals in $\mathrm{M} / \mathrm{T}$ cellular networks 45

3.2 The effects of GABAergic inhibition on M/T cell dynamics . . . . . . . . . 48

3.2.1 Localisation of GABA in the OB at larval stages $49-54$. . . . . . . 48

3.2.2 The influence of gabazine on $\mathrm{M} / \mathrm{T}$ cell odour-evoked activities . . . . 51

3.2.3 The influence of gabazine on $\mathrm{M} / \mathrm{T}$ cell oscillations and synchrony . 57

3.2.4 The influence of gabazine on $\mathrm{M} / \mathrm{T}$ cell baseline $\left[\mathrm{Ca}^{2+}\right]$ levels . . . . 63

3.3 Backpropagating $\mathrm{Ca}^{2+}$ signals and correlation analysis in dendritic sub-

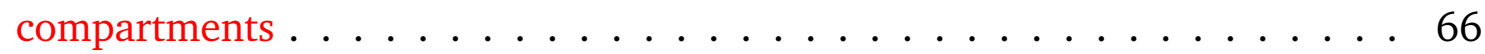

3.3.1 Backpropagation of somatically evoked spikes in M/T cell dendrites . 66

3.3.2 Correlation analysis of $\mathrm{Ca}^{2+}$ fluctuations along $\mathrm{M} / \mathrm{T}$ cell dendrites . . 71

3.3.3 Activity Correlation Imaging of the dendrites of $\mathrm{M} / \mathrm{T}$ cells $\ldots$. . . . 77

4 Discussion $\quad 81$

4.1 Integration of thermic and chemosensory inputs . . . . . . . . . . . 81

4.2 The role of GABA-mediated inhibition . . . . . . . . . . . . 82

4.3 Localisation of inhibitory synapses on the dendrites of M/T cells . . . . . . 85

5 Bibliography $\quad 86$

$\begin{array}{ll}\text { Acknowledgements } & 105\end{array}$

$\begin{array}{ll}\text { Curriculum Vitae } & 107\end{array}$ 


\section{List of Figures}

1.1 The olfactory system of larval $X$. laevis . . . . . . . . . . . . 13

1.2 Organisation of the MOB (horizontal section) . . . . . . . . . . 15

1.3 The $\gamma$-glomerulus, a thermosensitive neuropil in the larval Xenopus brain 20

1.4 Periglomerular and granule cells of the vertebrate OB . . . . . . . . . . 22

2.1 Principle of ACI . . . . . . . . . . . . . . . . 33

2.2 Fluorescent spectra of Alexa Fluor 488 (AF488), propidium iodide (PI) and Alexa Fluor $647($ Af647) $\ldots \ldots \ldots$. . . . . . . . . . . 36

3.1 A periglomerular, mitral/tufted and granule cell . . . . . . . . . . 39

3.2 Different connectivity patterns of $\mathrm{M} / \mathrm{T}$ cells . . . . . . . . . . . . . . 40

3.3 Amino acid-sensitive glomeruli and $\mathrm{M} / \mathrm{T}$ cells . . . . . . . . . . . . . 43

3.4 Thermosensitivity of the $\gamma$-glomerulus and connected M/T cells . . . . 44

3.5 Integration of temperature and odour sensitivity in individual mitral cells 45

3.6 Dual-sensitive M/T cells and their differential tuning . . . . . . . . . 47

3.7 Excitation and inhibition of $\mathrm{M} / \mathrm{T}$ cells in response to odour stimuli . . . 48

3.8 GABA staining in the glomerular layer . . . . . . . . . . . . . . . 49

3.9 GABA staining in the mitral/tufted and granule cell layers . . . . . . . 50

3.10 Gabazine alters $\mathrm{M} / \mathrm{T}$ cells' odour responses. . . . . . . . . . . . . . . . 52

3.11 Excited vs inhibited M/T cells in response to odour stimuli . . . . . . . 53

3.12 Gabazine increases the similarity between odour-evoked outputs (1). . 55

3.13 Gabazine increases the similarity between odour-evoked outputs (2). . 56

3.14 Gabazine does not correlate M/T cells' activities. . . . . . . . . . . . . . . 57

3.15 Synchronous patterns of sister M/T cells . . . . . . . . . . . . . . 59

$3.16 \mathrm{M} / \mathrm{T}$ cell oscillations . . . . . . . . . . . . . . . . . . . 61

3.17 Gabazine raises intracellular calcium levels (1). . . . . . . . . . . . 64

3.18 Gabazine raises intracellular calcium levels (2). . . . . . . . . . . . 65

3.19 Spontaneous AP-induced $\mathrm{Ca}^{2+}$ transients in $\mathrm{M} / \mathrm{T}$ cell dendrites . . . . . . 68

3.20 Resolution of single $\mathrm{Ca}^{2+}$ spikes . . . . . . . . . . . . . . . . . . . . 69

3.21 Propagation of somatically evoked APs and $\mathrm{Ca}^{2+}$ spikes in a M/T cell dendrite and glomerulus . . . . . . . . . . . . . . 70 
3.22 High correlation of dendritic sub-compartments during spontaneous

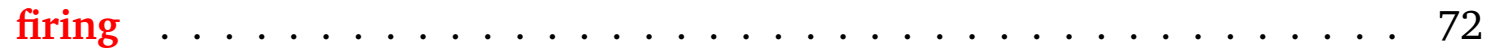

3.23 Correlation fluctuations of dendritic sub-compartments during evoked

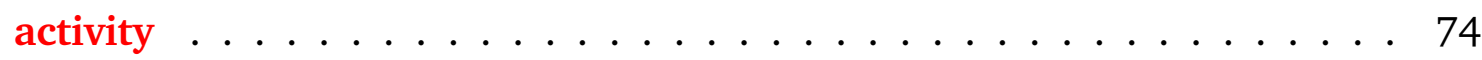

3.24 Gabazine increases the cross-correlation of $\mathrm{Ca}^{2+}$ signals along dendrites. 76

3.25 ACI of M/T cells loaded with Fluo-4 AM . . . . . . . . . . . . . . 78

3.26 ACI of M/T cells loaded with Fluo-8 $\mathrm{K}^{+}$salt $\ldots \ldots \ldots$. . . . . . . . . 79

\section{List of Tables}

1 Main targets of OB principal neurons (M/T cells) in amphibians and mammals . . . . . . . . . . . . . . . . . . 17

2 Morphological analysis of $\mathrm{M} / \mathrm{T}$ cells and their number of glomeruli, neurites and dendritic branches per cell . . . . . . . . . . . . . . 40

3 Comparison of the frequency distribution of $\mathrm{M} / \mathrm{T}$ cell activities before

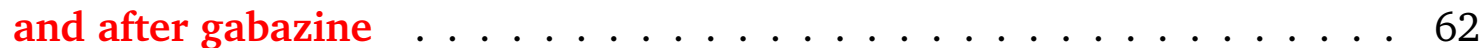




\section{List of abbreviations}

ACI: Activity Correlation Imaging

AM: Acetoxymethyl ester

AOB: Accessory olfactory bulb

AP: Action potential CNG: Cyclic Nucleotide-Gated

GABA: $\gamma$-Aminobutyric acid

GBZ: Gabazine (competitive $\mathrm{GABA}_{\mathrm{A}}$ receptor antagonist) GCs: Granule cells

GG: Grüneberg ganglion

M/T: Mitral/tufted

MOB: Main olfactory bulb

OB: Olfactory Bulb

ORNs: Olfactory receptor neurons

PGCs: Periglomerular cells

TRP: Transient Receptor Potential 


\section{Summary}

Olfactory information collected in the nose is conveyed from the axon terminals of olfactory receptor neurons to the dendritic tufts of mitral/tufted (M/T) cells across glutamatergic synapses. These synaptic interactions occur within glomeruli, the spherical neuropil structures where presynaptic and postsynaptic fibres intermingle. The second-order projection neurons, the $\mathrm{M} / \mathrm{T}$ cells carry out sensory processing and integration of the olfactory signals. In Xenopus laevis larvae, sensitivity to temperature drops is encoded by a group of receptor neurons terminating a particular glomerulus, called the $\gamma$-glomerulus. Interestingly, several studies brought evidence that some $\mathrm{M} / \mathrm{T}$ cells receive their input from more than one glomerulus. Yet, the implications of such a connectivity in terms of multi-processing and encoding of olfactory information have not yet been investigated. We hypothesised that the multiple glomerular innervation by $\mathrm{M} / \mathrm{T}$ cells would enable them to collect and integrate both chemical and thermic information. Consequently, $\mathrm{Ca}^{2+}$ imaging experiments performed in olfactory bulb slices revealed that most temperature-sensitive M/T cells also responded to chemical odourants, indicating that the dual-sensitivity of these cells is a function of their one-to-many glomerular connectivity.

Furthermore, Xenopus M/T cells display upon odourant stimulation three types of temporal activity patterns: activated, inhibited, unresponsive, which corroborate previous research showing that reciprocal and lateral $\mathrm{M} / \mathrm{T}$ cell inhibition affects odour representations in the rodent bulb. Inhibitory periglomerular and granule cells establish contact with $\mathrm{M} / \mathrm{T}$ cells through dendrodendritic synapses and constitute a scalable inhibitory lever on $\mathrm{M} / \mathrm{T}$ cell outputs. In order to test the effect of GABA-mediated inhibition on Xenopus $\mathrm{M} / \mathrm{T}$ cells, the $\mathrm{Ca}^{2+}$ dynamics of $\mathrm{M} / \mathrm{T}$ ensembles were compared in the presence or absence of gabazine, a $\mathrm{GABA}_{\mathrm{A}}$ receptor antagonist. The blockade of inhibition drastically altered the patterns of odour responses in M/T cells. Moreover, gabazine did not desynchronise correlated patterns of spontaneous activity across these neurons, but enhanced them. These results demonstrate that GABAergic inhibition of $\mathrm{M} / \mathrm{T}$ cells drives odour discrimination and contrast enhancement of overlapping odour signals in these neurons. In contrast, it plays a minor role, if any, in the coupling of M/T cells' baseline activities.

Finally, simultaneous patch-clamp recordings and $\mathrm{Ca}^{2+}$ imaging proved that action 
potentials (APs) and AP-related $\mathrm{Ca}^{2+}$ signals backpropagate in the dendrites of Xenopus $\mathrm{M} / \mathrm{T}$ cells. Spontaneous and somatically evoked APs activated $\mathrm{Ca}^{2+}$ channels generating $\mathrm{Ca}^{2+}$ spikes were observed in dendritic branches and glomerular endings. Besides, the cross-correlation analysis of $\mathrm{Ca}^{2+}$ fluctuations along M/T cell dendrites exposed differential activities of dendritic sub-compartments. Early evidence suggests that gabazine enhances the uniformity of backpropagating spikes along dendrites. 


\section{Introduction}

\subsection{The sense of smell}

"A rose by any other name would smell as sweet." The veracity of Juliet's statement, assessed from a neuroscientific point of view may very well depend on which stage of odour perception is being considered. Olfaction, the sense of smell is a complex task whereby the brain perceives, registers and discriminates air- or water-borne odour molecules. It is a process observed across phyla, from invertebrates like Caenorhabditis elegans to higher mammals. There are several stages of odour encoding and processing in vertebrates. The physical parameters of odour identity and concentration are transduced by the olfactory receptor neurons into electrical signals in the nose and encoded by olfactory bulb neurons. This information is then conveyed to higher brain centres for further processing and integration with cognitive functions such as memory and emotions.

Odour perception is a critical function in many animal species, driving a range of behaviours such as the search for food and habitat, mating, flight responses, social recognition and interactions among others. In humans, olfaction plays a key role at the individual and collective scales in the assessment food quality and palatability as well as social acceptance as attested by the blooming economic success of the food industry and perfume companies in their production of flavourings, food enhancers and fragrances. Furthermore, over the last decades, engineering efforts have targeted the development of electronic sensors (also called artificial noses or "E-noses") for the detection of toxic substances and environmental hazards or for early diagnostics of disease. This technology, in its attempts to replicate the efficiency of the human and animal nose relies on substantial findings in olfactory research from the identification of olfactory receptors (OR) and their families to the understanding of how the olfactory system establishes odour codes. The human nose harbours 5 to 6 million receptor neurons (ORNs) and ca. 100 million ORs coded by about 800 genes to meet the challenge of performing the discrimination of overlapping odours at nanomolar concentrations.

Answering some of these ongoing questions on odour perception necessitates a variety of approaches, from genetic studies to behavioural tests, but also benefits from the study 
of different species in order to comprehend the inherent and fundamental principles of olfaction. In this view, Xenopus laevis is an animal model befitting these purposes since the free-swimming larvae possess a "simple" yet functional olfactory system, easily approachable for experiments.

\subsection{The olfactory system of Xenopus laevis}

Xenopus laevis, also known as the African clawed frog is an anuran amphibian originating from Sub-Saharan Africa. The natural habitat of these animals is semi-terrestrial and semi-aquatic, and they primarily use the sense of smell to locate food sources. The nose of adult $X$. laevis consists of three olfactory organs, well adapted to the dual lifestyle of these frogs ${ }^{1,2}$. The largest cavity, called principal cavity ("air-nose") detects volatile molecules. the middle cavity ("water-nose") and the vomeronasal organ are both filled with water and are specialised in the detection of water-borne molecules and pheromones, respectively. In the pre-metamorphic larvae, however, only two of those cavities yet exist: the principal cavity as the water-nose and the vomeronasal organ ${ }^{3}$ (Figure 1.1A). During the developmental stages 49-54 (according the classification by Nieuwkoop and Faber ${ }^{4}$ ), the brain is not yet encapsulated by cartilage, nor is there any cribriform plate separating the nasal cavities from the olfactory bulb, which greatly facilitates the dissection and manipulation of nose-brain explants.

\subsubsection{Olfactory epithelium}

The olfactory epithelium of larval X. laevis is composed of ORNs, the sensory cells transmitting olfactory information to the bulb, sustentacular cells playing the role of both glial and epithelial cells and providing physical and neurotrophic support for the ORNs, and basal cells, the olfactory progenitors replenishing ORN pools ${ }^{5}$. Receptor neurons have a long dendrite terminating in a knob with cilia or microvilli ${ }^{3}$, where olfactory transduction is initiated. Both hairs not only increase the sensory surface but also set the mucus of the cavity in motion in which odour molecules dissolve. ORNs of the main olfactory epithelium (MOE) of the principal cavity possess about several hundreds of OR genes classified in two categories: one (class I) resembling OR fish genes and the other (class II) being similar to 
the mammalian genes ${ }^{6,7}$, as well as some vomeronasal receptors (V2Rs) ${ }^{8,9,10}$. The axons of these neurons fasciculate into the olfactory nerve, reach the axon sorting zone at the entrance of the olfactory bulb and divide again to innervate different areas of the olfactory bulb in the glomerular layer (Figure 1.1B-C). In the vomeronasal organ, microvillous ORNs predominantly express V2Rs ${ }^{8,9}$ and send their axons down the olfactory nerve to the accessory olfactory bulb (AOB).
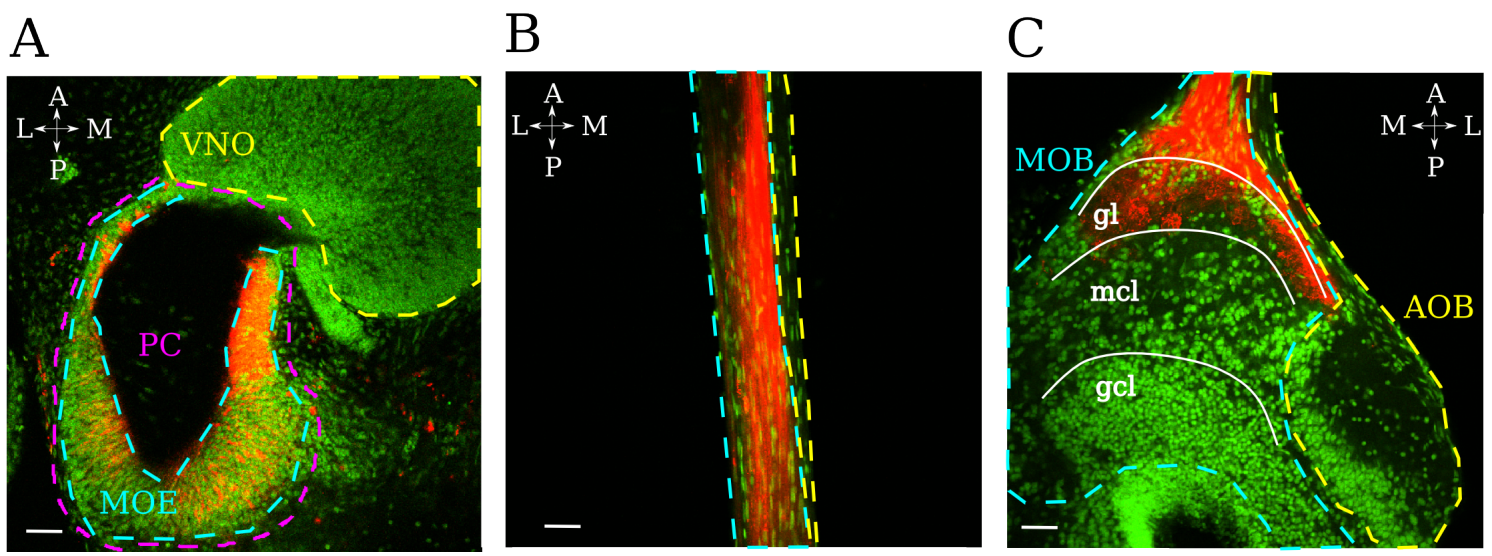

Figure 1.1: The olfactory system of larval $X$. laevis

The principal cavity (PC) and the vomeronasal organ (VNO) form the two olfactory organs of the pre-metamorphic animal (A). Olfactory receptor neurons (red) of the main olfactory epithelium (MOE) in the principal cavity send their axons down the olfactory nerve (B) and terminate in glomeruli in the main olfactory bulb (MOB)(C). Olfactory bulb neurons span several layers in the MOB: a glomerular layer (gl), mitral/tufted cell layer (mcl) and granule cell layer $(\mathrm{gcl})$. Vomeronasal receptor neurons also fasciculate in the olfactory nerve and innervate glomeruli of the accessory olfactory bulb (AOB). The organisation of the AOB is less defined but also consists of glomerular zone (black unstained region)(C) and some mitral/tufted and granule cells. Red (pseudocolor) staining: Dextran Alexa Fluor 488; Green (pseudocolor) staining: propidium iodide. Scale bar $=50 \mu \mathrm{m}$

Great progress has been achieved in understanding the transduction cascade and physiological mechanisms taking place in olfactory neurons, and they have been intensely reviewed $^{11,12,13,14,15,16}$. In short, odours bind olfactory receptors, proteins with 7 transmembrane domains coupled to an olfaction-specific G protein, which, when activated triggers the opening of ion channels via the release of second messengers. The entry of $\mathrm{Ca}^{2+}$ and $\mathrm{Na}^{+}$ions triggers a depolarising receptor potential amplified by the efflux of $\mathrm{Cl}^{-}$ions, which leads to the generation of action potentials carrying the chemosensory information 
to the olfactory bulb. Recent studies have brought evidence that two streams of odour processing co-exist in the main olfactory epithelium (MOE) of X. laevis ${ }^{10,17}$. A group of ORNs (belonging to the "medial stream") expresses G $\alpha_{\text {olf }}$ whose activation results in the opening of cyclic nucleotide-gated (CNG) and chloride channels channels via the canonical cAMP cascade. ORNs of the lateral stream possess a cAMP-independent pathway mediated by $\mathrm{G} \alpha_{\mathrm{i}} / \mathrm{G} \alpha_{\mathrm{o}}$ proteins which stimulates phospholipase C, thus activating transient receptor potential channel 2 (TRPC2) channels ${ }^{10}$.

\subsubsection{Glomerular layer}

OB neurons are spread across 3 main layers of the MOB: the glomerular layer, the mitral/tufted cell layer and the granule cell layers ${ }^{18}$ (Figure 1.1C). The unmyelinated axons of the olfactory nerve enter the olfactory bulb (OB) in the sorting zone and partially defasciculate as they terminate in numerous tufts in the glomerular layer of the ventral $\mathrm{MOB}^{19}$. The dorsal MOB in larval stages consist of fibre meshwork ${ }^{18,19}$. ON fibres originating from the VNO innervate the AOB located laterally between the dorsal and the ventral MOB. Some ORN axons, known as extrabulbar olfactory projections bypass the olfactory bulb and innervate the preoptic area ipsilaterally and the hypothalamus bilaterally ${ }^{20,21,22,23}$. Other extrabulbar fibres cross the midline of the brain at the anterior commissure and project back to the contralateral olfactory bulb ${ }^{23,24}$. Backtracing experiments demonstrated that extrabulbar fibres take origin in the principal and/or lateral cavity ${ }^{23,24}$. The terminal tufts of ORN axons form abundant en-passant synapses with the dendritic tufts of olfactory second-order neurons, the mitral/tufted (M/T) cells. Pre- and postsynaptic fibres intermingle in neuropil structures resembling thread balls called glomeruli, whose sizes range between 10-40 $\mu \mathrm{m}$. Glomeruli serve as single functional units for initial processing and coding of olfactory information ${ }^{25}$. It is generally assumed that every receptor neuron expresses one type of OR and each glomerulus receives input from receptor neurons endowed with the same OR, also known as the "one receptor - one neuron" rule (Cf reviews ${ }^{26,27}$ ). Though it remains unclear whether this dogma holds true for $X$. laevis tadpoles, a recent study reported that ORN axons of pre- and post-metamorphic animals branch and often terminate in two glomeruli ${ }^{28}$. This branching pattern is a deviation from the consensus wiring logic that in vertebrates 
each receptor neuron projects to a single glomerulus (cf review ${ }^{29}$ ).

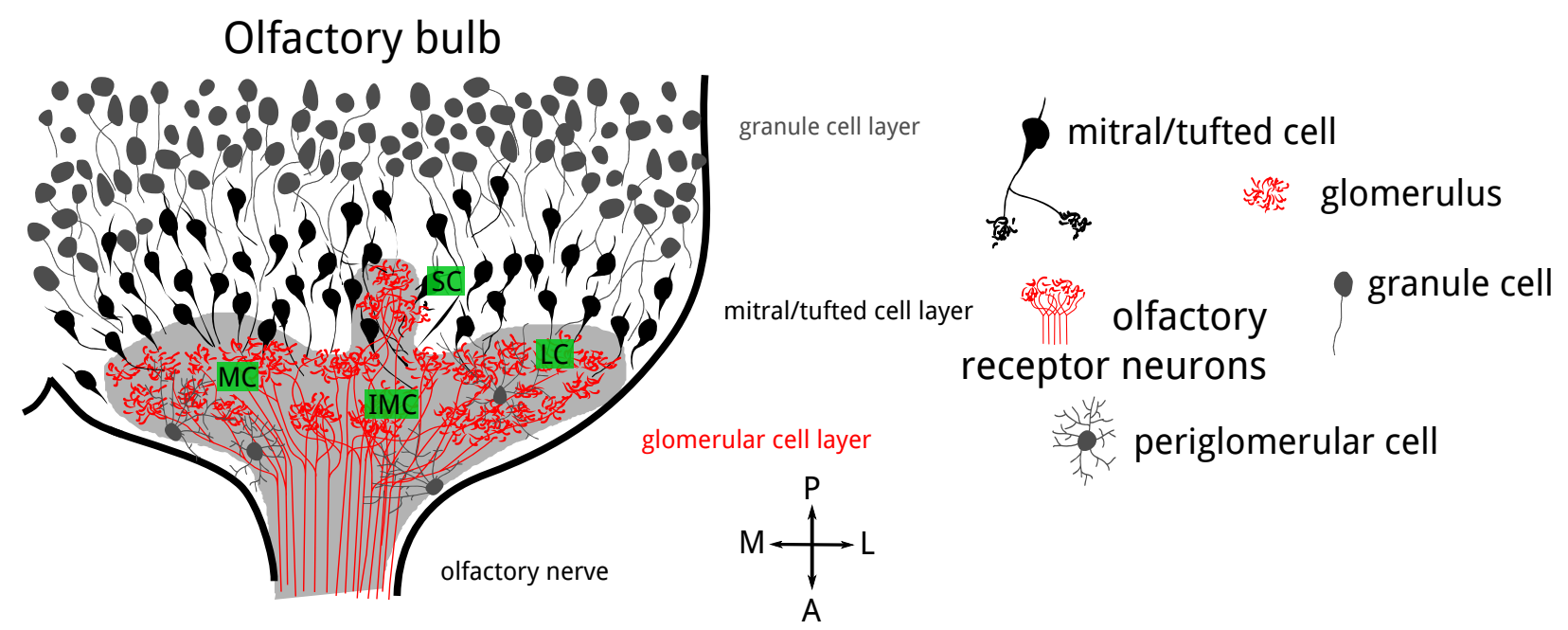

Figure 1.2: Organisation of the MOB (horizontal section)

Schematic representation of MOB layers and neurons. Olfactory information collected in the nose is conveyed from the axon terminals of ORNs to the dendritic tufts of mitral/tufted cells. The first olfactory synapses occur within glomeruli, spherical neuropil structures where pre- and postsynaptic fibres intermingle. The glomerular layer can be divided in 4 regions or clusters: the medial cluster (MC), intermediate cluster (IMC), small cluster (SC) and lateral cluster (LC). Periglomerular cells and granule cells are inhibitory cells and the last $\mathrm{OB}$ neurons to be generated ${ }^{2}$. Figure adapted from $\operatorname{Re}^{30}$.

At stages 49-54, 349 \pm 14 glomeruli were counted in the MOB and $69 \pm 10$ in the $\mathrm{AOB}^{31}$. Glomeruli of the MOB have been classified into 8 projection fields according to Gaudin and Gascuel $^{32}$ and 4 clusters according to Manzini et al. ${ }^{31}$, the latter classification overlapping with a glomerular chemotopic map. The medial, intermediate, small and lateral clusters roughly comprise 100, 70, 5 and 175 glomeruli respectively ${ }^{31}$ (Figure 1.2). ORNs of the cAMP-mediated medial stream connect with glomeruli of the medial cluster ${ }^{33}$. These cells and glomeruli are stimulated by forskolin (an activator of the adenylate cyclase) and respond to the application of alcohols, aldehydes, and ketones. ORNs of the cAMPindependent lateral stream project to glomeruli of the lateral cluster, which is sensitive to amino acids ${ }^{31,33,34}$. Bile acids and amines provoke more widely-distributed responses in the lateral, intermediate and medial clusters. Finally, the 3 to 5 glomeruli of the small cluster display particular sensitivities, with one of them responding forskolin and a broad range of amino acids as well as to mechanical stimuli, and another one being activated by temperature drops in the nose ${ }^{24}$. Similar chemotopy, i.e. the concept that adjacent 
glomeruli have identical or overlapping odour spectra has been observed in mice and rats on a large scale. Aldehydes and thiazoles activate glomeruli in the anterior and posterior regions of the dorsal bulb, respectively ${ }^{35}$. Although the placement and identity of identifiable glomeruli is fairly conserved across animals in Xenopus and rodents, the mapping of odours on a finer scale is less evident, and global chemotopy in the bulb is still under debate $36,37,38$.

Periglomerular cells (PGCs) are GABAergic interneurons which populate the glomerular layer ${ }^{18,19}$. They are found in between glomeruli but their somata do not form a wall around individual glomeruli as in mammals and other species ${ }^{19}$ (Figure 1.2). Neither are there any encapsulating glial processes around the glomeruli in the larval stages. Only $175 \pm 20$ PGCs in the MOB and $69 \pm 10$ PGCs in the AOB were numbered at stages 54-56, which equates to a cell-to-glomeruli ratio of 1:2 in the MOB.

\subsubsection{Mitral/tufted and granule cell layers}

Mitral/tufted (M/T) cells are the second-order neurons (also called projection neurons) of the olfactory bulb. In rodents, mitral and tufted cells are clearly distinguishable based on several criteria ${ }^{39,40}$, notably by (i) the diameter of their somata ${ }^{41,42,43}$, (ii) their respective positions in the layers of the $\mathrm{OB}$ and thereby the length of their primary dendrite ${ }^{44,45}$, (iii) their sensitivities to odourants ${ }^{46,47}$, (iv) their firing rates and spike-timing in relation to respiration cycle ${ }^{48},(v)$ and their brain targets ${ }^{49,50}$. Some of these differences have not been observed or not yet been investigated in larval $X$. laevis. Accordingly, the adjective "mitral/tufted" is a consensus term employed in studies focusing on amphibians, as well as other organisms used for olfactory research as the fruit fly (Drosophila melanogaster) and zebrafish (Danio rerio). It is also recurrent in mammalian research when discussing physiological properties shared by both mitral and tufted cells.

The axons of M/T cells form a medial and a lateral olfactory tract which projects to several nuclei in the adult frog brain. Table 1 summarises the central projections of M/T cells which were identified in several anurans including Xenopus ${ }^{51}$, and their homologues in mammals ${ }^{37}$. 


\begin{tabular}{ll}
\hline Amphibians & Mammals \\
\hline Postolfactory eminence & Primary olfactory cortex \\
Medial, dorsal and lateral pallium & Piriform cortex \\
Medial and lateral septum & Septal nuclei \\
Striatum & Olfactory tubercle (ventral striatum) \\
Amgydala & Amgydala \\
\hline
\end{tabular}

Table 1: Main targets of OB principal neurons (M/T cells) in amphibians and mammals

$\mathrm{M} / \mathrm{T}$ cells in mammals display a particular morphology, with a long apical primary dendrite innervating a single glomerulus in the MOB, and secondary dendrites spreading laterally. In contrast, Xenopus $\mathrm{M} / \mathrm{T}$ cells receive input from one or more glomeruli via branched primary dendrites ${ }^{19,52}$, which is reminiscent of the innervation pattern of $\mathrm{M} / \mathrm{T}$ cells in the mammalian $\mathrm{AOB}^{53,54}$. The glomerulus-to-M/T cell ratio is estimated to $1: 5$ for Xenopus ${ }^{19}$ and between 1:10 and 1:21 for rodents ${ }^{55}$. All M/T cells linked to the same glomerulus and thus receiving the same information transmitted by ORNs are called sister $\mathrm{M} / \mathrm{T}$ cells. New reports investigating the activity patterns of these cells confirmed that they are characterised by highly correlated baseline and odour-evoked activities ${ }^{56,57,58,59}$. Moreover, sister M/T cells are connected via gap junctions, which is one of the mechanisms driving synchronous spiking of these neurons ${ }^{56,60}$.

Odour identity and concentration are encoded by mitral/tufted cells in spike frequencies, interspike intervals and first spike latencies ${ }^{61,62}$. As in many, if not all neural networks, the behavioural output of $\mathrm{M} / \mathrm{T}$ cells is sculpted by inhibition. $\mathrm{M} / \mathrm{T}$ cells of vertebrates receive $\gamma$-aminobutyricacid(GABA)-ergic input from inhibitory PGCs in the glomerular layer and granule cells (GCs) in the mitral/tufted cell layer via dendrodendritic synapses ${ }^{63}$, where they express $\mathrm{GABA}_{\mathrm{A}}$ receptors ${ }^{64}$ (Figure 1.4B). Granule cells are the most abundant cell type in the olfactory bulb. The granule cell layer of larval Xenopus harbours $3096 \pm 186$ at stages $54-56^{19}$. The morphology of these cells differs from that of mitral cells in that they are axonless and grow spines along their dendrites. GCs and PGCs are the OB neurons which are generated at last—from stage 41 onward-and maturate from stage $48^{2,65}$. 
After metamorphosis (stage 65), neurogenesis continues, but the majority of newborn cells integrates the granule cell layers. In rodents, 10,000 to 40,000 neural progenitors reach the olfactory bulb, and about half of them differentiating into mature GCs and PGCs ${ }^{66,67}$; Lledo, 2006; ${ }^{68}$. Within a month from their generation, these cells integrate bulbar circuits without perturbing odour representations established across OB layers.

\subsection{Non-chemical olfaction}

In the last decades, a branch of olfactory research has focused on how environmental factors as temperature, humidity, and pressure affect olfactory sensitivity. Some of the findings illustrate the effect of these factors on olfaction, namely that (i) the expression of olfactory receptors and gene regulation in receptor neurons are regulated with high ambient temperatures in Drosophila ${ }^{69,70}$, (ii) the detection and identification of odours improves in hyperbaric conditions and is impaired at high altitudes ${ }^{71}$, (iii) and odour threshold decreases in humid compared to dry conditions in humans ${ }^{72}$, On top of these effects, several studies brought evidence that the vertebrate olfactory system also responds to rapid changes of pressure and temperature beside its perception of chemical stimuli $24,73,74$. While mechanosensitivity and chemosensitivity are often observed in ORNs of olfactory subsystems like the septal organ or the Grüneberg ganglion, the main olfactory epithelium is not excluded.

\subsubsection{Mechanosensitivity}

It was reported that the septal organ of mice is not only sensitive to chemosensory cues but also to puffs of odour-free Ringer's solution applied to an explant consisting of nasal epithelium and the septum ${ }^{73}$. In the same study, Grosmaitre and colleagues also demonstrated that $50 \%$ of the MOE neurons also responded to these mechanical stimuli. Blocking the adenylate cyclase III or suppressing the expression of the CNG channel CNGA2 inhibited pressure (and odour) responses. These common elements of sensory transduction are expressed by canonical ORNs of the MOE and ORNs of the septal organ ${ }^{75}$, thereby accounting for the broad expression of pressure sensitivity in the rodent nose. Another supporting argument comes from a novel study arguing that most ion channels of the Tran- 
sient Receptor Potential (TRP) family are mechanosensitive ${ }^{76}$, TRP-expressing cells being found within the MOE and vomeronasal organ ${ }^{75}$. Possible rationales for the importance of mechanosensivity of ORNs included an increase of the sensitivity to weak stimuli or low concentration odourants during sniffing, and/or the synchronisation of odour perception with respiration cycles. These putative roles maybe relevant for odour processing in mammals, but not for lower vertebrates as $X$. laevis where sensitivity to pressure pulses has also been described. In these animals, short Ringer and air puffs triggered the elevation of intracellular $\left[\mathrm{Ca}^{2+}\right]$ in ORNs of the MOE terminating in a unique glomerulus of the small cluster, the $\beta$-glomerulus ${ }^{24,77}$.

\subsubsection{Thermosensitivity}

In Drosophila, heat and cold-activated TRP channels are expressed by thermosensory neurons of the antenna which relay temperature signals to projection neurons of the antennal lobe (also called protocerebrum) ${ }^{78}$. The second-order neurons of the antennal lobe, the insect equivalent of the vertebrate olfactory bulb, target brain centres known for sensory (including olfactory) processing as the mushroom body and the lateral horn ${ }^{79}$. There is now piling evidence that temperature perception not only occurs at the periphery (e.g. skin) but also within the vertebrate olfactory system. Several studies shed light on the thermosensory neurons of the Grüneberg ganglion (GG), an olfactory subsystem, located at the tip of the nose of rodents. GG neurons acted as detectors of chemical stimuli (some thiazoles and pyrazines) ${ }^{80,81}$, alarm pheromones ${ }^{82}$, and interestingly, cool ambient temperatures too ${ }^{83,81}$. These thermosensitive cells have a sensitivity range of about $10^{\circ} \mathrm{C}$ between $9{ }^{\circ} \mathrm{C}$ and $20^{\circ} \mathrm{C}$ and project to the necklace glomeruli of the rodent olfactory bulb $^{84,85,86,87}$. In contrast, temperature sensitive neurons of larval Xenopus show a dynamic range of $5.4^{\circ} \mathrm{C}$ and respond to temperature fluctuations rather than absolute values ${ }^{24,88}$. Backtracing experiments identified the position of these neurons within the main olfactory epithelium, while their axons target another unique glomerulus of the small cluster: the $\gamma$-glomerulus ${ }^{24,77,88}$ (Figure 1.3C). 

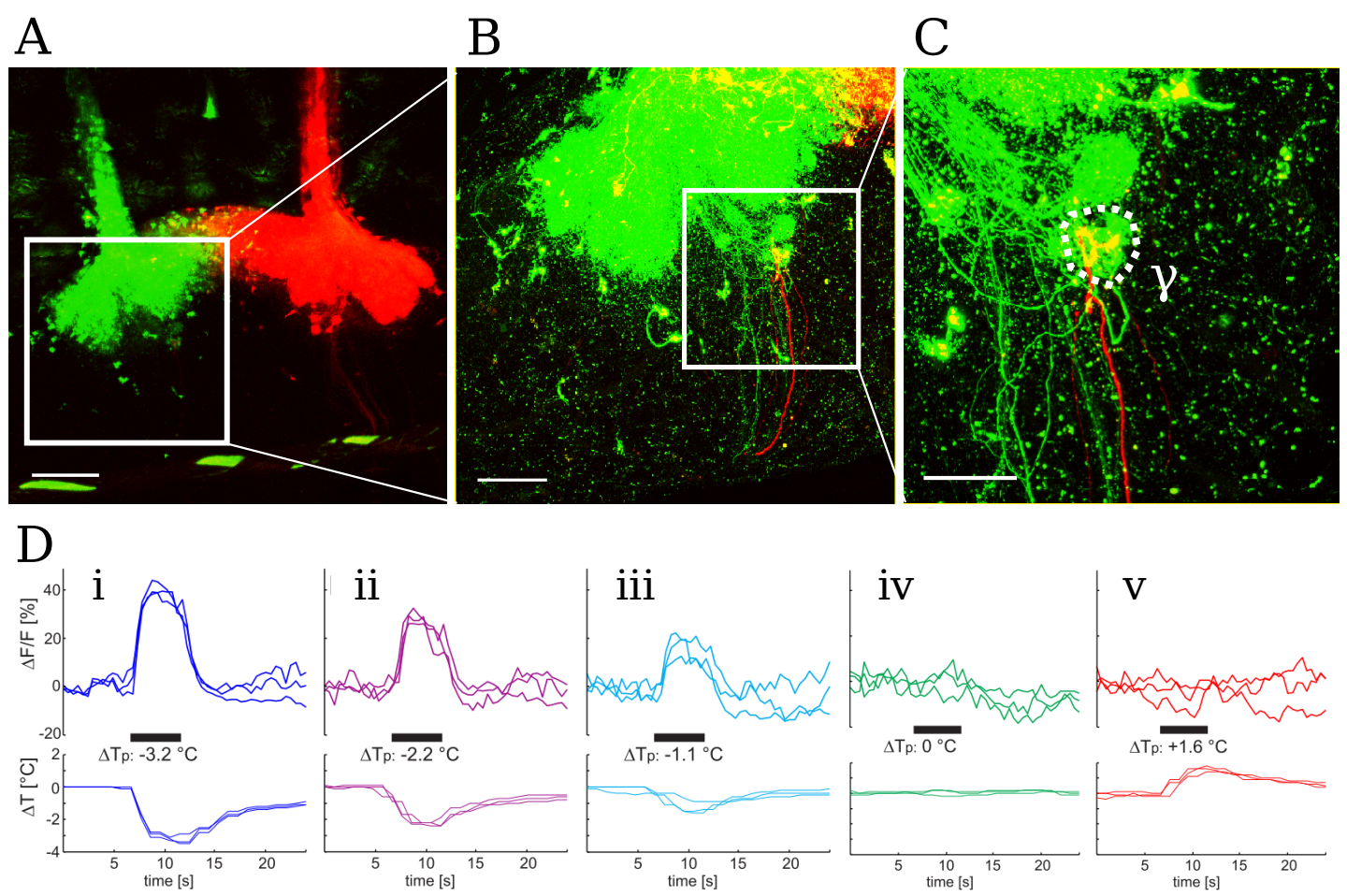

Figure 1.3: The $\gamma$-glomerulus, a thermosensitive neuropil in the larval Xenopus brain (A) Whole-mount nose-brain preparation of a pre-metamorphic animal, where Dextran Alexa Fluor 546 was electroporated in the right nostril, and Dextran Alexa Fluor 647 in the left nostril. The brain was imaged upside-down for a better visualisation of the ventral glomerular layers; scale bar: $200 \mu \mathrm{m}$. (B) Blown-up view of (A). The white rectangle highlights the small cluster and extrabulbar olfactory fibres; scale bar: $100 \mu \mathrm{m}$. (C) Blown-up view of (B), showing the small cluster which comprises the $\gamma$-glomerulus $(\gamma)$. Note its innervation by olfactory receptor neurons located in the contralateral nasal cavity (red); scale bar: $50 \mu \mathrm{m}$. (D) $\mathrm{Ca}^{2+}$ responses of the presynaptic fibres of $\gamma$-glomerulus to temperature drifts induced at the nasal epithelium (Subfigure reused with permission from $\operatorname{Ref}^{24}$ ). The $\gamma$-glomerulus solely responds to negative temperature changes. Each plot shows the time traces of 3 repetitive applications. $\Delta \mathrm{F} / \mathrm{F}$ : Normalised fluorescence intensity changes of Dextran Fluo-4 (10 kDa); $\Delta \mathrm{T}$ : temperature fluctuations recorded by a NiCr-Ni thermosensor; $\Delta \mathrm{Tp}$ : temperature difference measured in the nose of the animal upon application of cooled Ringer's solution.

The olfactory bulb of each hemisphere possesses a single thermosensitive glomerulus in pre-metamorphic Xenopus laevis. Each $\gamma$-glomerulus is the target of ipsilateral and contralateral thermosensitive $\mathrm{ORNs}^{24,88}$ (Figure 1.3A-C). The contralateral projections follow the route of extrabulbar fibres in the contralateral hemisphere, but cross the midline at the anterior commissure and turn back in the other hemisphere to innervate the $\gamma$ glomerulus. Thus, the $\gamma$-glomerulus receives temperature information from the left and 
right nostrils of the animal.

Increases of temperature did not activate the $\gamma$-glomerulus, neither did any other odourant known to stimulate the olfactory system of $X$. laevis. Only negative temperature jumps triggered reversible $\mathrm{Ca}^{2+}$ responses in the pre- and postsynaptic fibres of the $\gamma$ glomerulus(Figure 1.3D). The activation of $\mathrm{M} / \mathrm{T}$ cells in responses to temperature drops in the nose of tadpoles indicated that thermosensitive information is conveyed to the olfactory bulb for sensory processing ${ }^{88}$. These results were the first line of evidence that OB glomeruli and second-order neurons integrate temperature perception in the vertebrate brain. Further proof was provided by the findings of a recent study in which the activation of necklace glomeruli by thermic stimuli was measured by the expression of the activity-dependent marker c-Fos in juxtaglomerular cells ${ }^{74}$.

The olfactory bulb appears to process temperature information along with smell perception which raises the question whether both modalities, chemo- and thermosensitivity would share cellular networks.

\subsection{Inhibition in the olfactory bulb}

The activity of $\mathrm{M} / \mathrm{T}$ cells is regulated by periglomerular and granule cells, which are the two main classes of inhibitory neurons in the vertebrate bulb. These GABAergic cells predominantly control the transmission of olfactory information, glomerular processing as well as the sensitivity and specificity of odour representations by regulating odour tuning and contrast enhancement of M/T cells $63,89,90,91,92 . \mathrm{M} / \mathrm{T}$ cell inhibition occurs at two levels, at the apical dendritic tufts of M/T cells within the glomerular layer and the dendrodendritic synapses between mitral and granule cells in the M/T cell layer (Figure 1.4B). PGCs and GCs establish a GABAergic circuitry driving recurrent and lateral inhibition of M/T cells ${ }^{93,94}$. Recurrent or reciprocal inhibition is a feedback mechanism whereby glutamatergic $\mathrm{M} / \mathrm{T}$ cells activate PGCs and GCs via dendrodendritic synapses. In response to their excitation, these inhibitory cells release GABA onto M/T dendrites of the same cell which binds $\mathrm{GABA}_{\mathrm{A}}$ receptors, and thus reduces the firing frequency and excitability of $\mathrm{M} / \mathrm{T}$ cells ${ }^{95}$. Lateral inhibition is a process by which the activity of a M/T cell recruit a PGC or GC, which in turn inhibit another $\mathrm{M} / \mathrm{T}$ cell. The effects of recurrent and lateral inhibition were observed 
in spontaneous and stimulus-induced response patterns of glomeruli and $\mathrm{M} / \mathrm{T}$ cells in rodents $^{96,97}$, zebrafish $^{98}$ and frogs ${ }^{30}$.
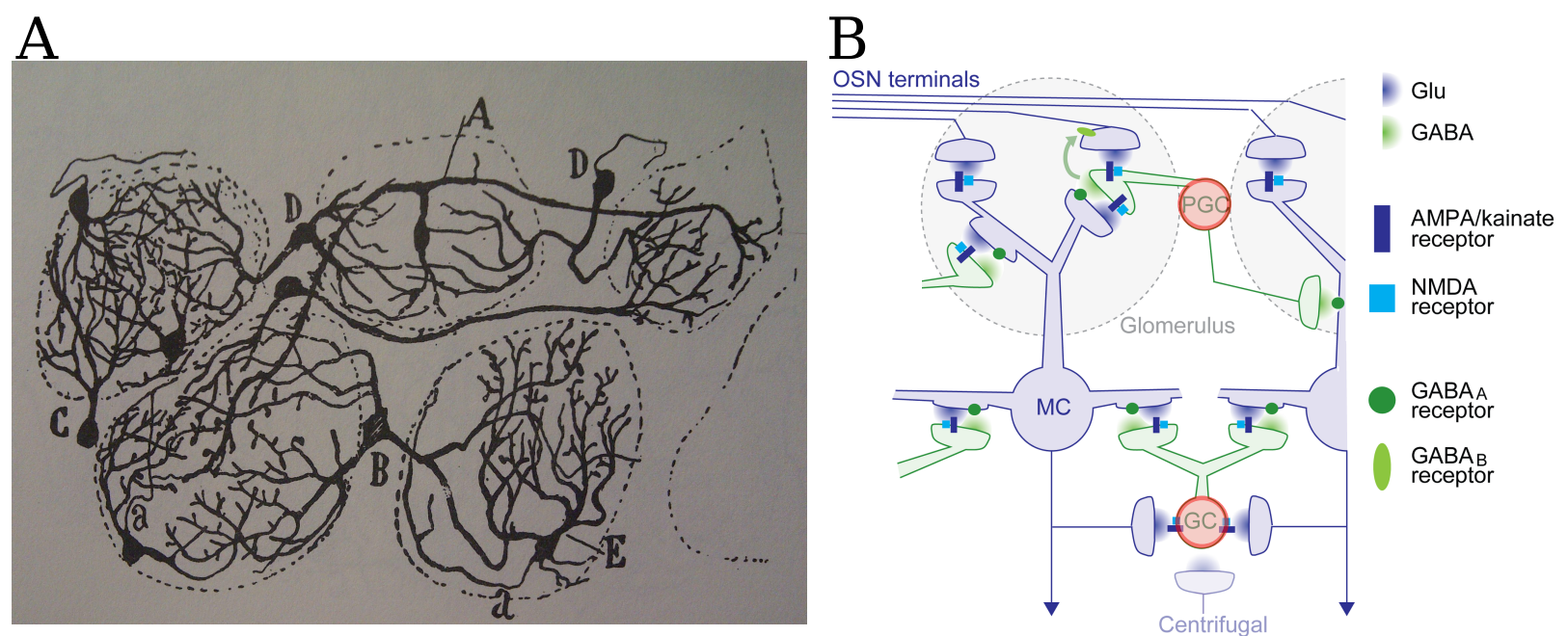

Figure 1.4: Periglomerular and granule cells of the vertebrate OB

(A) Drawing from the late $20^{\text {th }}$ century of periglomerular cells of a cat glomerular layer innervating one $(C, E)$, two $(B, D)$ or three glomeruli $(A)^{41}$. Some PGCs have axons, others don't. (B) Schematic representation of synaptic contacts established by PGCs and GCs in the OB across vertebrate species. PGCs activated by ORN inputs act inter- and intraglomerularly to inhibit the dendritic tufts of $\mathrm{M} / \mathrm{T}$ cells by acting on $\mathrm{GABA}_{\mathrm{A}}$ receptors. They also exert feedback inhibition of olfactory nerve terminals by releasing GABA binding to presynaptic $\mathrm{GABA}_{\mathrm{B}}$ receptors. $\mathrm{M} / \mathrm{T}$ cells in turn control the excitability of PGCs by releasing glutamate onto their AMPA and NMDA receptors. Granule cells are axonless neurons meditating dendodentritic interactions with $\mathrm{M} / \mathrm{T}$ cells. Backpropagating action potential trigger glutamate release along M/T dendrites onto GC spines glutamate onto GC spines expressing AMPA and NMDA receptors. The resulting excitation of GC spines causes GABA release onto $\mathrm{GABA}_{\mathrm{A}}$ receptors anchored on the dendritic shaft of $\mathrm{M} / \mathrm{T}$ cells. Feedback inhibition of M/T cells by PGCs or GCs is generally termed "recurrent inhibition". OSN: olfactory sensory neurons (e.g. ORNs), MC: mitral/tufted cells. Modified with permission from $\operatorname{Ref}^{99}$.

$\mathrm{GABA}_{\mathrm{A}}$ receptors are ionotropic channels permeable to chloride and bicarbonate which mediate fast inhibitory signalling. In the majority of mature neurons, the increase of $\mathrm{GABA}_{\mathrm{A}}$ conductances following the opening of channels causes a net inflow of anions leading to a hyperpolarization of the voltage of the postsynaptic membrane. The resulting hyperpolarising inhibitory postsynaptic potential (IPSP) reduces the probability of AP generation. $\mathrm{GABA}_{\mathrm{A}}$ receptors are pentameric hetero-oligomers formed by the combinatorial assembly of subunits of 7 classes: $\alpha 1-6, \beta 1-3, \gamma 1-3, \delta, \epsilon 2, \theta 2, \pi 1-3 .{ }^{100,101}$. Most $\mathrm{GABA}_{\mathrm{A}}$ receptors consist of two $\alpha$-subunits, two $\beta$-subunits and one $\gamma$-subunit, although a high 
degree of heterogeneity has been observed ${ }^{102}$. Mammalian M/T cells express high levels of $\alpha 1, \alpha 3, \beta 1-3$ and $\gamma 2$ subunits. In contrast, GCs predominantly express $\alpha 2$, and $\alpha 4-5$

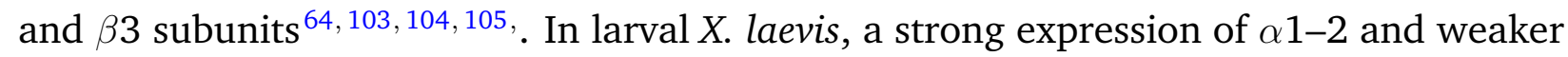
expression of $\alpha 3$ mRNAs have been reported in the forebrain ${ }^{106}$.

Single vesicle release of GABA only activates ligand-gated $\mathrm{GABA}_{\mathrm{A}}$ receptors anchored in the postsynaptic density and there is very little to no spread of GABA around the synaptic cleft. However, AP-evoked fusion of multiple GABA vesicles with the presynaptic membrane in several terminals causes GABA spillover and accumulation in and around the synaptic site, which both opens synaptic and extra-/peri-synaptic $\mathrm{GABA}_{\mathrm{A}}$ receptors ${ }^{107}$. The opening of synaptic $\mathrm{GABA}_{\mathrm{A}}$ receptors promotes rapid "phasic" currents, whereas the activation of high-affinity "tonic" extrasynaptic $\mathrm{GABA}_{\mathrm{A}}$ receptors generates a long lasting inward chloride current. The blockade of phasic only and/or tonic currents depends on the identity and concentration of $\mathrm{GABA}_{\mathrm{A}}$ receptor antagonists, the most used being picrotoxin, gabazine (SR95531) and bicuculline. Moreover, the subunit composition of synaptic and extrasynaptic receptors influences the biophysical properties of $\mathrm{GABA}_{\mathrm{A}}$ receptors as well as their sensitivity to the afore-mentioned drugs ${ }^{107}$.

\subsubsection{The role of periglomerular cells}

PGCs are located at the first relay centre of olfactory processing, which facilitates their role in gating signal transmission and regulating contrast enhancement and inhibition of weak odour signals ${ }^{108}$. ON terminals make excitatory synaptic contacts (glutamatemediated) onto the dendrites of M/T cells and PG cells within glomeruli. In the rodent bulb, most PGCs extend their dendrites into one glomerulus and at times to multiple glomeruli. The PG cell-to-glomeruli ratio in larval Xenopus equals 1:2 (at stages 54-56), which either signifies that the dendrites of Xenopus PGCs branch into multiple glomeruli, or that a consequent population of glomeruli is not (yet) innervated by these interneurons in pre-metamorphic animals. Cleland and Sethupathy reasoned that PGCs, due to their small soma size and high input resistance, are easily activated by weak odour inputs and thus immediately suppress $\mathrm{M} / \mathrm{T}$ cell responses ${ }^{90}$. In contrast, strong odour inputs forcibly would excite M/T cells and overpower PGC inhibition of M/T cells. The resulting 
effect of this intraglomerular computation is that $\mathrm{M} / \mathrm{T}$ cells exhibit an excitatory response to high-potency odourants, while not being activated by to odour ligands of weak or moderate potency ${ }^{109}$. By this means, PGCs perform on-centre/off-surround decorrelation, whereby overlapping representations of similar odours are transformed so as to correlate less. This process sharpens the odour receptive field of M/T cells, increases the specificity of odour responses and for the similar odour optimises the coding of their differences over their commonalities ${ }^{91}$. Another intraglomerular processing potentially regulated by PGCs is the pattern decorrelation of sister M/T cells ${ }^{93}$. Sister M/T cells share common olfactory excitatory inputs, are linked via gap junctions ${ }^{56,110}$ at their dendritic tufts, and show synchronised EPSPs due to glutamate spillover at dendritic sites ${ }^{110,111}$. These three factors represent the main drivers of the correlated or synchronous temporal activities observed in these cells ${ }^{58,112}$. Intraglomerular lateral inhibition between sister M/T cells is thought to diminish the synchrony of sister M/T cells and to weaken the redundancy of the odour-evoked signals being sent to higher brain centres ${ }^{113}$. It has been proposed that interglomerular inhibition (between glomeruli) of $\mathrm{M} / \mathrm{T}$ cells plays a minimal role in contrast enhancement compared to intraglomerular inhibition (within a glomerulus) ${ }^{114}$. While the former is odour-specific and achieves surround inhibition of olfactory representations, the latter is non-specific and also decorrelates the representations of overlapping signals, yet at the cost of a reduced odour sensitivity ${ }^{90,91,108}$.

$10-16 \%$ of PGCs are dopaminergic tyrosine hydroxylase-immunoreactive neurons ${ }^{115,116}$. These cells synapse onto the presynaptic buttons of ORN axon terminals, which express dopamine $\mathrm{D} 2$ receptors and $\mathrm{GABA}_{\mathrm{B}}$ receptors ${ }^{117,118}$. Several studies described how ORN inhibition by PGCs mediated via the presynaptic metabotropic $G A B A_{B}$ and $D_{2}$ dopamine receptors serves to control gain output, i.e. modulate the amplitude of odour-evoked inputs $^{114,119}$. It was firstly shown that spontaneous and olfactory nerve-evoked firing of M/T cells was decreased by dopamine as well as D2 agonists and enhanced by D2 antagonists $^{119}$. Furthermore, McGann and colleagues brought evidence that GABA, via its binding to $\mathrm{GABA}_{\mathrm{B}}$ receptors decreases the amplitude of odourant-evoked signals in the presynaptic fibres of glomeruli. The blockade of $\mathrm{GABA}_{\mathrm{B}}$ receptors increased evoked neurotransmitter release but did not alter the spatial representation in the glomerular layer of mice ${ }^{114}$. $\mathrm{GABA}_{\mathrm{B}}$ receptors are $\mathrm{G}$ protein-coupled receptors consisting of two 
subunits: B1 which harbours the ligand binding site and B2 which is essential for G-protein coupling. Interestingly, the mRNA of B1 and B2 subunits has also been identified in olfactory epithelium and forebrain of $X$. laevis tadpoles ${ }^{106}$.

\subsubsection{The role of granule cells}

GCs are the most abundant population of inhibitory interneurons in the bulb. Upon M/T cell firing, the action potentials backpropagate into all dendritic shafts ${ }^{96,120,121}$ and trigger local release of glutamate onto AMPAR- and NMDA-expressing GCs. The depolarisation of GC spines causes subsequent release of GABA into the synaptic cleft, which binds to synaptic and extrasynaptic ionotropic $\mathrm{GABA}_{\mathrm{A}}$ receptors on $\mathrm{M} / \mathrm{T}$ dendrites. Spatially restricted excitation of GC spines and dendrites triggers recurrent inhibition, whereas somatic excitation and global spiking of GCs can affect a larger number of MCs through lateral inhibition ${ }^{122}$. This process is commonly regarded as another bulbar computation achieving specific decorrelation of odour representations in second-order neurons ${ }^{123}$.

One hypothesis about the role of GCs proposes that activity-dependent lateral inhibition targets a population of $\mathrm{M} / \mathrm{T}$ cells firing at intermediate rates after odour presentation ${ }^{123,124}$. Slow firing M/T cells would not recruit GCs, while fast spiking neurons would saturate GCs' own firing rates. However, M/T cells retaining moderate AP frequencies would be sensitive to GC inhibitory inputs. The resulting effect would diminish the number of M/T cells firing at intermediate rates to produce contrast enhancement dependent on the activity of different M/T cell populations.

While PGCs play a predominant role in regulating the efficiency of ON-to-M/T cell transmission of olfactory signals, GCs shape the output of M/T cells by controlling their firing rates and interburst intervals (i.e. the periods of inhibition). Granule cells establish reciprocal contacts with multiple $\mathrm{M} / \mathrm{T}$ cells and can thus control the inhibition of different glomeruli and the M/T cells connected to them ${ }^{125}$. Computational findings provided new insights in the successive operations occurring within OB layers ${ }^{126}$. The authors argued that GCs achieve temporal decorrelation over larger timescales and (odour) spatial domains, a process which is dependent on a preceding contrast enhancement by the glomerular microcircuits. 
Moreover, fast local field potential oscillations in the beta and gamma frequency ranges have been since long observed in the OB of insects $(20-30 \mathrm{~Hz})^{127}$, zebrafish $(20-30 \mathrm{~Hz})^{128}$, and rodents $(15-90 \mathrm{~Hz})^{129,130}$. Several studies make a strong case for the importance of GABAergic inhibition in establishing $\mathrm{M} / \mathrm{T}$ synchronous firing driving oscillatory spiking in the 20-70 Hz range $\mathrm{H}^{131132,133}$. There is emerging evidence that the synchronisation of $\mathrm{M} / \mathrm{T}$ temporal activities which relies on feedback communication between M/T and GCs is achieved via (i) precisely timed inhibitory inputs ${ }^{132}$, (ii) asynchronous inhibition and positive feedback loop ${ }^{134}$, and/or (iii) optimal dendrodendritic synapse location ${ }^{135}$, among other rationales.

Glutamatergic and GABAergic metabotropic receptors regulate the strength of synaptic inputs between M/T cells and GCs as well as the excitability of the latter cells. Metabotropic glutamate receptors (mGluRs) localised on GCs modulate GABA-mediated inhibition at reciprocal synapses. Electrophysiological experiments brought forth proofs that glutamate binding to mGluR2 reduces spontaneous GABA release from granule cells in the mouse $\mathrm{AOB}^{136}$. In larval Xenopus laevis, activated mGluR2/3-like receptors inhibit calcium influx through high-voltage-activated (HVA) calcium channels, hence causing a reduced spontaneous GABA exocytosis in the same synaptic cleft ${ }^{137}$. Along the same line, it has been demonstrated that dendritic $\mathrm{GABA}_{\mathrm{B}}$ receptors are likewise crucial for the modulation of recurrent $\mathrm{M} / \mathrm{T}$ cell inhibition by inhibiting HVA calcium channels and hindering GABA release from granule cells in the rat $\mathrm{OB}^{138}$. The activation of mGluR5, however, increases GC excitability, which boosts recurrent inhibition of mitral/tufted cells ${ }^{139}$.

Moreover, it has been shown that M/T neurons express dopamine D2 receptors in mice or D2-like receptors (D2Rs) in anuran frogs ${ }^{140,141}$. The localisation of these receptors in the frog was restricted to the M/T cell layer ${ }^{140}$. As their mammalian homologues, PGCs of adult $X$. laevis express tyroxine-hydroxylase immunoreactivity ${ }^{115,142}$. Dopamine released from PGCs hampers the synaptic transmission from M/T cells to GCs by reducing the propagation of action potentials (APs) along M/T cell dendrites and decreasing the neurotransmitter release of glutamate. Both effects lead to a drop in synaptic excitation of GCs which eventually lowers their inhibitory action onto $\mathrm{M} / \mathrm{T}$ cells. In the adult frog (Rana ridibunda), agonists of dopamine receptors caused a strong reduction of $\mathrm{M} / \mathrm{T}$ spontaneous firing rates, thereby confirming the role of dopamine in the regulation of M/T excitability, and thus, M/T 
sensitivity also ${ }^{140}$. Interestingly, a former study in the same anuran revealed the presence of dopamine-immunopositive somata in the glomerular, mitral/tufted and granule cell layers. It remains unclear whether these dopamine-expressing cells may be a mixed population of PGCs and GCs or PGC neural progenitors migrating towards the glomerular layer.

Further modulation of the GC-M/T synapses arises from bulbopetal neurons located in higher brain centres. The mammalian OB receives centrifugal projections from glutamatergic neurons of the pirifom cortex as well as two nuclei in the basal forebrain: the horizontal limb of the diagonal band of Broca (HDB) and the magnocellular preoptic area (MCPO) ${ }^{143,144,145}$. The latter two nuclei harbour cholinergic and GABAergic neurons ${ }^{144}$. Kratskin and colleagues retrogradely traced in the frog brain of the anuran Rana temporaria these GABAergic bulbopetal fibres whose cell bodies were located in the medial, dorsal and lateral pallium, as well as in the nucleus of the diagonal band and the medial septum ${ }^{146}$. These latter two nuclei are reminiscent of the mammalian HDB/MCPO by their respective location and histochemical profiles. GABA-positive cells were also found in both structures of Rana temporaria, while cholinergic neurons were identified in Xenopus laevis and Rana perezi. In addition, noradrenergic fibres originating in the locus coeruleus also innervate the olfactory bulb of rodents ${ }^{43,147,148}$, and the effect of norepinephrine on the OB circuitry has also been described in larval Xenopus ${ }^{149,150}$. Glutamatergic and GABAergic corticobulbar axons synapse abundantly onto GCs ${ }^{151,152}$, and the targets of all these feedback projections appear to be mainly inhibitory neurons. Research over the last 5 years have shed light on how these feedback axons indirectly act on M/T cells via inhibitory interneurons and modulate OB outputs $47,153,154,155$.

Although many studies provided valuable insight into some of the purposes of GABAmediated inhibition, such as contrast enhancement and the regulation odour specificity and sensitivity, the relative contribution of PGCs versus GCs remains controversial ${ }^{91,113,156 .}$ There is suggestive evidence that similar inhibitory roles played by both types of interneurons shape olfactory coding in larval X. laevis ${ }^{77,157}$. However, no thorough investigation has been undertaken to assess the importance of GABAergic inhibition in the control of M/T cell odour representations, pattern decorrelation and M/T cell synchrony insofar. 


\subsection{Scope of the thesis}

The work reported in this dissertation dealt with three topics:

1) Dual sensitivity and structure-function relationship of $M / T$ cells (Results - Section 3.1)

Xenopus $\mathrm{M} / \mathrm{T}$ cells are characterised by a multiple innervation pattern: each neuron samples one-to-many glomeruli. Since temperature signals are conveyed to the vertebrate olfactory bulb, the hypothesis that some $\mathrm{M} / \mathrm{T}$ cells may innervate both the temperature-sensitive $\gamma$-glomerulus and an additional glomerulus led to the following research question: Does the olfactory bulb integrate chemo- and thermosensitive inputs? 3D-volume $\mathrm{Ca}^{2+}$ imaging, line-illumination microscopy, Activity Correlation Imaging (ACI) and single-cell filling were the main techniques used to tackle this question.

2) The effects of GABAergic inhibition on M/T cell dynamics (Results - Section 3.2)

PGCs and GCs are generated in larval Xenopus at stage 41 and mature from stage 48 onward. The goal of this series of experiments was to examine the effects of GABAergic inhibition in the developping olfactory bulb. The general question being asked was: How does GABAergic inhibition shape the spontaneous, odour-evoked and correlated dynamics of M/T cells? GABA immunohistochemistry of the olfactory bulb was first carried out. Subsequently, pharmacological experiments with gabazine, a $\mathrm{GABA}_{\mathrm{A}}$ receptor antagonist were combined with $\mathrm{Ca}^{2+}$ imaging of $3 \mathrm{D}$ volumes.

3) $\mathrm{Ca}^{2+}$ spike propagation and correlation along the dendrites of $\mathrm{M} / \mathrm{T}$ cells (Results Section 3.3)

Action potentials and AP-induced $\mathrm{Ca}^{2+}$ signals backpropagate in the primary and lateral dendrites of $\mathrm{M} / \mathrm{T}$ cells of mammals with little attenuation. Here, the research question was three-fold: (i) Do somatically induced $\mathrm{Ca}^{2+}$ spikes backpropagate in $\mathrm{M} / \mathrm{T}$ dendrites of $X$. laevis tadpoles without attenuation? (ii) Do inhibitory synapses onto mitral cell affect the propagation of these signals along M/T dendrites? (iii) Can the location of inhibitory synapses thus be inferred? Several methods were thereby employed: combined patch-clamp recordings and $\mathrm{Ca}^{2+}$ imaging, $\mathrm{ACI}$ on $\mathrm{M} / \mathrm{T}$ dendrites and pharmacological application of gabazine. 


\section{Materials and Methods}

All experiments with laboratory-bred Xenopus laevis tadpoles were performed according to the guidelines approved by the Göttingen University Committee of Ethics in Animal Experimentation. $X$. laevis being a poikilothermal animal, all experiments were carried out at room-temperature. Standard chemicals were purchased from Merck Millipore or Sigma-Aldrich (Schnelldorf, Germany) unless stated otherwise.

\subsection{Nose-brain acute slices}

This procedure was performed according to Scheidweiler et al. ${ }^{158}$. Pre-metamorphic Xenopus of stages $49-54^{4}$ were anesthesized in ice-cold water and sacrificed. A block of tissue containing the two nasal cavities, olfactory nerves and olfactory bulbs, and the telencephalon was dissected using a scalpel. Subsequently, the brain tissue was glued to a magnetic platform and immersed in a chamber containing frog Ringer's solution (98 mM $\mathrm{NaCl}, 2 \mathrm{mM} \mathrm{KCl}, 1 \mathrm{mM} \mathrm{CaCl} 2,2 \mathrm{mM} \mathrm{MgCl}_{2}, 5 \mathrm{mM}$ glucose, $5 \mathrm{mM}$ Na-pyruvate, $10 \mathrm{mM}$ HEPES, adjusted to pH 7.8 and 230 mOsm). A vibratome (Leica VT1000) was used to slice off the dorsal part of the olfactory bulb, which, at these developmental stages is devoid of glomeruli and is merely a meshwork of fibres. The resulting $300 \mu \mathrm{m}$-thick slice exposed the 3 layers of the olfactory bulb, facilitating the analysis of the structure and function of OB neurons. The preparation was placed in a recording chamber and constantly perfused with Ringer's solution.

\subsection{Calcium imaging and pharmacological treatment in acute slices}

Nose-brain preparations were incubated for $1 \mathrm{~h}$ with a staining solution containing 18 $\mu \mathrm{M}$ Fluo-4 AM ( $\mathrm{K}_{\mathrm{D}}$ for $\mathrm{Ca}^{2+}=325 \mathrm{nM}$; Life Technologies, OR, USA) or Fluo-8 AM (K for $\mathrm{Ca}^{2+}=389 \mathrm{nM}$; TEFlabs, TX, USA), 5\% DMSO (Merck Millipore), 1\% pluronic acid F-127 (Sigma-Aldrich), and $50 \mu \mathrm{M}$ MK571 (Alexis Biochemicals, Grünberg, Germany). F-127 and DMSO facilitated the dissolution of the hydrophobic AM esters in aqueous solution. During the incubation time, endogenous esterases cleaved the AM groups, thus trapping the calcium dyes intracellularly. MK571, an inhibitor of the multidrug resistance- 
associated protein transporter was added to enhance the staining efficiency by impeding dye extrusion ${ }^{159}$. After several washes with pure Ringer's solution, the slices were placed in a recording chamber and placed under a 40X /0.8 water-immersion objective. Fluo-4 and Fluo-8 were excited at 488 nm (Sapphire 488 LP, Coherent, Santa Clara, USA) and the fluorescence was detected by a line CCD camera (AViiVA SM2, e2V, Essex, England). $2 \mathrm{D}$ and $3 \mathrm{D}$ timeseries were acquired with a custom-built line illumination microscope ${ }^{52}$ scanning at $30 \mathrm{~Hz}$ for single frames and ca. $5 \mathrm{~Hz}$ for stacks, respectively. In pharmacological

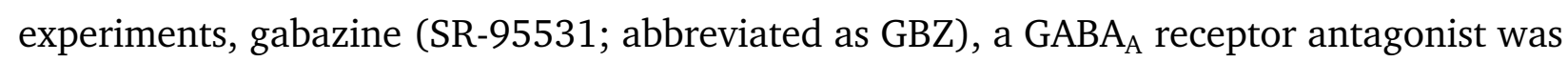
purchased from Sigma-Aldrich, diluted in Ringer's solution at $100 \mu \mathrm{M}$ and perfused over the olfactory bulb slices. After a 5-6 min incubation, it was washed out by a perfusion of pure Ringer's solution.

\subsection{Stimulus application}

Amino acids have been proved to be effective odourants for Xenopus tadpoles ${ }^{160}$ as they likely serve as food cues for fish and amphibia. Thus, a mixture of the following 14 amino acids was standardly used as stimulus for olfactory receptor neurons lining the nasal epithelium: L-alanine, L-arginine, L-cysteine, L-histidine, L-isoleucine, L-leucine, L-lysine, Lmethionine, L-phenylalanine, L-proline, L-serine, L-threonine, L-tryptophane, and L-valine, at $50 \mu \mathrm{M}$ each. Temperature drops were achieved by applying $1 \mathrm{~mL}$ of cool Ringer's solution $\left(\mathrm{T}=0{ }^{\circ} \mathrm{C}\right.$ ) to the olfactory epithelium of the animal. The application of room-temperature Ringer's solution $\left(\mathrm{T}=20-22^{\circ} \mathrm{C}\right)$ served as a negative control. The resulting fluctuations of temperature were monitored with a NiCr-Ni thermosensor (GTF 300, Greisinger Elektronik, Regenslauf, Germany) positioned closely to the nasal cavity. All water-borne stimuli were applied via a custom-built funnel applicator ${ }^{161}$, with its outlet placed in front of the left or right olfactory epithelium. The stimulus solutions were released from an electronic pipette (HandyStep electronic, Brand $\mathrm{GmbH}$, Wertheim, Germany) modified to be triggered by a TTL signal initiated by the microscope. Each stimulation was repeated twice to assess the reproducibility of $\mathrm{Ca}^{2+}$ responses after an minimal interstimulus interval of 150 seconds. The perfusion of Ringer's solution over the slice was not interrupted during the release of the stimulus solution into the funnel in order to minimise flow disturbances in the nostril. 


\subsection{Single-cell filling and morphological reconstruction}

M/T cells were individually filled with Alexa Fluor 488 Biocytin (427 $\mu \mathrm{M}$ ) or Alexa Fluor 594 Biocytin $(100 \mu \mathrm{M})$ according to a standard procedure ${ }^{162}$. Borosilicate patch pipettes (1.8 OD, Hilgenberg, Germany) with a resistance of 10-15 $\mathrm{M} \Omega$ were pulled with a vertical two-step puller (PC-10, Narishige, Japan). The fluorophores were dissolved in an intracellular solution of the following composition (in mM): 80 K-gluconate, $2 \mathrm{NaCl}, 11 \mathrm{KCl}, 2$ $\mathrm{MgSO}_{4}, 10$ HEPES (pH 7.8 with $\mathrm{NaOH}$ ), 0.2 EGTA, 5 Na-ATP, 1 Na-GTP. Acute slices of the olfactory bulb were prepared and placed in a recording chamber. The pipette filled with the staining solution was lowered in the mitral/tufted cell layer under a 40X/0.8 or $63 \mathrm{X} / 0.95$ water-immersion objective. After the formation of the gigaseal, the cell membrane was ruptured and the cell clamped in whole-cell voltage-clamp configuration. The membrane potential was held at $-60 \mathrm{mV}$ while the cell was loaded with the dye for about $20 \mathrm{~min}$. Subsequently, the morphology was imaged under the line illumination microscope by taking 3D stacks. Alexa Fluor 488 and Alexa Fluor 594 were excited at $488 \mathrm{~nm}$ and $568 \mathrm{~nm}$, respectively. After the image acquisition, the arborisations of a few M/T cells were semi-manually reconstructed with the free software Neuromantic ${ }^{163}$ (http://www.reading.ac.uk/neuromantic).

\subsection{Data analysis and processing}

Image and data analyses were performed in MATLAB (MathWorks) and MatVis, a graphical user interface developed by Stefan Junek). 3D image stacks were shift-corrected and bleach-corrected only when necessary. Shift correction along the $\mathrm{x}$ - and $\mathrm{y}$ - and z-directions was achieved by a custom-written MATLAB script written by Mihai Alevrea and earlier described $^{88}$. Bleach correction was performed by subtracting the linear decay characterising photobleached signals using Legendre transform ${ }^{164}$. 


\subsection{1 $\Delta \mathrm{F} / \mathrm{F}$ and response criterion}

Odour-induced $\left[\mathrm{Ca}^{2+}\right]$ changes were displayed as fluorescence pixel intensities or represented as $\Delta \mathrm{F} / \mathrm{F}$ :

$$
\frac{\Delta F}{F}=\frac{F(t)-F_{0}}{F_{0}}
$$

$\mathrm{F}(\mathrm{t})$ is the raw fluoresence over time after subtraction of the camera background and $F_{0}$, the average of $10 \%$ of the entire data points, prior to the stimulus application.

The signals of the pixels within a region of interest were averaged to generate a single fluorescence value. $\mathrm{A} \Delta \mathrm{F} / \mathrm{F}$ rise was considered a response if a roi showed a higher mean change in fluorescence $(\Delta \mathrm{F} / \mathrm{F})$ over the $4 \mathrm{~s}$ after stimulus application than its maximum value over the $4 \mathrm{~s}$ preceding it.

\subsubsection{Fourier analysis}

Raw fluorescence signals were converted from the time domain to the frequency representation using the fast Fourier transform (fft) built-in function of MATLAB. The positive halves of the Fourier transform were averaged within a M/T cell pool and plotted in a spectrum showing the magnitude of the signals over their frequencies. Since the spontaneous firing rates of Xenopus $\mathrm{M} / \mathrm{T}$ cells are relatively low, and associated $\left[\mathrm{Ca}^{2+}\right]$ waves even slower ${ }^{58}$, the $\mathrm{fft}$ frequencies were low-pass filtered at $3 \mathrm{~Hz}$.

\subsubsection{Activity Correlation Imaging}

Activity Correlation Imaging (ACI) is a method which uses each neuron's specific activity waveform as a contrast variable to build a detailed picture of the network connectivity ${ }^{52}$. To briefly summarise the principle of ACI, the temporal signal of a region of interest is selected as a reference trace and cross-correlated with every other pixel in the scanned volume (Figure 2.1). As individual neurons often exhibit specific temporal patterns, multiple correlation maps of different activity can be acquired and combined. This approach yields a high-contrast, multi-colour, 3D visualisation of neural ensembles and their connectivity. 


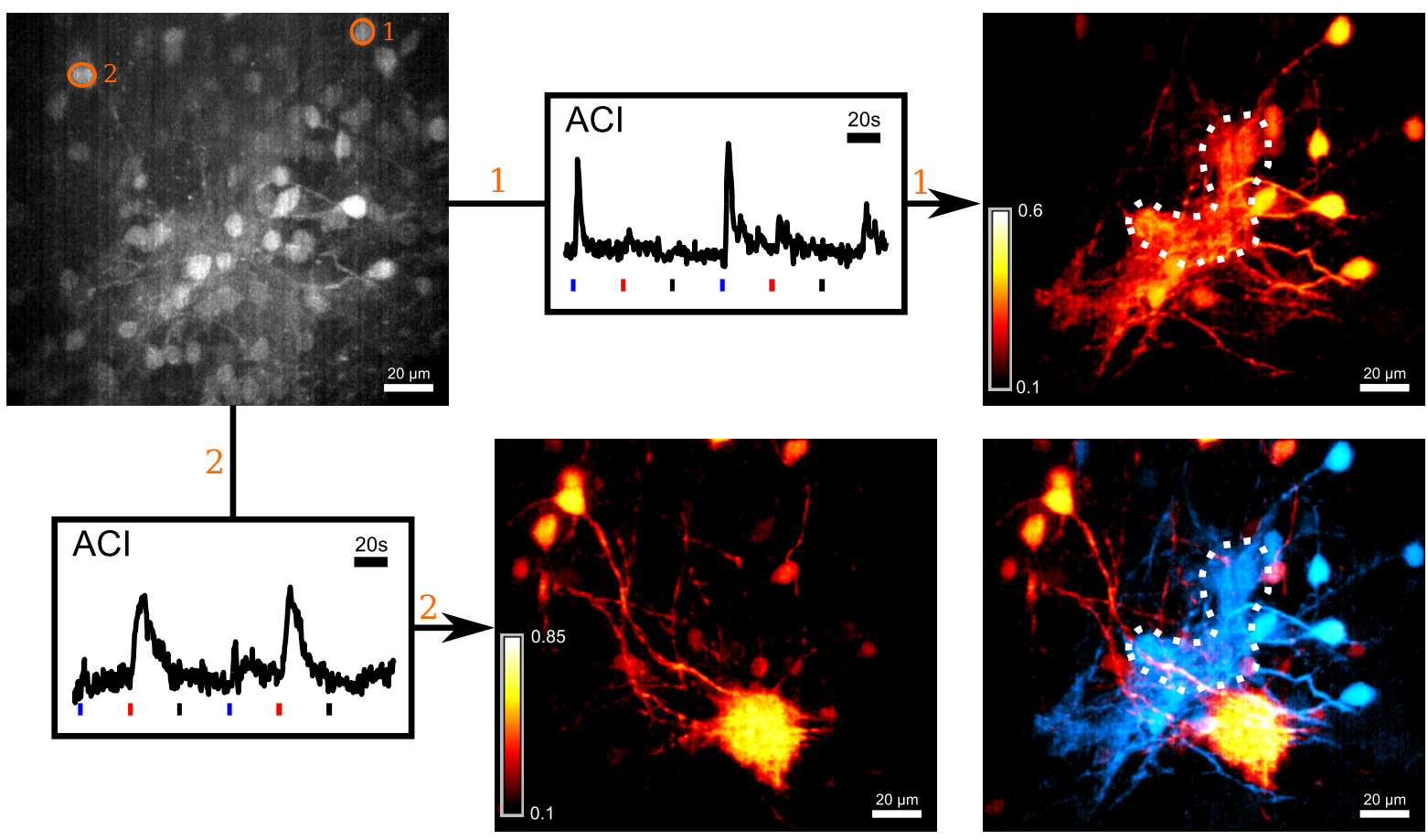

Figure 2.1: Principle of ACI

Two regions of interest Roi1 and Roi2 are drawn from the somata of M/T cells, and their specific $\mathrm{Ca}^{2+}$ temporal patterns are extracted. Next, correlation maps of individual image planes are calculated based on the reference signals of Roi1 and Roi2. The maps are displayed as z-projections of the maximal correlation values and reveal the connectivity of M/T cells. Finally, colour-coding each map allows the visualisation of the structural organisation networks of different activity. Figure adapted from $\operatorname{Ref}^{30}$.

The correlation factor $c_{i j}$ between a reference trace $r_{j}(t)$ and the time trace $v_{i}(t)$ of each pixel in the volume is given by the formula:

$$
c_{i j}=\frac{\sum_{t=1}^{T}\left(v_{i}(t)-\overline{v_{i}}\right) \cdot\left(\left(r_{j}(t)-\overline{r_{j}}\right)\right.}{\left\|v_{i}(t)-\overline{v_{i}}\right\| \cdot\left\|r_{j}(t)-\overline{r_{j}}\right\|},
$$

where $t$ is the number of data points ranging from 1 to $T$. The calculation of $c_{i j}$ outputs a number between -1 and 1 , whereby a negative value indicates a negative correlation between the two temporal signals, and positive value, a positive correlation. 


\subsection{Cell electroporation of ORNs}

The electroporation of the nasal cavity of Xenopus laevis was carried out to stain the dendrites, cell bodies, and axons of olfactory receptor neurons. Tadpoles of stages 49-54 were electroporated according to a method formerly described in detail by Kludt et al. ${ }^{24}$ and Brinkmann et al. ${ }^{30}$. Briefly, animals were anesthesized in 3\% tricaine methane sulfonate (MS-222) and placed under a stereomicroscope. Dye crystals of $10 \mathrm{kDa}$-Dextran Alexa Fluor 488 or $10 \mathrm{kDa}-$ Dextran Alexa Fluor 647 (Thermo Scientific) were positioned in the mucosae until full dissolution, and platinum electrodes were inserted in each nostril, and 6 square pulses of $20 \mathrm{~V}$ and $20 \mathrm{msec}$ were applied at $1 \mathrm{~Hz}$ using a custom-made electroporator. For some experiments, Dextran Alexa Fluor 488 was electroporated in one nasal cavity, and Dextran Alexa Fluor 647, in the contralateral nostril, thus bringing about a differential staining of ipsilateral and contralateral receptor neurons. The animals were allowed to recover in tap water, and supplemented with food after fully regaining their swimming behaviours. As dextran-conjugates passively diffuse at a rate of ca. 1-2 mm/day, the brains of electroporated animals were imaged from 2 to 10 days after the procedure to allow the staining of axons terminals in glomeruli.

\subsection{Nose-brain explant (whole-mount preparation)}

A few days after ORN electroporation, pre-metamorphic animals were anaesthetised in ice water and sacrificed by severing the spinal cord. A block of tissue containing the nostrils, the olfactory nerves and bulbs was dissected out and flipped so that the ventral surface faced upwards. The brain explant was fixed with needles inserted through the skin and a drop of Ringer's solution was added to prevent the tissues and cell layers from collapsing upon dissection. Hereafter, the meninges covering the ventral olfactory bulb were removed with fine scissors, thereby exposing the neuropil for imaging. The whole-mount preparation was placed in a recording chamber and a platinum net was secured on top of it. 


\subsection{Anti-GABA immunohistochemistry}

$X$. laevis animals of stages 49-54 which had previously undergone ORN electroporation with Dextran Alexa Fluors 488, 546 or 647 (Thermo Fisher Scientific) were anaesthetised in ice water and sacrificed. A block of tissue containing the nostrils, the olfactory nerves and bulbs was dissected out and fixed in 4\% paraformaldehyde (Sigma, USA) at roomtemperature for $3 \mathrm{~h}$. The immunohistochemical localisation of GABA was carried out according to the procedure described in Nezlin et al. ${ }^{18}$, with some modifications. The brain preparations were subsequently immersed in 30\% saccharose (Carl Roth GmbH, Germany) for $2-3$ days at $4{ }^{\circ} \mathrm{C}$ and then mounted in Tissue-Tek embedding matrix (Sakura, The Netherlands). $50 \mu \mathrm{m}$-thick horizontal slices were sectioned at $-2{ }^{\circ} \mathrm{C}$ using a LEICA CM1850 cryostat, thaw-mounted on Superfrost Plus microscope slides (Thermo Scientific), and air-dried at room temperature. After 3 washes of $5 \mathrm{~min}$ in PBS, the sections were blocked in a solution containing PBS, $0.1 \%$ Triton-X-100, and $2 \%$ normal goat serum (NGS) for $3 \mathrm{~h}$ at room temperature, and incubated at $4{ }^{\circ} \mathrm{C}$ overnight with an primary antibody against GABA (1:1000; rabbit polyclonal IgG; Immunostar, WI, USA) diluted in the blocking solution. On the following day, the sections were washed 3 times for $20 \mathrm{~min}$ in PBS and incubated for 3-4 h at room temperature with a fluorescent secondary antibody: either donkey-anti-rabbit Alexa Fluor 647-conjugate or goat-anti-rabbit Alexa Fluor 488-conjugate (1:500; IgG; Life Technologies) diluted in 1\% NGS/PBS. After 3 washes of 20 min in PBS, a counterstaining solution containing propidium iodide (PI) at $5 \mu \mathrm{g} / \mathrm{mL}$ in PBS covered the slides for 25 min. Finally, all slides were once more washed in PBS for $30 \mathrm{~min}$, mounted in DAKO mounting medium (DAKO, USA) under a coverslip (Carl Roth GmbH, Germany), and imaged under a laser-scanning confocal microscope (LSM 780 /AxioExaminer, Carl Zeiss) using a W Plan-Apochromat 20X /1.0 DIC objective. Figure 2.2 illustrates the excitation and emission wavelengths of Alexa Fluor 488, propidium iodide and Alexa Fluor 647, the fluorophores used to stain olfactory bulb layers. As PI was excited by both the $488 \mathrm{~nm}$-laser and the emitted light of AF488, its usage was avoided in combination with anti-GABA immunostaining in order to prevent bleed-through contamination. 

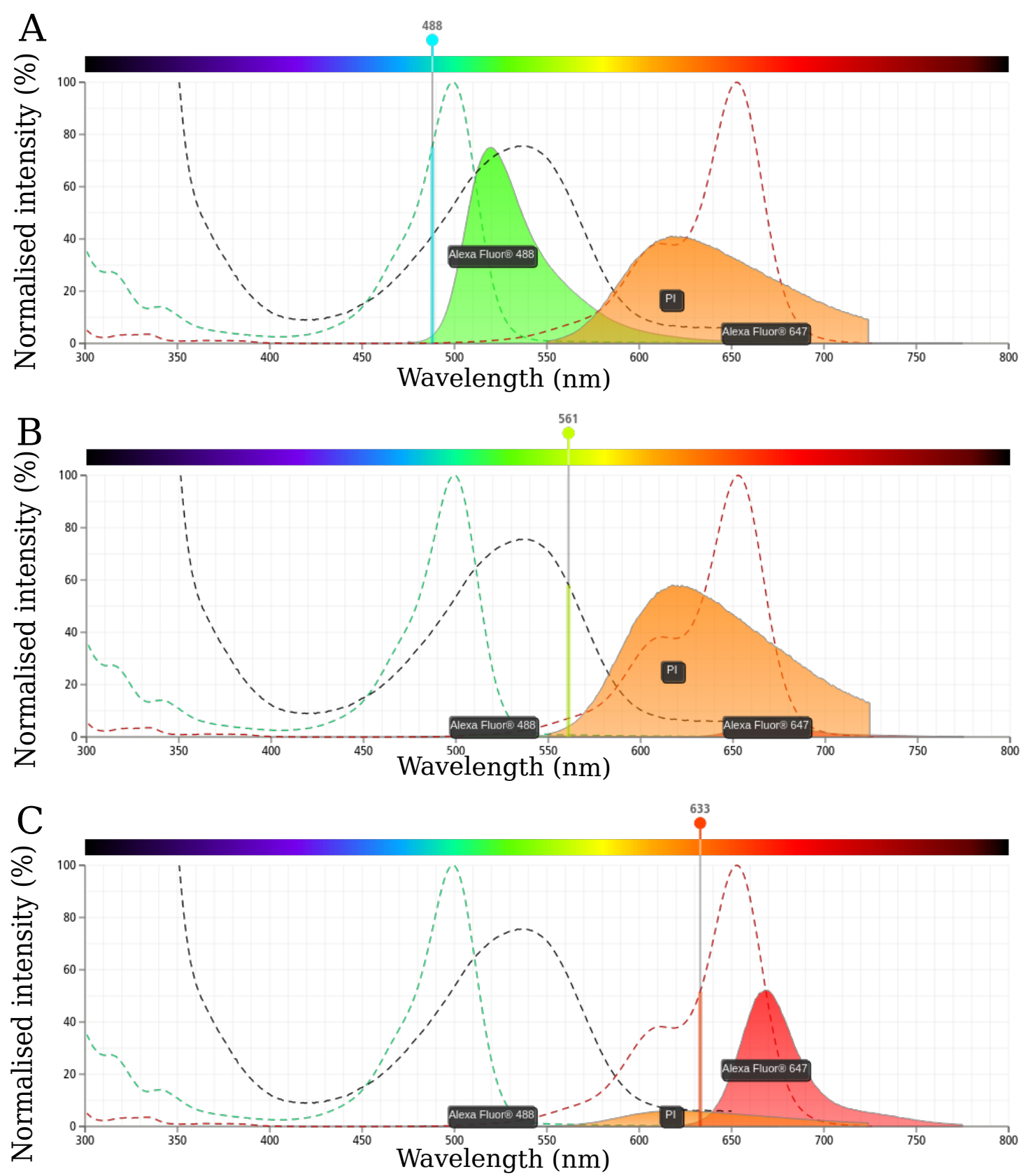

Figure 2.2: Fluorescent spectra of Alexa Fluor 488 (AF488), propidium iodide (PI) and Alexa Fluor 647 (AF647)

The relative spectral intensities of these fluorophores are displayed upon laser excitation at $488 \mathrm{~nm}$ (A), $561 \mathrm{~nm}$ (B) and $633 \mathrm{~nm}$ (C). The green, black and red dashed lines delimit the excitation spectra of AF488, PI, and AF647, respectively. The emission spectra of AF488, PI, and AF647 are shown in green, orange and red, respectively. These plots were obtained using the BD Biosciences Spectrum Viewer online tool. 


\subsection{Combined electrophysiological and calcium imaging recordings}

Simultaneous calcium imaging and patch clamp measurements in M/T cells of Xenopus laevis had been carried out and described in a former study ${ }^{157}$. A similar protocol was developed for these experiments. No bath loading of the acute slices with AM dyes was done prior to establishing a loose seal patch clamp. Instead, single M/T cells were clamped in whole-cell configuration, and the internal solution supplemented with Fluo- $8 \mathrm{~K}^{+}$salt (TEFlabs, TX, USA) was allowed to diffuse inside the neuron. Borosilicate patch pipettes (1.5 OD, Harvard Apparatus, UK) with a resistance of 6-8 M $\Omega$ were pulled with a horizontal DMZ-Universal puller (5318904120B, Zeitz Instruments) and filled with an intracellular solution of the following composition (in $\mathrm{mM}$ ): $80 \mathrm{~K}$-gluconate, $2 \mathrm{NaCl}, 11 \mathrm{KCl}, 2 \mathrm{MgSO}_{4}$, 10 HEPES (pH 7.8 with NaOH), 0.2 EGTA, 5 Na-ATP, 1 Na-GTP. For single-cell calcium imaging experiments, Fluo- $8 \mathrm{~K}^{+}$salt was added to the pipette solution, as well as Alexa Fluor 594 Biocytin for the analysis of M/T cell morphology, at at final concentration of $200 \mu \mathrm{M}$ and $100 \mu \mathrm{M}$ respectively. A positive pressure of 15-20 hPa was constantly applied to the pipette whilst being lowered to the brain slice. $\mathrm{M} / \mathrm{T}$ cells were identified and targeted based on their position within the mitral/tufted cell layer in acute slices of the olfactory bulb. In voltage-clamp mode, the holding potential of M/T cells was $-60 \mathrm{mV}$, and when switching to current clamp recordings, a negative current was automatically introduced to maintain the membrane potential of the cell around the same value (usually $-60 \mathrm{mV}$ ) The electrophysiological parameters and signals were recorded with a HEKA EPC9 Amplifier controlled by the PatchMaster software. $\mathrm{Ca}^{2+}$ imaging was achieved with line illumination microscope — newly built by Alexander Brinkmann — enabling the excitation of two fluorophores. Fluo-8 was excited with at $488 \mathrm{~nm}$ (Sapphire $488 \mathrm{LP}$, Coherent, Santa Clara, USA), whereas Alexa Fluor 594 Biocytin, added for morphological analysis was excited with at $568 \mathrm{~nm}$ (Sapphire $568 \mathrm{LP}$, Coherent, Santa Clara, USA). The onset and end of each calcium imaging sequencewas recorded as a third input channel of the amplifier and displayed on the PatchMaster interface.

After the patch-clamp and calcium imaging measurements, the identity of M/T cells was confirmed based on the AF 594 staining of dendrites terminally sprouting in glomeruli. 


\subsubsection{Depolarising pulses and fitting of $\mathrm{Ca}^{2+}$ spikes}

$\mathrm{Ca}^{2+}$ spikes were evoked by depolarising voltage steps or current injections to the M/T cell soma. In voltage-camp experiments, the membrane potential was depolarised from -60 to $0 \mathrm{mV}$ in 3 pulses of $10 \mathrm{~ms}$ each and interstimulus interval of $2 \mathrm{~s}$, repeated after $10 \mathrm{~s}$. The entire stimulation sequence with its 6 voltage pulses lasted $20 \mathrm{~s}$ in total. In the current clamp configuration, 3 successive current injections of $0.3 \mathrm{nA}$ for $8 \mathrm{~ms}$ each (inspired from Ref. ${ }^{165}$ ), and $2 \mathrm{~s}$ of interstimulus interval were triggered and reiterated after $10 \mathrm{~s}$. Similarly, the completion of the 6 current pulses also lasted 20 s. Each current pulse triggered a somatic action potential, recorded in the voltage channel.

For the correlation analysis of $\mathrm{Ca}^{2+}$ fluctuations along $\mathrm{M} / \mathrm{T}$ cell dendrites, the slow $\mathrm{Ca}^{2+}$ waves were first fitted with Gaussian curves and then subtracted from the overall signals. As a result, the correlation was calculated based on the backpropagating $\mathrm{Ca}^{2+}$ spikes only. In some experiments, the backpropagating $\mathrm{Ca}^{2+}$ spikes were approximated with double exponential rise/decay curves. The main algorithm — written by Mihai Alevrafor generating the fit curve $f_{(t]}$ was defined as follows:

$$
f_{(t]}=A \cdot\left(1-e^{-\left(t-t_{0}\right) / \tau_{r}}\right) \cdot\left(e^{-\left(t-t_{0}\right) / \tau_{d}}\right),
$$

where, $A$ represents the amplitude of the spike, $t$, the time vector of the signal, $t_{0}$, the time point of one spike occurrence, $\tau_{r}$ the rise time, and $\tau_{d}$, the decay time. The fit curve was subsequently used as a reference trace for calculating cross-correlations within single dendrites. 


\section{Results}

\subsection{Dual sensitivity and structure-function relationship of M/T cells}

\subsubsection{Glomerular innervation patterns of $\mathrm{M} / \mathrm{T}$ cells}

Single neurons located in the M/T cell layer were targeted for dye loading with Alexa Fluor 488 Biocytin or Alexa Fluor 594 Biocytin. Only the cells clearly connected to at least one glomerulus were regarded as $\mathrm{M} / \mathrm{T}$ cells. If periglomerular or granule cells bordering the $\mathrm{M} / \mathrm{T}$ cell layer were unintentionally filled, their identity was easily recognisable based on the singular morphological traits. PGCs typically showed a bushy dendritic arborisation, whereas GCs grew spines on their dendrites (Figure 3.1A,C).
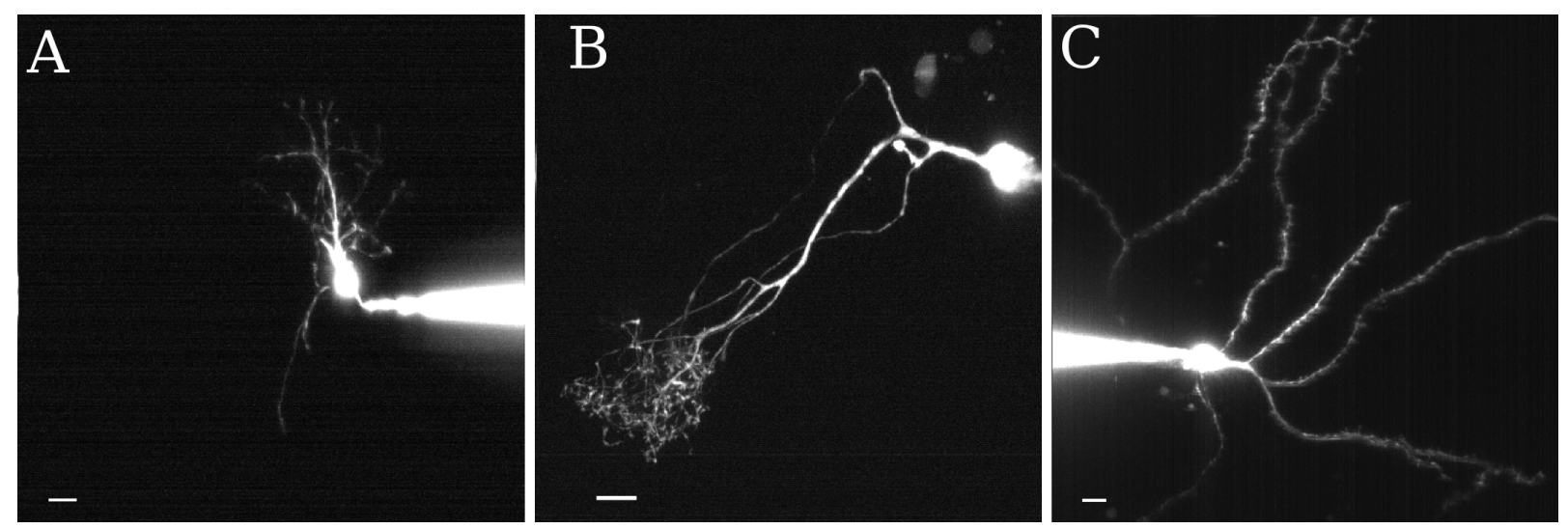

Figure 3.1: A periglomerular, mitral/tufted and granule cell

Single cell filling of a PGC (A), M/T cell (B) and GC (C) with Alexa Fluor 488 Biocytin $(A, B)$ and Alexa Fluor 594 Biocytin (C). Note the highly branched "bushy" dendritic tree of PGCs, the glomerular innervation by M/T cells and the long spiny dendrites of GCs. All images are z-projections of the maximal intensities. Scale bars: $10 \mu \mathrm{m}$.

$28 \mathrm{M} / \mathrm{T}$ cells were analysed for their general dendritic morphologies, i.e. their number of glomeruli, neurites and branches. $57 \%$ of all cells connected to only one glomerulus and $43 \%$ to two or more glomeruli. 3 of them only were unipolar, the majority of them (88\%) being bipolar or displaying a complex dendritic structure. All principal neurites bifurcated at least once, giving rise to $1^{\text {st }}$ order branches, and most of $(71 \%)$ showed $2^{\text {nd }}$ or higher order branches (Figure 3.2). 


\begin{tabular}{clllllll}
\hline Number per M/T cell & $\mathbf{0}$ & $\mathbf{1}$ & $\mathbf{2}$ & $\mathbf{3}$ & $\mathbf{4}$ & $\mathbf{5}$ & $\mathbf{6 - 1 0}$ \\
\hline Glomeruli & 0 & 16 cells & 9 cells & 1 cell & 2 cells & 0 & 0 \\
Neurites & 0 & 3 cells & 11 cells & 10 cells & 4 cells & 0 & 0 \\
$1^{\text {st }}$ order branches & 0 & 0 & 19 cells & 1 cell & 4 cells & 1 cell & 3 cells \\
$2^{\text {nd }}$ order branches & 8 cells & 0 & 10 cells & 1 cell & 6 cells & 2 cells & 1 cell \\
\hline Total $(\boldsymbol{n}=\mathbf{2 8}$ cells) & & & & & & \\
\hline
\end{tabular}

Table 2: Morphological analysis of M/T cells and their number of glomeruli, neurites and dendritic branches per cell

The number of glomeruli, neurites (all processes growing from the soma), $1^{\text {st }}$ order branches and $2^{\text {nd }}$ order branches per M/T cell was counted. Subsequently, the 28 cells filled with Alexa Fluor 488 Biocytin or Alexa Fluor 594 Biocytin were divided into each category.
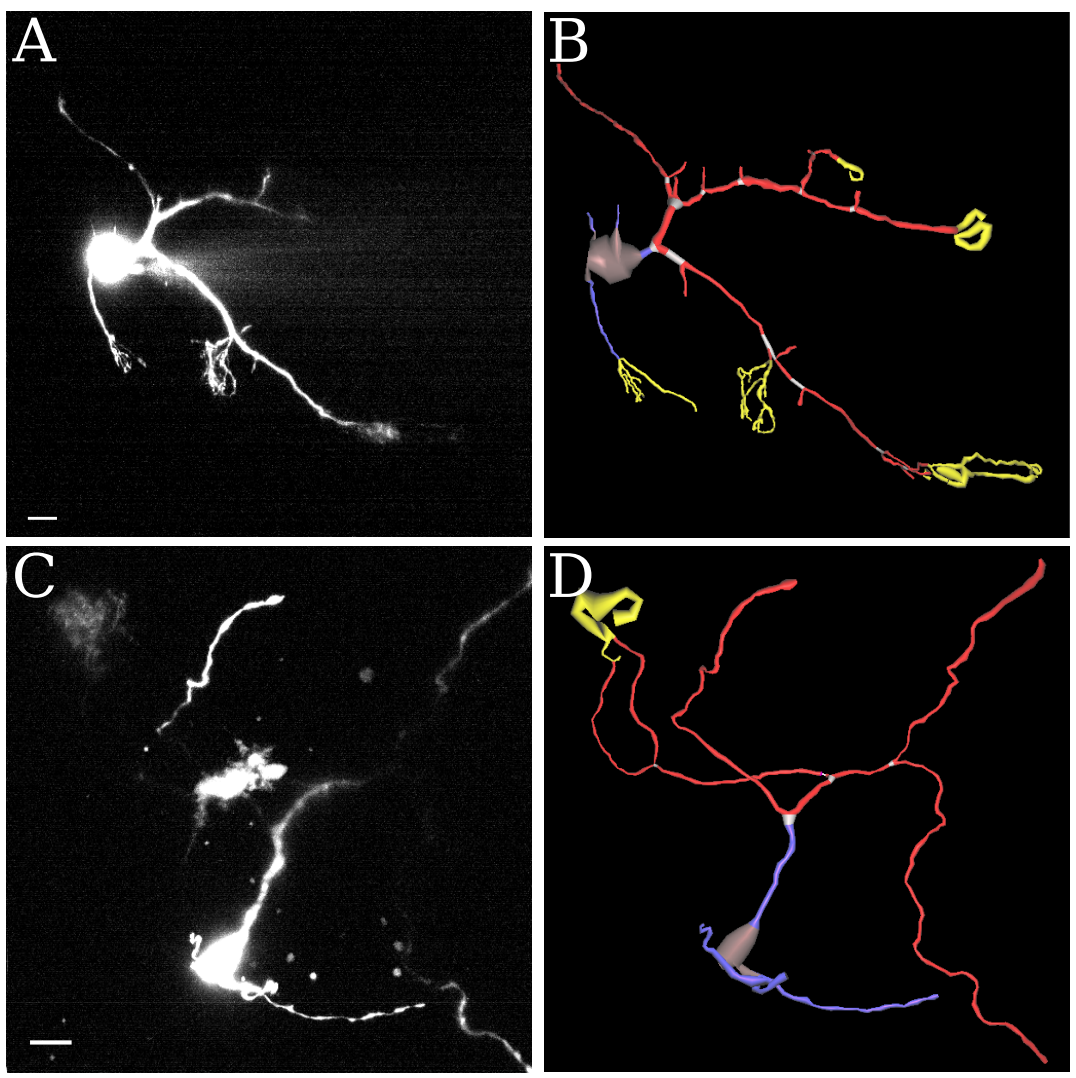

Figure 3.2: Different connectivity patterns of $\mathrm{M} / \mathrm{T}$ cells

(A,C) Single-cell filling of 2 mitral/tufted cells with Alexa Fluor 488 Biocytin. The first M/T cell (A) innervates multiple glomeruli, while the second one (C) only connects to a single glomerulus. These images are z-projections of the maximal intensities. Scale bars: $10 \mu \mathrm{m}$. (B,D) 3D reconstructions of the M/T cells. Somata are colour-coded in dark grey, neurites in purple, $1^{\text {st }}$ and $2^{\text {nd }}$ order branches in red, branching points in light gray, and glomeruli and yellow. 
Since each glomerulus serves as a functional unit of early olfactory processing, these $\mathrm{M} / \mathrm{T}$ cells sampling more than one glomeruli receive several olfactory inputs which they likely integrate at their soma. As amino acid sensitivity and temperature sensitivity have been reported in the bulb, the multiple glomerular innervation by some M/T cells may enable them to collect and integrate both chemical and thermic information. In order to verify this hypothesis, $\mathrm{Ca}^{2+}$ imaging experiments were performed on OB slices bulk-loaded with the calcium indicator Fluo-4 AM. A highly concentrated mixture of 14 amino acids (50 $\mu \mathrm{M}$ ) was used to stimulate chemosensitive networks, and subsequently, cold Ringer's solution $\left(0^{\circ} \mathrm{C}\right)$ was applied to trigger responses in the thermosensitive $\gamma$-glomerulus and connected $\mathrm{M} / \mathrm{T}$ cells. Both stimuli were applied twice to control the reproducibility of $\left[\mathrm{Ca}^{2+}\right]$ responses.

\subsubsection{Chemosensitivity in the OB}

The application of amino acids to the olfactory epithelium of $X$. laevis tadpoles brought about strong and reversible $\left[\mathrm{Ca}^{2+}\right]$ responses in glomerular and mitral/tufted cell layers (Figure 3.3). Horizontal sections of the OB provided access to M/T cells of the superficial layers M/T cells easily reached by the calcium indicator. Amino-sensitive glomeruli, located on the ventral surface, however were less efficiently stained owing to a poor dye penetration into the deepest layers (below ca. $80 \mu \mathrm{m}$ from the top surface). Therefore, ACI was applied in order to better visualise $\mathrm{M} / \mathrm{T}$ cell processes and the activated glomeruli. Correlation maps were calculated using the soma of a responsive $\mathrm{M} / \mathrm{T}$ cell as a region of interest (Roi) to extract a reference trace of the fluorescence signal.

\subsubsection{Temperature sensitivity in the OB}

The application of $1 \mathrm{~mL}$ of cold Ringer's solution $\left(0^{\circ} \mathrm{C}\right)$ to the nostril of the animal caused an average temperature drop of $-1.1^{\circ} \mathrm{C}$ measured by thermosensor positioned in the recording chamber. These negative temperature fluctuations (T-jumps) only activated the $\gamma$-glomerulus and the connected M/T cells (Figure 3.4). The position of the $\gamma$-glomerulus being extremely ventral, this structure was often poorly reached and stained by Fluo-4 and often not identifiable. Although the innervation of the $\gamma$-glomerulus by M/T cells was rarely 
observable in these experiments, the presence of temperature-sensitive $\mathrm{M} / \mathrm{T}$ cells confirmed its activation by T-jumps induced at the nasal epithelium. 

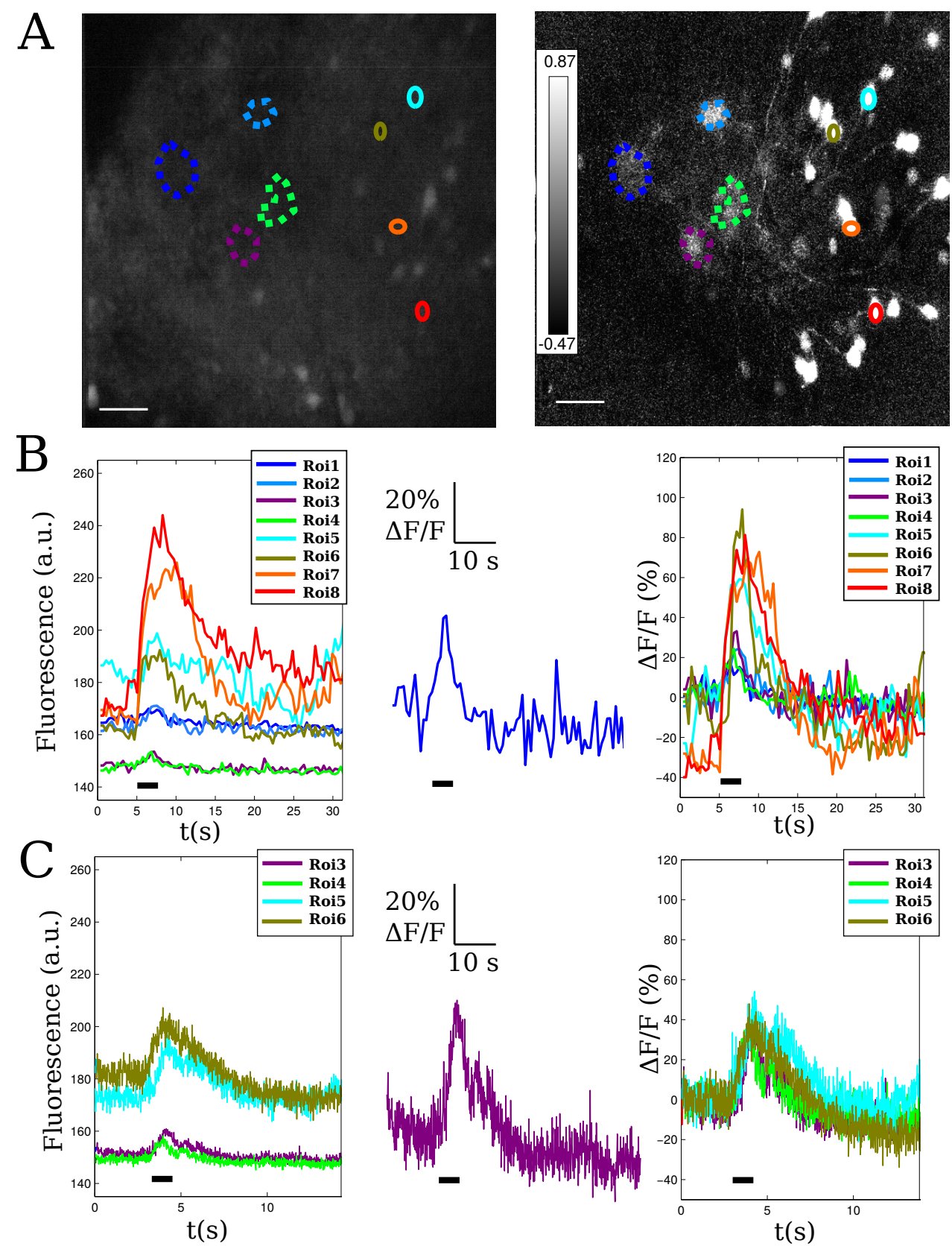

Figure 3.3: Amino acid-sensitive glomeruli and $\mathrm{M} / \mathrm{T}$ cells

(A) Left: Raw fluorescence image of an olfactory bulb slice. These images are z-projections of the mean intensities of a $30 \mu \mathrm{m}$-thick volume in one frame. Dotted regions of interest represent glomeruli activated by the amino acid application. The oval/circular smallest regions surround amino acid-sensitive M/T cells. Right: Maximal z-projection correlation maps calculated for 10 planes. The colour bar indicates the black-to-white colour intensities assigned to the correlation values. ACI yields a better contrast for visualising glomerular-to$\mathrm{M} / \mathrm{T}$ cell connectivity based on activity. Scale bars: $50 \mu \mathrm{m}$. (B) Left: Raw fluorescence signal of the 8 Rois in A plotted over time. Middle: Temporal signal of an amino acid-sensitive glomerulus (Roi1). Right: $\Delta \mathrm{F} / \mathrm{F}$ signals plotted over time. The black bars beneath the graphs represent the application of $1 \mathrm{~mL}$ of a mixture of 14 amino acids (cf Materials and Methods) at $50 \mu \mathrm{M}$. (C) Repeated measurement with a second application of the same stimulus. The responses of Rois 3 to 6 are shown. 

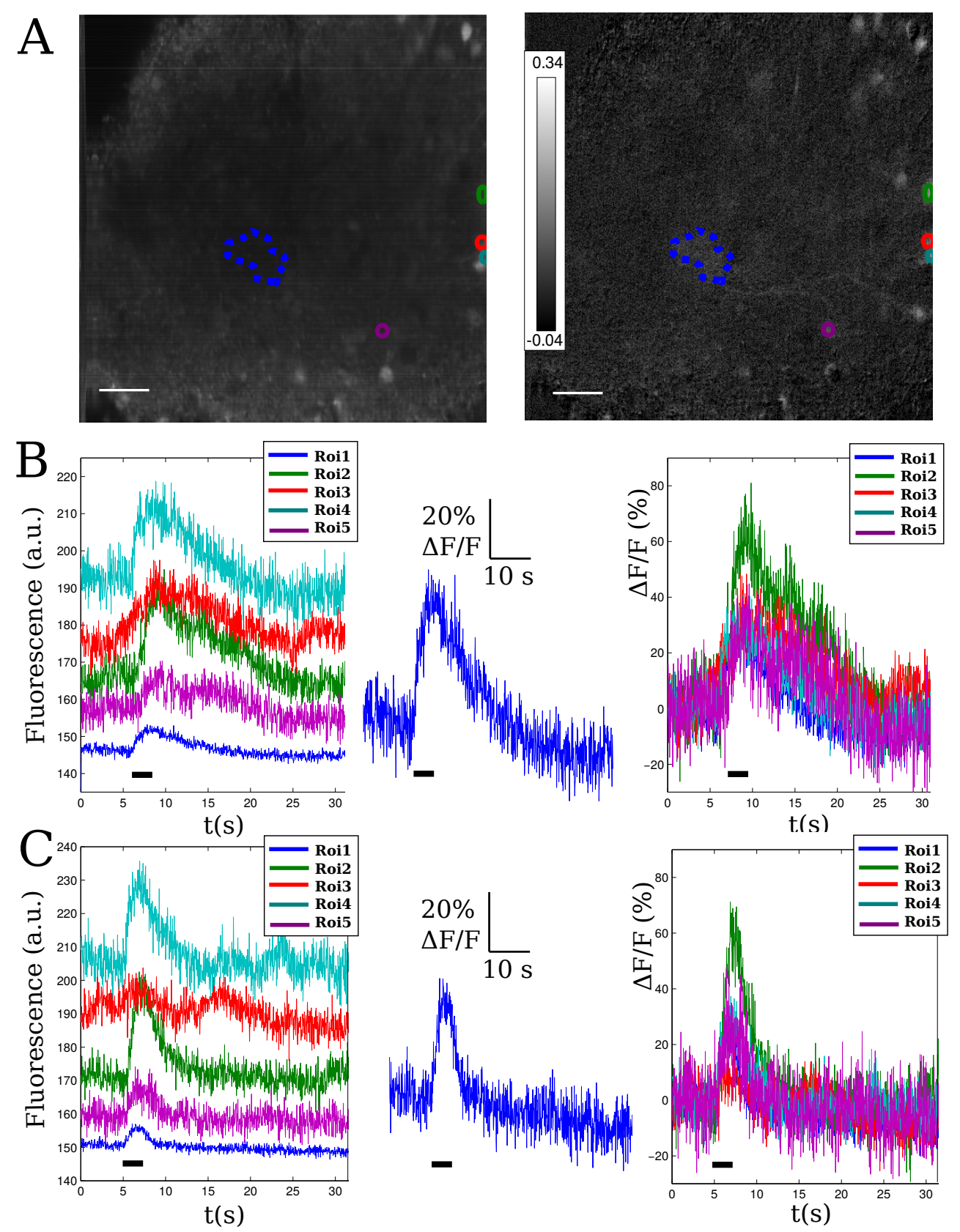

Figure 3.4: Thermosensitivity of the $\gamma$-glomerulus and connected M/T cells

(A) Left: Raw fluorescence image of a single plane within the olfactory bulb. The image is shown as mean intensity of the signals over time. The dotted blue regions of interest represent the thermosensitive $\gamma$-glomerulus, and the oval/circular smallest regions surround $\mathrm{M} / \mathrm{T}$ cells also activated by the temperature drop. Right: Correlation map of the same plane. The colour bar indicates the black-to-white colour intensities assigned to the correlation values. The innervation of the $\gamma$-glomerulus by Roi5 and others is faintly seen. Scale bars: $50 \mu \mathrm{m}$. (B) Left: Raw fluorescence signal of the 5 Rois in A plotted over time. Middle: Temporal signal of the $\gamma$-glomerulus (Roi1). Right: $\Delta \mathrm{F} / \mathrm{F}$ signals plotted over time. The black bars beneath the graphs represent the application of $1 \mathrm{ml}$ of a mixture of Ringer's solution at $0{ }^{\circ} \mathrm{C}$. (C) Repeated measurement with a second application of the same stimulus. 


\subsubsection{Integration of temperature and odour signals in $\mathrm{M} / \mathrm{T}$ cellular networks}

Subsequently, M/T cells were screened for both thermo- and chemosensitivity in OB slices. Calcium imaging measurements of 3D volumes were acquired with the line-illumination microscope in order to scan multiple M/T cell layers. The fields of view had average dimensions of ca. $350 \times 450 \times 40 \mu \mathrm{m}$ and were sufficiently large to comprise the lateral glomerular cluster where calcium responses to amino acids were most frequently observed, as well as the $\gamma$-glomerulus(Figure 3.5). Following the applications -in a changing order - of cold Ringer's solution, amino acids, and room-temperature Ringer's solution $\left(20-22{ }^{\circ} \mathrm{C}\right)$, the numbers of thermosensitive, chemosensitive and dual-sensitive cells were counted. 151 of out 183 cells were amino acid-sensitive only, 13 were exclusively coldsensitive, and 19 showed dual responses to both stimuli ( $n=9$ animals). Overall, 19 of the 32 thermosensitive mitral cells (59\%) were also activated by the chemical mixture. Interestingly, these dual-sensitive cells did not display the same strength of $\Delta \mathrm{F} / \mathrm{F}$ responses to both stimuli(Figure 3.5).
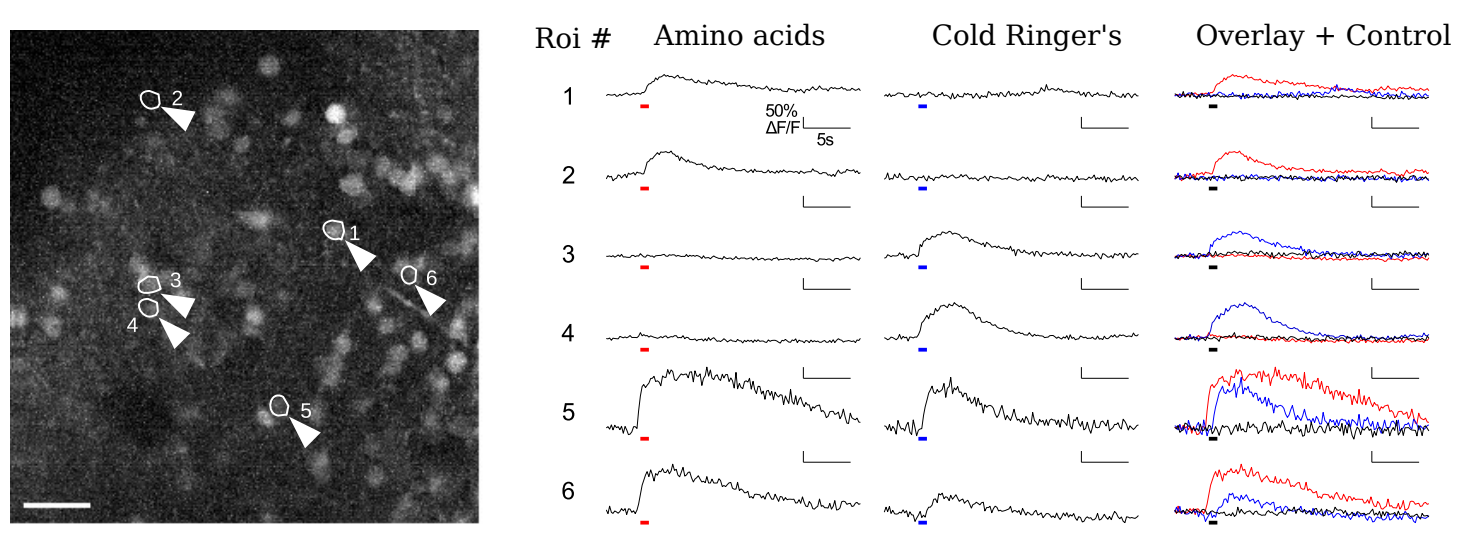

Figure 3.5: Integration of temperature and odour sensitivity in individual mitral cells Left: Z-projection of the maximal intensities of a $30 \mu \mathrm{m}$-thick volume of an OB slice. The Arrowheads highlight $6 \mathrm{M}$ /T cells. Scale bars: $50 \mu \mathrm{m}$ Right: $\left[\mathrm{Ca}^{2+}\right]$ responses of the 6 Rois to the amino acid mixture, cold Ringer's solution. The most right column shows an overlay of the stimulus-induced signals and additionally plots in black the baseline fluctuations when ambient temperature Ringer's solution is applied (negative control). The red and blue bars under the traces indicate the application of amino acids and cold Ringer's solution, respectively. Figure adapted from $\operatorname{Ref}^{88}$. 
Bulk staining with Fluo-4 AM enabled the simultaneous measurement of stimulusinduced $\mathrm{Ca}^{2+}$ dynamics over dozens of $\mathrm{M} / \mathrm{T}$ cells, which was advantageous for screening the OB for the presence of dual-sensitive cells. However, as mentioned aforehand, the AM dye often did not penetrate cell layers beyond $80 \mu \mathrm{m}$ from the slice surface. Therefore, in an attempt to reveal the glomerular innervation of dual-sensitive $\mathrm{M} / \mathrm{T}$ neurons, bolus loading experiments were carried out in intact nose-brain explants ("whole-mount" preparations). These experiments were performed by Alexander Brinkmann. The neuropil surrounding the small glomerular cluster (including the $\gamma$-glomerulus) was targeted by a glass pipette filled with Fluo-8AM, approaching the OB from the ventral side. For a better orientation within the bulb and the identification of the small cluster, ORNs were aforehand electroporated with Dextran Alexa Fluor 647 to reveal the presynaptic glomerular organisation. After bolus loading and successful dye uptake by nearby $\mathrm{M} / \mathrm{T}$ cells in the vicinity, successive applications of cold Ringer's solution followed by the application of a single amino acid L-histidine (10 $\mu \mathrm{M})$. Chemosensitive, thermosensitive and dual-sensitive $\mathrm{M} / \mathrm{T}$ cells were observable in 5 out of 7 animals. Neurons of the latter category did not respond to both with the same strengths, as reported in the previous experiments (cf Figure 3.5). Some were more strongly activated by the temperature drops than by L-histidine, and vice versa (Figure 3.6). Additionally, correlation maps were calculated using purely thermosensitive or purely chemosensitive responses as reference traces. Most cold-sensitive fibres were identified presynaptic or postsynaptic afferents to the $\gamma$-glomerulus. 
A

(I) Presynaptic staining

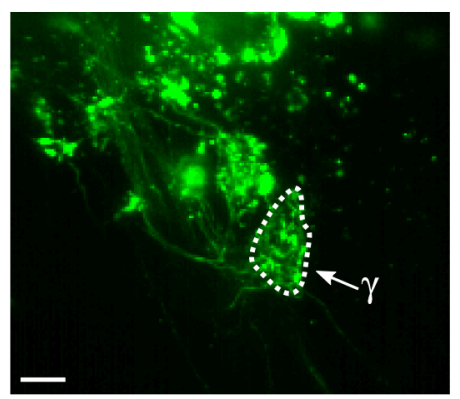

(II) Postsynaptic ACI

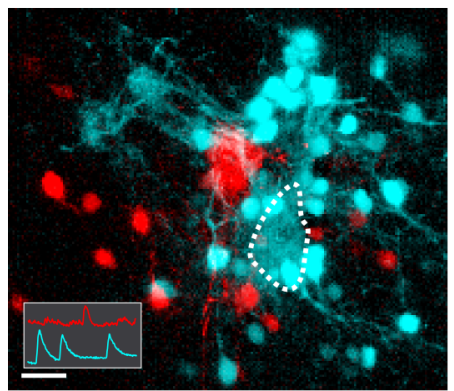

(III) Dual sensitive overlay

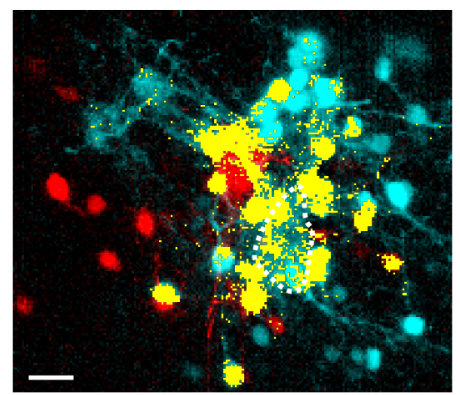

B

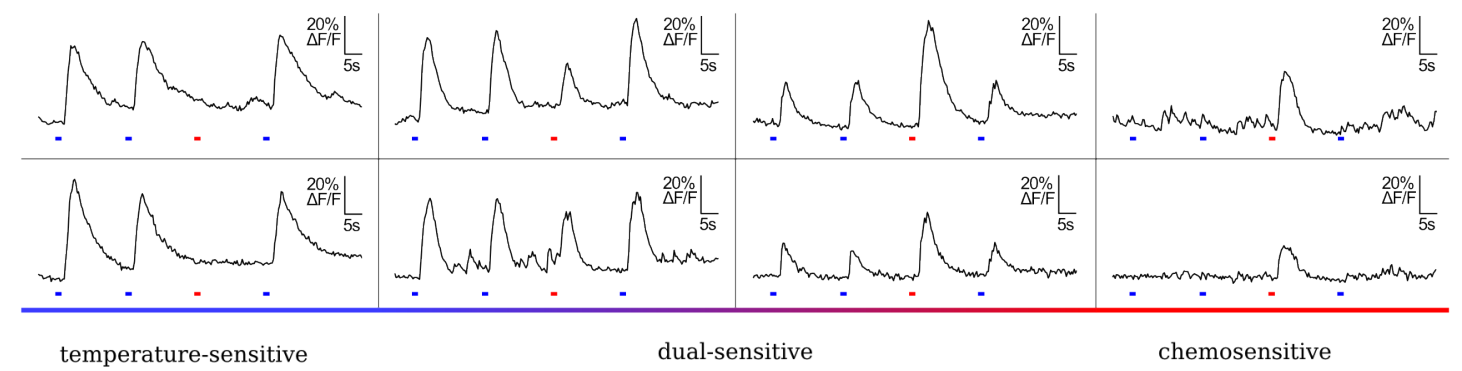

Figure 3.6: Dual-sensitive $M / T$ cells and their differential tuning

(A) Left: Presynaptic staining of ORNs with Dextran Alexa Fluor 647. The dotted region highlights the $\gamma$-glomerulus. Middle: ACI maps derived from temperarature-sensitive (blue) and chemosensitive (red) $\mathrm{Ca}^{2+}$ signals after bolus loading with Fluo-8 AM. The reference traces for calculating the correlation maps are shown in the bottom-left inset. Right: Pixelby-pixel calculation of the dual-sensitive regions responding to both stimuli (yellow). All images are z-projections of the maximum intensities of a $36 \mu \mathrm{m}$-thick volume, Scale bar: 50 $\mu \mathrm{m}$. (B) $\Delta \mathrm{F} / \mathrm{F}$ signals of $8 \mathrm{M} / \mathrm{T}$ cells to a stimulus sequence of thermic and chemical inputs. The red and blue bars under the traces indicate the application of amino acids and cold Ringer's solution, respectively. The response patterns ranged from pure thermosensitivity to exclusive histidine-sensitivity over various degrees of dual sensitivity. Figure adapted from $\operatorname{Ref}^{88}$.

Taken together, these findings described in this section demonstrate that most thermosensitive M/T cells also responded to chemical stimuli. Moreover, dual-responsive cells were differentially tuned to temperature and odourants. Thus, some M/T cells effectively integrate thermic and chemosensory inputs in the olfactory bulb. Interestingly, the olfactory bulb of $X$. laevis harbours $\mathrm{M} / \mathrm{T}$ cells which are connected to two or more glomeruli. Our results suggest that the dual-sensitivity observed in some $\mathrm{M} / \mathrm{T}$ cells is most likely a function of their multiple glomerular innervation patterns. 


\subsection{The effects of GABAergic inhibition on M/T cell dynamics}

When performing ACI using a stimulus-induced signal as a reference trace, the resulting correlation map highlights structures of positively correlated values (as in Figure 3.3), but also simultaneously exposes pixels displaying negative correlations. A closer look at the raw fluorescent signals of negatively correlated somata and dendrites of $\mathrm{M} / \mathrm{T}$ cells revealed different temporal patterns of these neurons: either non-sensitive to the stimulus applied, or inhibited (Figure 3.7).
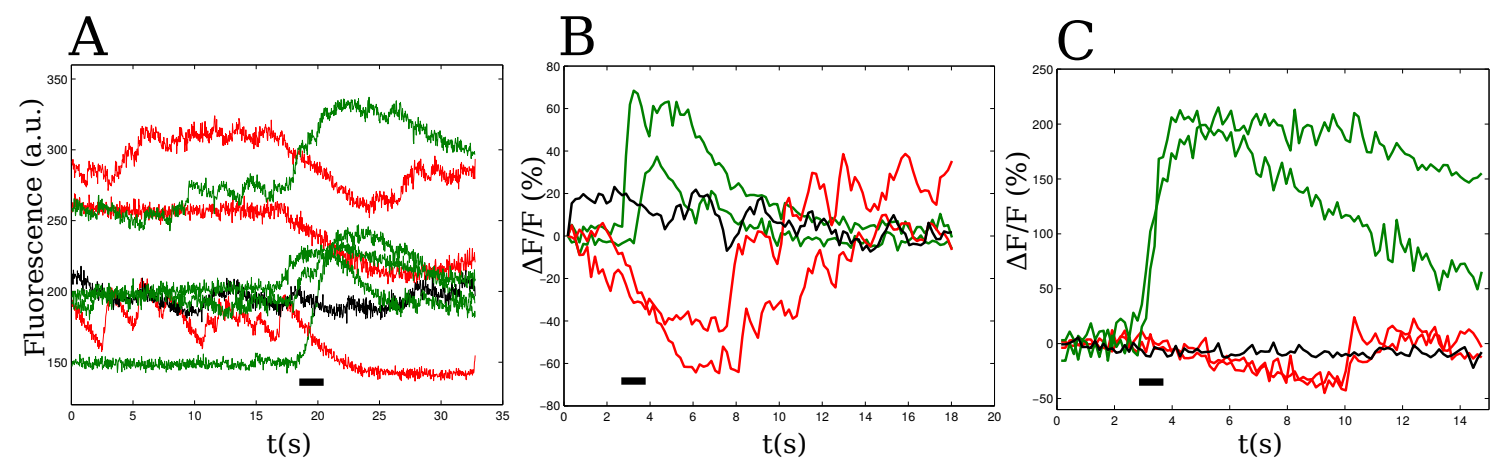

Figure 3.7: Excitation and inhibition of $\mathrm{M} / \mathrm{T}$ cells in response to odour stimuli (A) $\left[\mathrm{Ca}^{2+}\right]$ fluorescent signals of a group of $\mathrm{M} / \mathrm{T}$ cells before and after odour stimulation by $800 \mu \mathrm{L}$ of the amino acid mixture $(50 \mu \mathrm{M})$. The timing of application is indicated by the black bar beneath the graphs. The temporal patterns of these cells were regrouped in three categories and colour-coded: excited (green), inhibited (red) and non-responsive (black). (B-C) $\Delta \mathrm{F} / \mathrm{F}$ traces of 2 excited, 2 inhibited and 1 non-sensitive M/T cell in two other animals. Note the start of inhibition (in the red traces) following the odour stimulus and the recovery of spontaneous activity and/or the initial $\left[\mathrm{Ca}^{2+}\right]$ levels after a few seconds.

A former study combining electrophysiological measurements and calcium imaging of Xenopus $\mathrm{M} / \mathrm{T}$ cells brought evidence that decreases of internal $\left[\mathrm{Ca}^{2+}\right]$ levels coincided with the suppression of $\mathrm{M} / \mathrm{T}$ cell firing ${ }^{157}$. As a result of these consistent observations, the second part of the thesis addressed the role of GABAergic inhibition in shaping odour-evoked and spontaneous $\mathrm{M} / \mathrm{T}$ cell dynamics in the developing bulb.

\subsubsection{Localisation of GABA in the OB at larval stages 49-54}

Early work described how the inhibitory PGCs and GCs have a mature appearance from stages 48-49 onward ${ }^{2}$, but the presence of the GABA neurotransmitter in the OB of larval 
Xenopus had only been reported from stage $54^{19}$. Therefore, anti-GABA immunohistochemistry was performed in the brains of tadpoles of stages $49-54$, whose ORNs were first electroporated with Dextran Alexa Fluors. ORN and GABA staining was imaged using confocal immunofluorescence microscopy (Figure 3.8 and 3.9). Immunoreactive cells were observed around the glomeruli stained by Dextran Alexa Fluor 488, as well as in the granule cell layer.

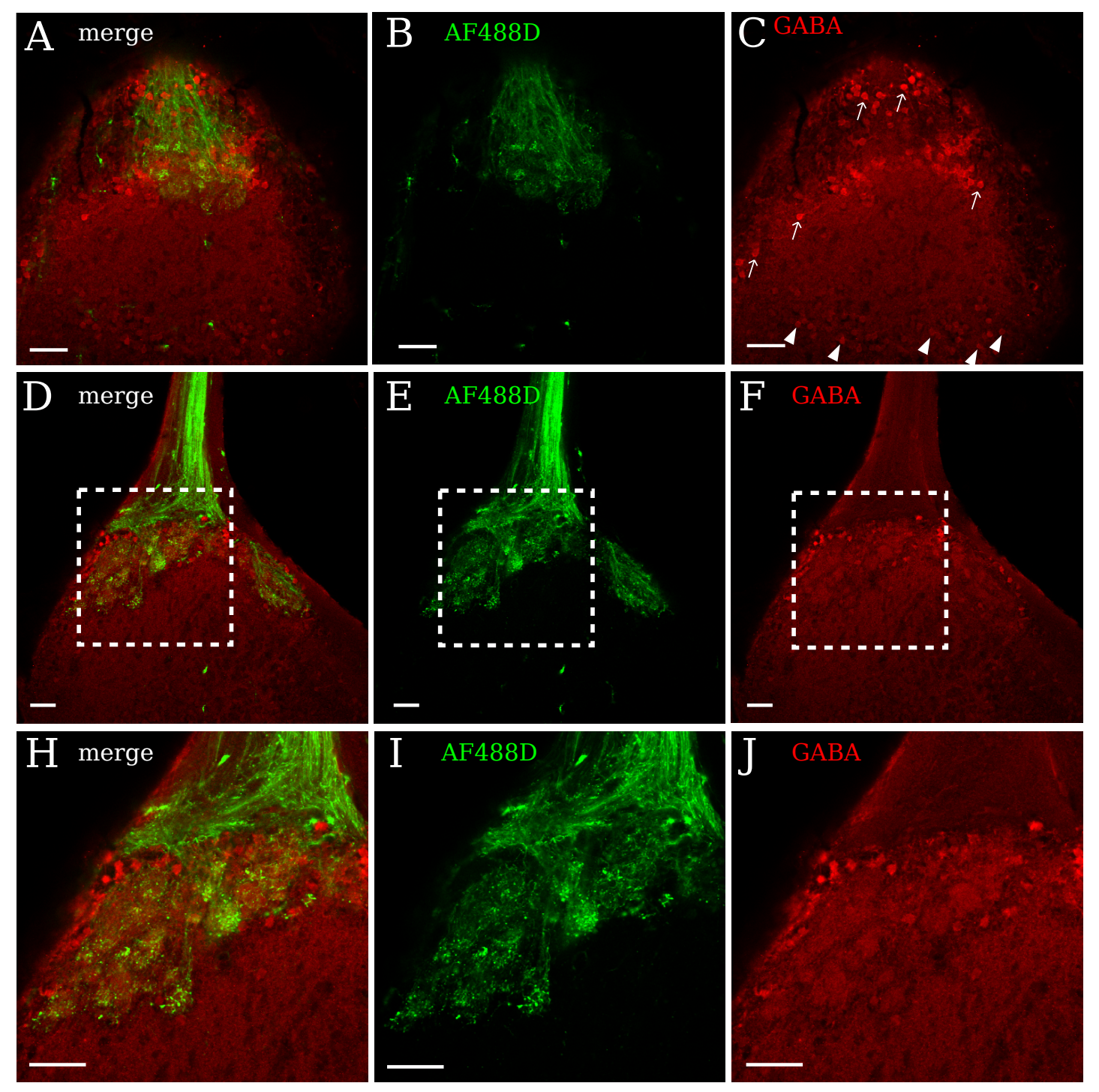

Figure 3.8: GABA staining in the glomerular layer

Horizontal sections of the olfactory bulb stained against GABA. (A) Overview of the GABA immunoreactivity in the glomerular, mitral/tufted and granule cell layers. (B) ORN axons terminating in glomeruli were stained by Dextran Alexa Fluor 488. (C) Note the GABApositive PGs (indicated by the white arrows) and GCs (indicated by the white arrowheads). (D-F) The white dashed rectangle highlights the staining in the glomerular layer. (H-J) Close-up view of the area indicated in (D-F). Scale bar $=50 \mu \mathrm{m}$. 
The neuropil around glomeruli and M/T cells was also intensely stained, although M/T cell somata clearly lacked GABA-immunoreactivity. In contrast to M/T cells, GCs showed some GABA staining in the cytosol around their nuclei, but little-to-no staining in their surroundings (Figure 3.9).
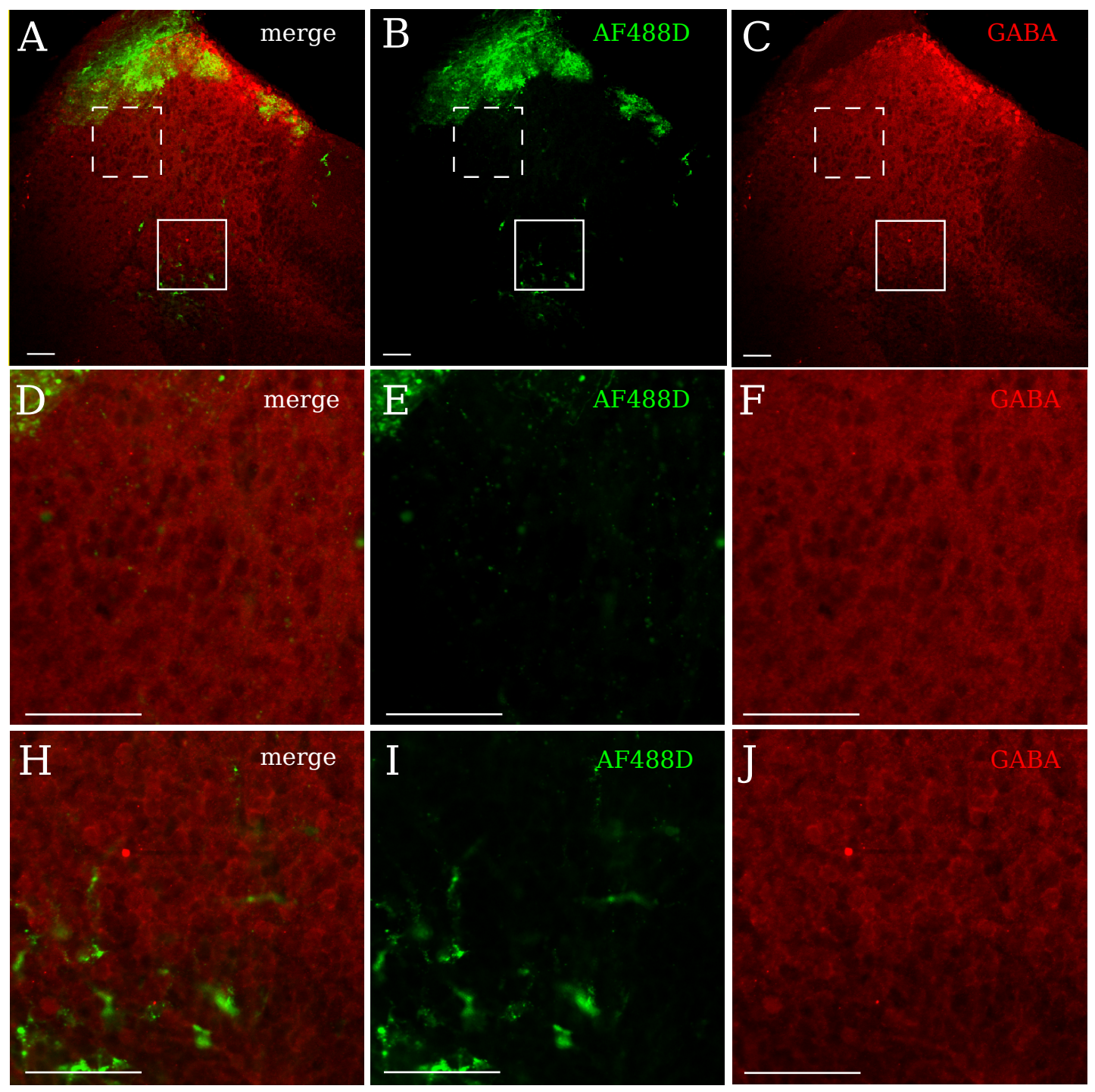

Figure 3.9: GABA staining in the mitral/tufted and granule cell layers Horizontal sections of the olfactory bulb stained against GABA. (A-C) Overview of the GABA immunoreactivity in the mitral/tufted (dashed rectangle) and granule cell (full rectangle) layers. (D-F) M/T cells were immunonegative for GABA, but the surrounding neuropil showed a strong staining. (H-J) GCs, in contrast were immunopositive, particularly in the cytosol encompassing their nuclei. (I) Note the extrabulbar olfactory fibres stained by ORN electroporation by Dextran Alexa Fluor 488. Scale bar $=50 \mu \mathrm{m}$.

After confirming the presence of GABA in the developing OB of X. laevis larvae, the next 
series of experiments investigated the functional role and importance of GABAergic transmission for $\mathrm{M} / \mathrm{T}$ cell activities using competitive $\mathrm{GABA}_{\mathrm{A}}$ receptor antagonists. Picrotoxin, gabazine (SR95531) and bicuculline methiodide (BMI) are the most widespread GABA receptor inhibitor used in pharmacological experiments. After initially comparing the effect of BMI $(100 \mu \mathrm{M})$ and gabazine $(100 \mu \mathrm{M})$ perfused over OB slices stained with Fluo-4 AM, gabazine (GBZ) with its stronger blockade of the activity of $\mathrm{M} / \mathrm{T}$ cellular networks was subsequently used for all the following experiments.

\subsubsection{The influence of gabazine on $\mathrm{M} / \mathrm{T}$ cell odour-evoked activities}

In order to assess whether gabazine affects odour discrimination, the response patterns of pairs of excited versus inhibited M/T cells were analysed. Calcium imaging experiments were undertaken in $300 \mu \mathrm{m}$-thick slices of the olfactory bulb bulk-stained with Fluo-4 AM. 2D planes of the olfactory bulb were imaged with the line-illumination microscope, and single frames acquired at a rate of $30 \mathrm{~Hz}$. Each measurement lasted $32.8 \mathrm{~s}$, the first half of which was without stimulus application in oder to record $\mathrm{Ca}^{2+}$ events and the baseline activies of M/T cells. In the second half, $800 \mu \mathrm{L}$ of the amino acid mixture at a concentration of $50 \mu \mathrm{M}$ was applied at the olfactory epithelium.

The responses of individual M/T cells to the amino acid stimulation in OB acute slices were compared before and after the perfusion of gabazine dissolved in Ringer's solution. Under normal conditions, i.e., when pure Ringer's solution was perfused over the OB slice, $\mathrm{M} / \mathrm{T}$ activities were either excited or inhibited by the odour input (cf section 3.2), As discussed in the introduction, this differential odour tuning is inherent to odour discrimination and contrast enhancement achieved by the olfactory bulb.

Some of the M/T cells which were formerly inhibited by the chemical stimulation positively responded to the odour stimulus during gabazine application (Figure 3.10A-B). Other $\mathrm{M} / \mathrm{T}$ neurons were freed from strong lateral inhibition and almost maintained their baseline $\left[\mathrm{Ca}^{2+}\right]$ levels after the stimulus (Figure 3.10C-D). 

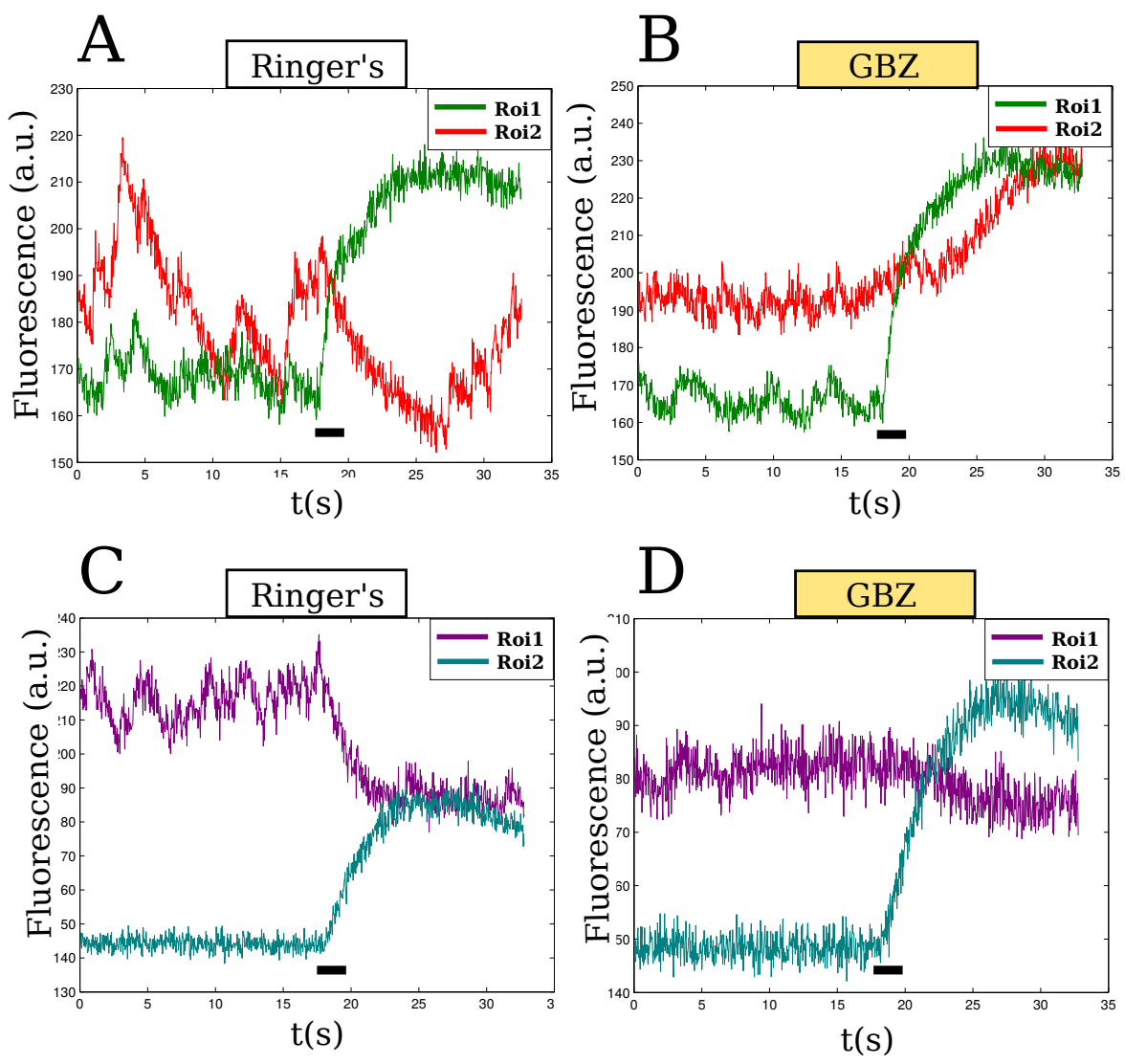

Figure 3.10: Gabazine alters $\mathrm{M} / \mathrm{T}$ cells' odour responses.

(A) Raw $\mathrm{Ca}^{2+}$ signals of an excited versus inhibited (exc/inh) M/T cell pair before and after the application of a mixture of 14 amino acids $(50 \mu \mathrm{M})$. The first neuron (Roi1) whose activity is depicted in green is strongly excited by the odour stimulus, whereas the red $\mathrm{Ca}^{2+}$ trace of the second neuron (Roi2) displays odour-induced lateral inhibition. (B) Raw $\mathrm{Ca}^{2+}$ signals of the same exc/inh M/T cell pair when gabazine (GBZ) at a concentration of $100 \mu \mathrm{M}$ has been perfused over the OB slice. Note the drastic change in the response of Roi2 to the stimulus. The response of Roi1 remains unchanged. (C-D) Raw $\mathrm{Ca}^{2+}$ signals of another exc/inh $\mathrm{M} / \mathrm{T}$ cell pair in the same animal. In the presence of gabazine, the activity of Roi1 was no longer inhibited by the odour input. The black bars beneath the graphs represent the application of $800 \mu \mathrm{L}$ of a mixture of 14 amino acids at $50 \mu \mathrm{M}$.

The cross-correlation factor $\mathrm{R}$ between the $\mathrm{Ca}^{2+}$ traces of 13 excited versus inhibited (exh/inh) M/T cell pairs identified in 4 animals was calculated before and after drug application. The calculation of $\mathrm{R}$ was defined by:

$$
R=\frac{\sum\left(x_{i}-\overline{x_{i}}\right) \cdot\left(x_{j}-\overline{x_{j}}\right)}{\left\|x_{i}-\overline{x_{i}}\right\| \cdot\left\|x_{j}-\overline{x_{j}}\right\|},
$$

where $x_{i}$ is the time trace of the excited M/T cell and $x_{j}$, that of the inhibited M/T cell. 
This $\mathrm{R}$ value ranged between -1 , which represents the strongest negative correlation, to +1 , which is obtained when two temporal signals are absolutely identical. In 9 out of 13 pairs, the $\mathrm{R}$ value shifted from negative to positive values. In 4 occurrences it increased to a less negative value. A paired Student's t-test was computed to compare $\mathrm{R}$ values before and after gabazine. The average $\mathrm{R}$ values were $-0.56 \pm 0.08$ SEM before the drug application and $0.35 \pm 0.16$ SEM afterwards $(\mathrm{p}<0.001)$.
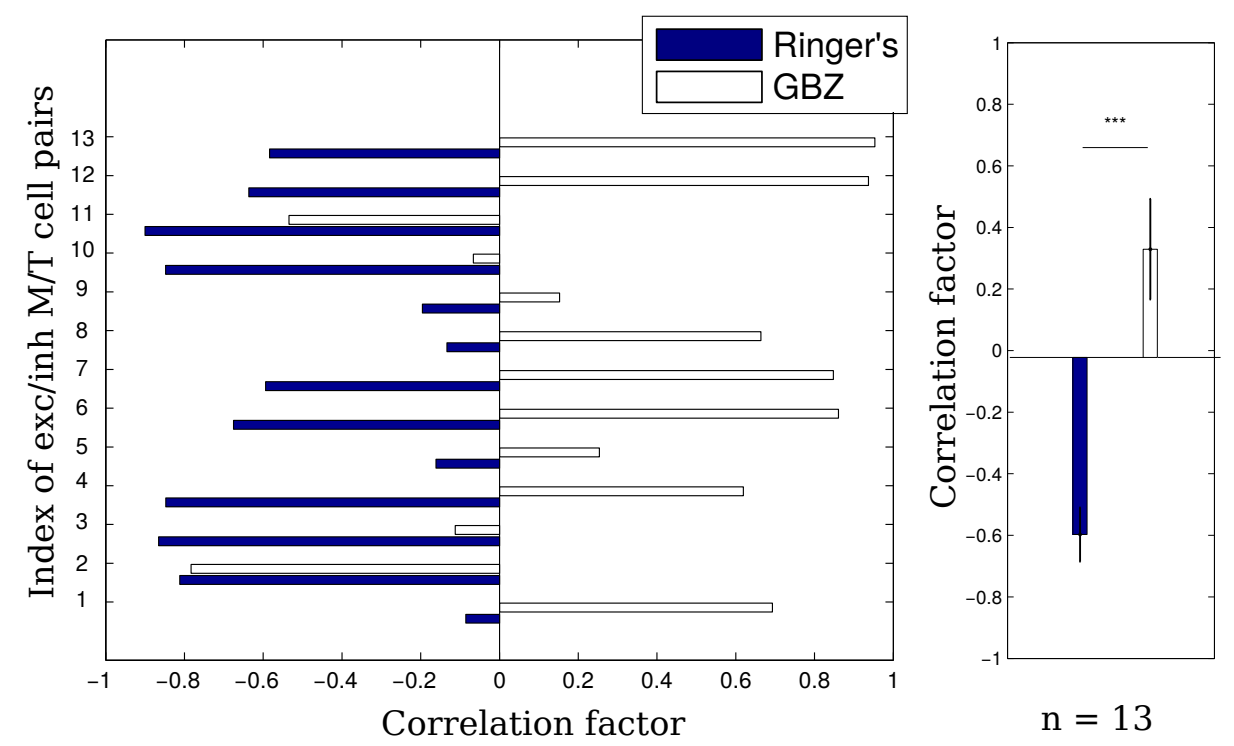

Figure 3.11: Excited vs inhibited $M / T$ cells in response to odour stimuli

Left: Index of $13 \mathrm{exc} / \mathrm{inh} \mathrm{M} / \mathrm{T}$ cell pairs plotted against the cross-correlation factor between each pair. In all pairs the correlation factor increased after gabazine (GBZ, $100 \mu \mathrm{M})$ was perfused over the slice. Right: Mean value of the correlation factors between exc/inh M/T cell pairs. Data are reported as mean \pm standard error of the mean (SEM). $13 \mathrm{M} / \mathrm{T}$ cell pairs, $\mathrm{n}=4$ animals; error bars: standard error of the mean (SEM); $* * *: \mathrm{p}<0.001$, paired Student's t-test.

Lateral inhibition is regarded as a means to diminish the redundancy of odour-induced responses of $\mathrm{M} / \mathrm{T}$ cells receiving the same glomerular inputs. Consequently, the similarity of $\left[\mathrm{Ca}^{2+}\right]$ rises was analysed in $\mathrm{M} / \mathrm{T}$ cells activated by odour stimulation. The imaging paradigm consisted of a few measurements of spontaneous and odour-evoked activity before gabazine perfusion followed a repetition of same measurements with the drug being washed over the acute slice. While dozens of neurons exhibited signal fluctuations during each single recording, only the M/T cells active throughout the entire session were considered in the subsequent analysis. Cross-correlated values were calculated between 
the temporal patterns of a pool of $6 \mathrm{M} / \mathrm{T}$ cells belonging to the same OB and correlation matrices of these neurons were established. A mean $\mathrm{R}$ value ranging from -1 to 1 was extracted, reflecting the degree of similarity between these $6 \mathrm{M} / \mathrm{T}$ cells within the pool. To facilitate the visual assessment of correlations in the matrices, all negative values were colour-coded and displayed as 0. Figure 3.12 illustrates the observations made in this series of experiments, using the data acquired in one of the acquisition sessions. In normal conditions, the application of the amino acid mixture triggered a sudden increase of $\left[\mathrm{Ca}^{2+}\right]$ levels in all cells of the pools. The time courses of the $\mathrm{Ca}^{2+}$ rises, however, differed from one cell to another. Some neurons showed lasting $\mathrm{Ca}^{2+}$ waves, while some others returned to baseline levels more rapidly. The average cross-correlation factor between these cells reached 0.79 (Figure 3.12A). Upon gabazine application, this value increased to 0.96 owing to a higher similarity of the temporal patterns of the same $6 \mathrm{M} / \mathrm{T}$ cells after the amino acid stimulation (Figure 3.12B). In order to differentiate whether gabazine equally affected the similarity of spontaneous M/T cell dynamics, the baseline activity of these cells were compared before and after the drug perfusion. The $\mathrm{R}$ value for spontaneous events was close to 0 before and after gabazine application, thus indicated that the cells retained different temporal patterns in an odour-free environment (Figure 3.12C-D).

The analysis of similarity across M/T cell pools was subsequently extended to 5 animals. The correlation factors of odour-induced activities were compared before and after pharmacological treatment (Figure 3.13A). R values averaged over 30 cells in these animals rose from $0.66 \pm 0.04$ before gabazine perfusion to $0.75 \pm 0.04$ afterwards. The statistical comparison of the two conditions using a paired Student's t-tests confirmed the trend earlier described. Gabazine application enhanced the identicalness of the responses of M/T cells activated by the olfactory input (Figure 3.13B). 

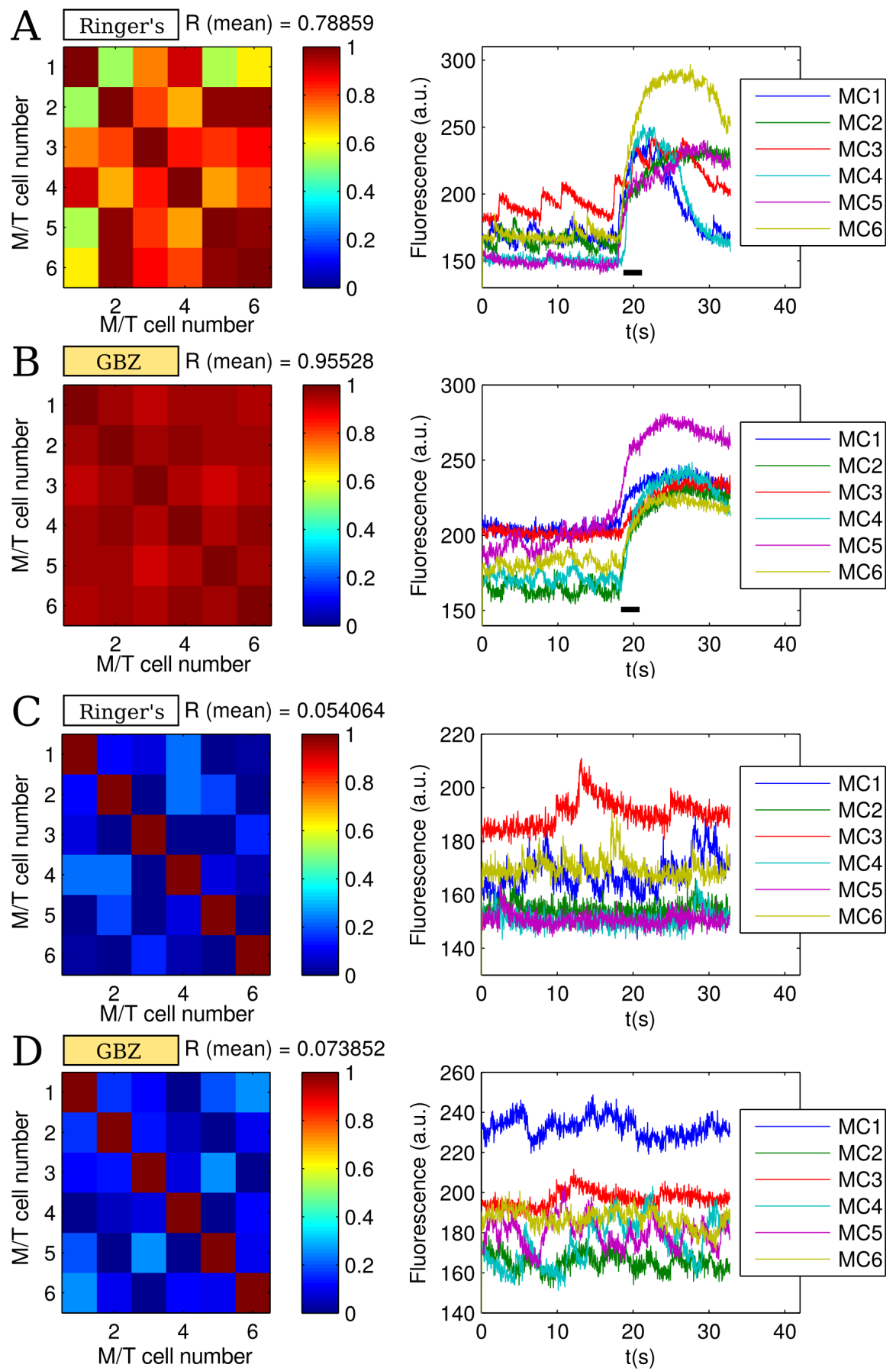

Figure 3.12: Gabazine increases the similarity between odour-evoked outputs (1). (A-B) Left: Correlation matrices of the odour-evoked activities of $6 \mathrm{M} / \mathrm{T}$ cells before (A) and after (B) the application of gabazine. The colour bars indicates the degree of correlation, 0 meaning no correlation at all, and 1 representing perfect identicalness. The mean $R$ values expresses high correlation, brought about by the synchronicity of odour responses observed in the right panels. Right: Raw fluorescent signals of the M/T cells used for calculating cross-correlation values displayed in the left panel. The $\mathrm{Ca}^{2+}$ traces of $6 \mathrm{M} / \mathrm{T}$ cells belonging to the same bulb were colour-coded. $\mathrm{MC}=\mathrm{M} / \mathrm{T}$ cell. 
Note the increase of correlation upon gabazine perfusion, and the greater similarity of stimulus-induced responses hereafter (B). The black bars beneath the graphs represent the application of $800 \mu \mathrm{L}$ of a mixture of 14 amino acids at $50 \mu \mathrm{M}$. (C-D) Left: Correlation matrix of the baseline activities of the same pool of cells as in (A-B) before (C) and after (D) drug application. Note the the low correlation between the $6 \mathrm{M} / \mathrm{T}$ cells and the diverse temporal patterns of spontaneous activity. Gabazine $(100 \mu \mathrm{M})$ did not seem to increase the correlation of these patterns.
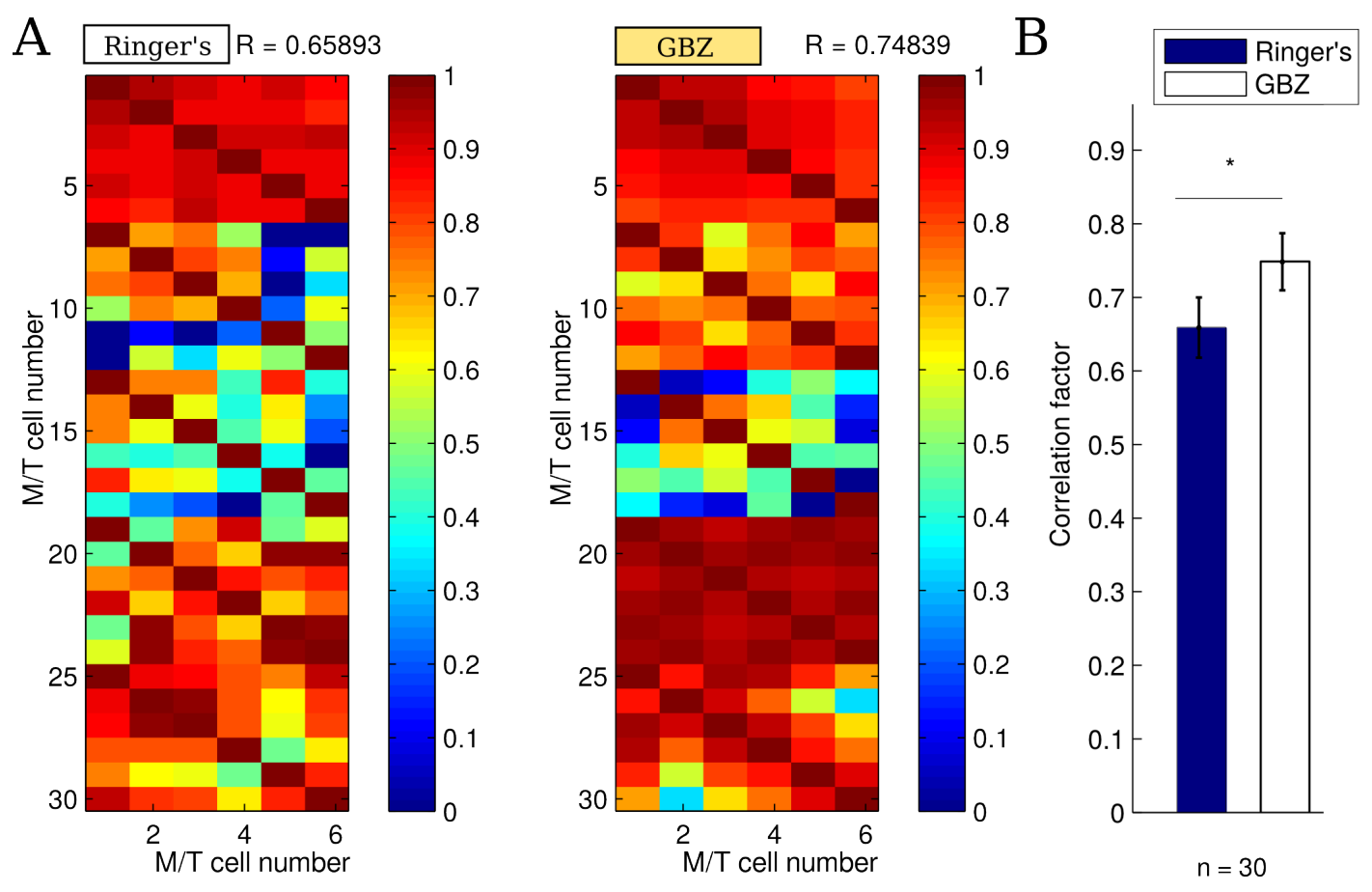

Figure 3.13: Gabazine increases the similarity between odour-evoked outputs (2). (A) Correlation matrices of the odour-evoked activities of $\mathrm{M} / \mathrm{T}$ cells before (left) and after (right) the application of gabazine $(100 \mu \mathrm{M}) . n=30$ cells (5 animals), (B): 30 correlation factors were compared before and after application of gabazine and a paired Student's t-test was performed. The values displayed are the means of $R$ values $\pm S E M ; *: p<0.05$.

In summary, the pharmacological experiments unravelled the role of GABAergic inhibition in shaping odour responses of $\mathrm{M} / \mathrm{T}$ cells. The blockade achieved by gabazine resulted in a suppression of inhibitory temporal patterns following olfactory inputs. Moreover, the M/T cells activated by these odour signals exhibited more redundant activities. The following question which was addressed is whether gabazine also modifies the $\mathrm{Ca}^{2+}$ dynamics of $\mathrm{M} / \mathrm{T}$ cells in baseline conditions, particularly regarding synchronous and oscillatory patterns. 


\subsubsection{The influence of gabazine on $\mathrm{M} / \mathrm{T}$ cell oscillations and synchrony}

Firstly, spontaneous temporal patterns of M/T cells were observed and compared in the presence and in the absence of the drug. A pool of randomly selected M/T cells, yet active throughout the recording session were selected and the correlation between their activities was analysed in both conditions. As the results illustrated in (Figure 3.12C-D) suggest, the perfusion of gabazine did not increase the correlation of spontaneous $\mathrm{Ca}^{2+}$ waves in the bulb. Figure 3.14 summarises the findings across several animals. M/T cell pools showed low correlation values (average $\mathrm{R}$ of $0.04 \pm 0.2$ SEM) before the pharmacological application. In the presence of gabazine, the $\mathrm{Ca}^{2+}$ dynamics of these cells did not further correlate with each other, and the average $R$ value remained similar ( $R=0.04 \pm 0.2$ SEM). No significant difference was observed in the correlation of the cell's spontaneous events.
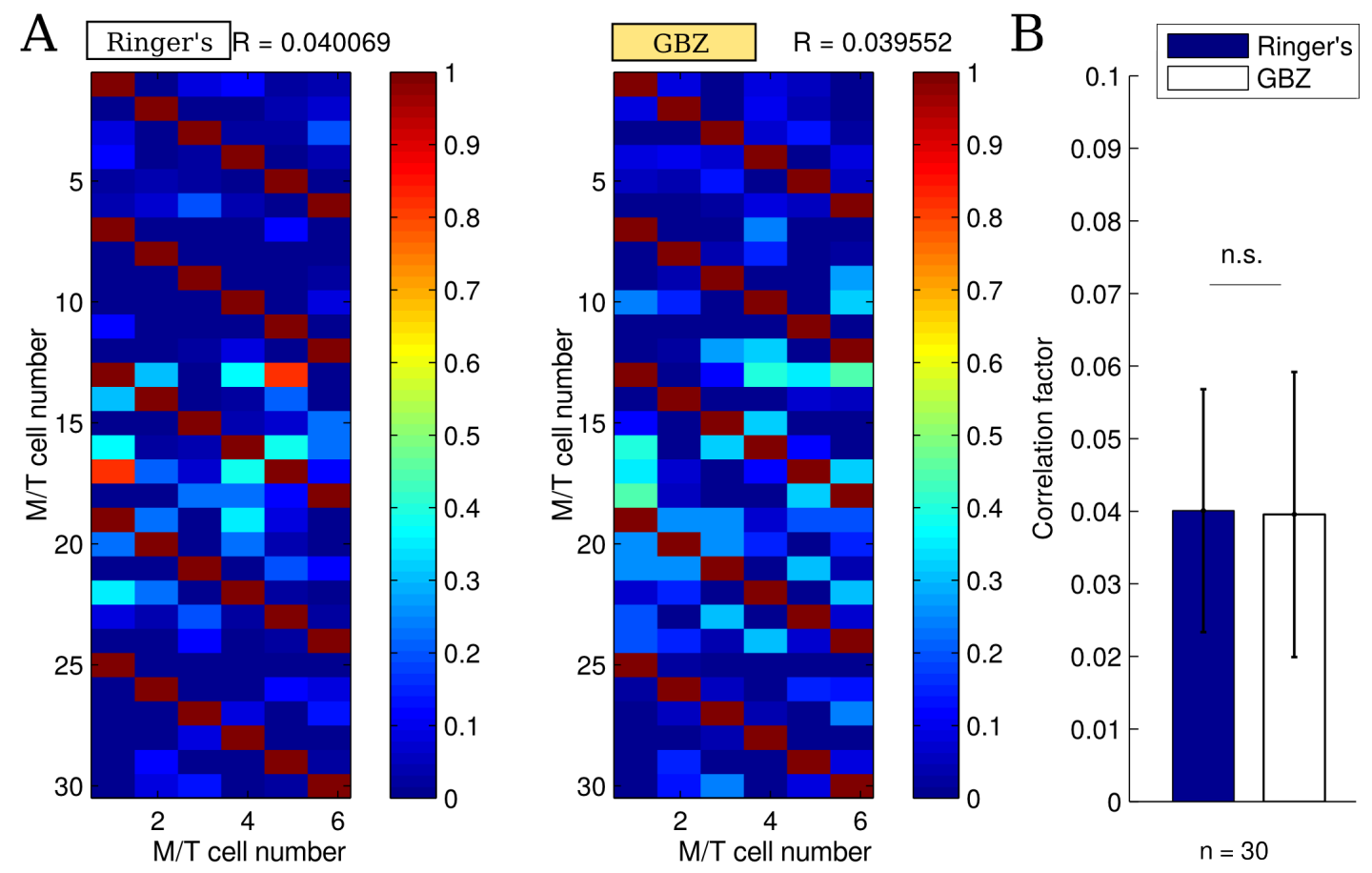

Figure 3.14: Gabazine does not correlate M/T cells' activities.

(A) Correlation matrices of the spontaneous activities of $\mathrm{M} / \mathrm{T}$ cells before (left) and after (right) the application of gabazine. The correlated values remained low in the presence and in the absence of the drug. $n=30$ cells (5 animals), (B): 30 correlation values were compared before and after application of gabazine and a paired Student's t-test was performed. The correlation among $\mathrm{M} / \mathrm{T}$ neurons did not increase after gabazine had been perfused to the OB slice. The values displayed are the means of $\mathrm{R}$ values \pm SEM; n.s. = non significant. 
The vertebrate olfactory bulb of Xenopus tadpoles harbours sister M/T cells sampling the same glomerulus or glomeruli. In mammals, these $\mathrm{M} / \mathrm{T}$ neurons show similar to identical firing rates but with different phase shifts ${ }^{59}$. In Xenopus larvae, sister M/T cells exhibited synchronous spiking and highly correlated $\mathrm{Ca}^{2+}$ dynamics ${ }^{58}$. Although gabazine did not seem to correlated the activities of randomly chosen M/T cells, its influence on the synchrony of sister $\mathrm{M} / \mathrm{T}$ cells was studied next.

In OB slices stained with Fluo-4 AM, sister M/T cells were identified whilst looking for pairs of neurons with strongly correlated spontaneous - not odour-evoked- $\mathrm{Ca}^{2+}$ signals (Figure 3.15A-B). Successive measurements of baseline activity were acquired before the perfusion of gabazine, during the pharmacological treatment, and after a 5-minute washout. The evolution of cross-correlation value between the two sister M/Ts was studied over the series of measurements. In each experiment, one pair of non-sister $\mathrm{M} / \mathrm{T}$ cells was taken as a reference and their correlation values plotted against that of the sister M/T pair. From the onset, the correlation factors of the synchronous M/T cells was higher than those between the non-sister cells (as expected) and remained higher (Figure 3.15C-F). Upon gabazine application, the correlation factor of sister M/T cells increased and stayed near to 1 throughout gabazine perfusion. In contrast, non-sister cells experienced a brief higher correlation at the onset of gabazine application, but their $\mathrm{R}$ values decreased afterwards over the course of time. The washout of gabazine had opposite effects on the two types of pairs. The correlation of sister M/T cells mostly sank, whereas that of non-sister cells increased back to their values prior to the drug.

These observations indicate that gabazine did not suppress the synchrony of sister $\mathrm{M} / \mathrm{T}$ cells, but potentially even increases it. Non-synchronous M/T cells remain uncorrelated spiking upon the blockade of GABAergic inhibition. The brief peak of correlation observed initially in these cells is most likely caused by the synchronised blockade of GABAergic inhibition causing a sudden rise of activity in the M/T cell populations when the drug is perfused and binds $\mathrm{GABA}_{\mathrm{A}}$ receptors for the first time. 

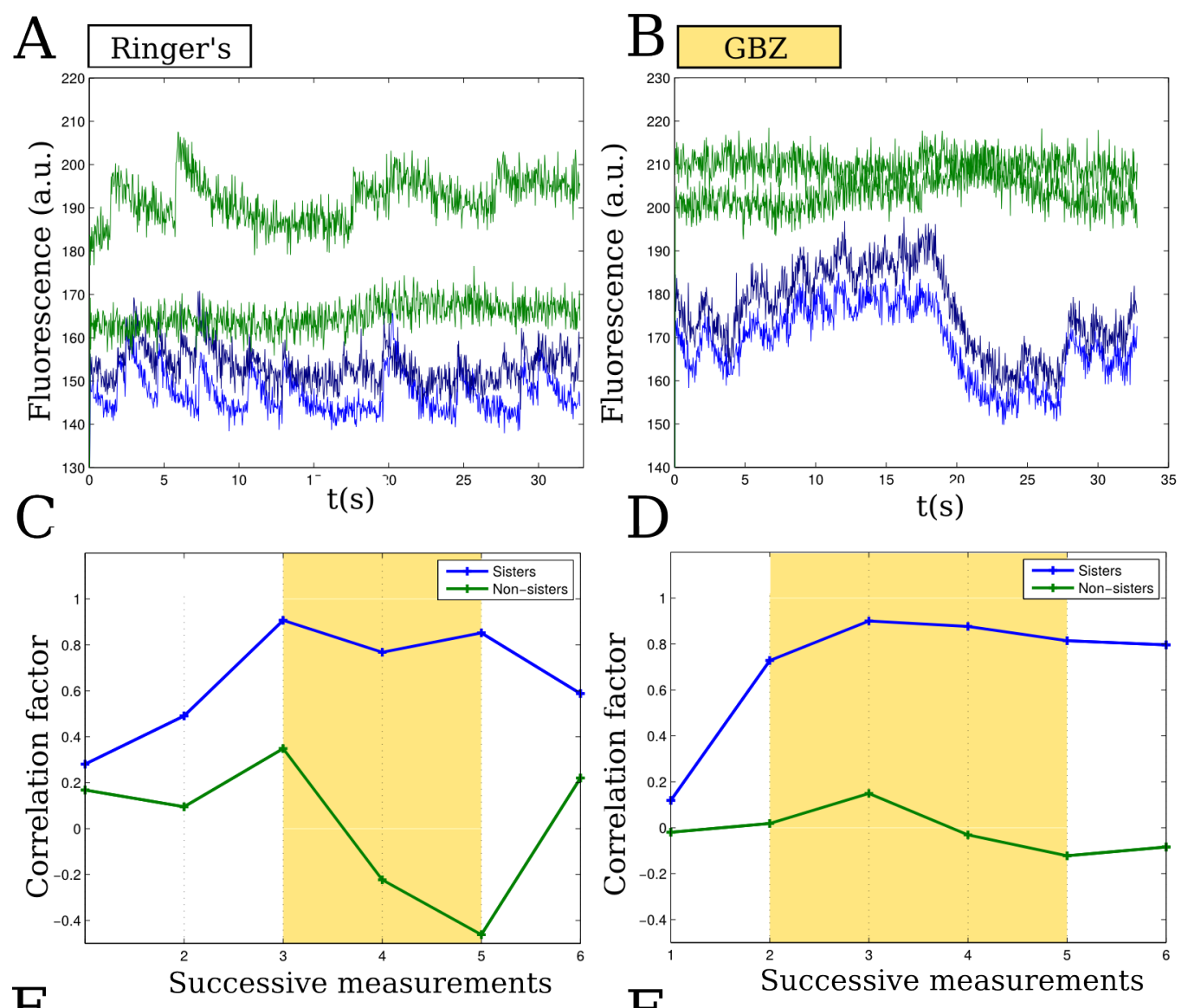

$\mathrm{E}$

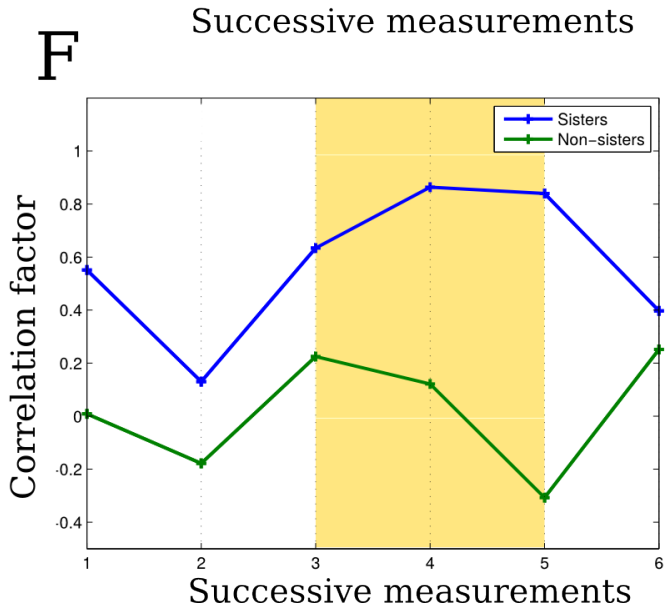

Figure 3.15: Synchronous patterns of sister M/T cells

(A) Spontaneous activities of two sister M/T cells (blue) and two non-sister M/T cells (green). Sister M/T cells show synchronised $\mathrm{Ca}^{2+}$ events. (B) Spontaneous activities of the same pairs in the presence of gabazine $(100 \mu \mathrm{M})$. Note that the synchrony of sister M/T cells is maintained, while the temporal patterns of non-sister M/T cells do not correlate. (C-F) Evolution of the correlation factors between pairs of sister (blue) and non-sister M/T cells (green) in 4 animals. The yellow background indicates the perfusion of gabazine over the slice. The interval between each measurement was 2 min on average, except between the $5^{\text {th }}$ and the $6^{\text {th }}$ (washout) where it lasted at least 5 min. 
Upon gabazine application, the correlation between sister M/T cells increased and remained high until dropping when the drug was washed out. For non-sister M/T cells, gabazine caused a brief rise of correlation followed by a decreasing trend. When gabazine was removed, these cells regained their original correlation values.

At the network level, GABAergic inhibition drives the oscillatory spiking of M/T cell populations in the beta and gamma frequency ranges in other species. Such global effect of the inhibitory network onto M/T cells has not yet been confirmed in Xenopus laevis. Initial observations of the $\mathrm{Ca}^{2+}$ waves in $\mathrm{M} / \mathrm{T}$ cells before and after gabazine application suggested a potential effect of the drug on the frequencies of these signals. In the absence of gabazine, $\mathrm{M} / \mathrm{T}$ cells showed small $\mathrm{Ca}^{2+}$ events of a duration of 1-3 s. When the drug was perfused over the slice, slower oscillations of larger amplitude and period (5-10 s) appeared and were superimposed on the more rapid signals (Figure 3.16A-D). Consequently, a Fourier analysis was undertaken to investigate whether the pharmacological treatment altered the frequency of $\mathrm{Ca}^{2+}$ waves in $\mathrm{M} / \mathrm{T}$ cells. The temporal patterns of fluorescence were converted into to the frequency domains using the fast Fourier transform. The magnitudes of the frequencies were averaged within a pool of M/T cells $(n \geqslant 35)$ and was plotted against the frequencies of $\mathrm{Ca}^{2+}$ signals. Since $\mathrm{M} / \mathrm{T}$ cells exhibit low firing rates (in the absence of odour inputs), and the induced $\mathrm{Ca}^{2+}$ spikes are inherently slower, only the low frequencies (below $3 \mathrm{~Hz}$ ) computed by the Fourier transform were considered. 

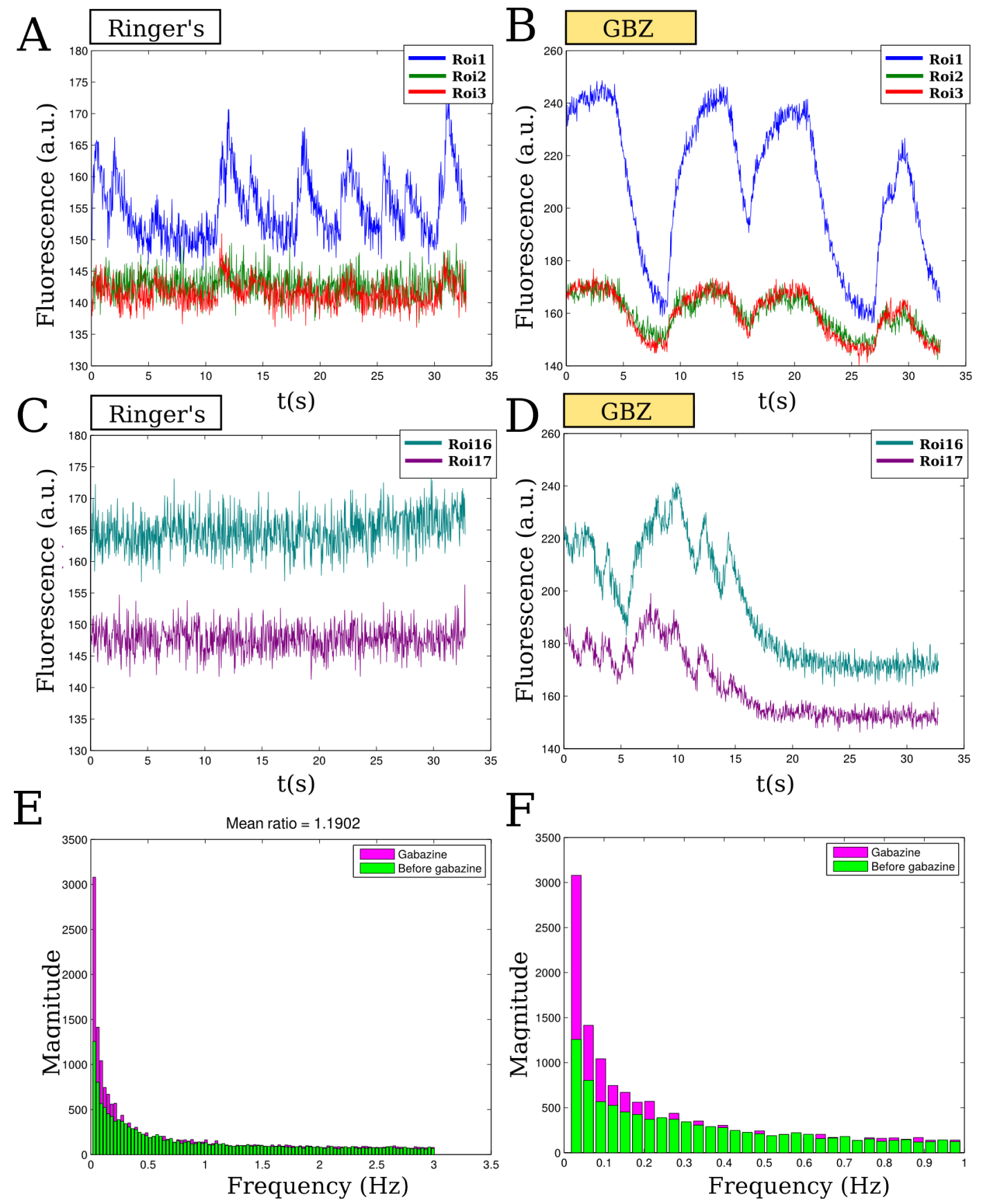

Figure 3.16: $\mathrm{M} / \mathrm{T}$ cell oscillations

(A) Spontaneous $\mathrm{Ca}^{2+}$ signals of 3 sister M/T cells. Rapid spikes of 1-3 s duration are observed. (B) Spontaneous $\mathrm{Ca}^{2+}$ signals of the same neurons upon gabazine application. Slow calcium waves of a duration of ca. $5 \mathrm{~s}$ and of higher amplitude are observed. (C-D) Temporal activity patterns of 2 other sister M/T cells of the same animal. These neurons exhibited little-to-no activity in the absence of gabazine (C). Hereafter, 10 s-long waves were superimposed on rapid calcium events (D). (E) Spectrum representation of the frequencies of $\mathrm{Ca}^{2+}$ oscillations calculated by a fast Fourier transform and and low-pass filtered at $3 \mathrm{~Hz}$. The magnitudes of the frequencies were averaged over $39 \mathrm{M} / \mathrm{T}$ cells. The frequencies of $\mathrm{M} / \mathrm{T}$ activities before and after gabazine application are represented in green and magenta, respectively. (F) Spectrum representation of the same frequencies below $1 \mathrm{~Hz}$. Note the higher magnitude of lower frequencies. 
In all pharmacological experiments ( $n=197,5$ animals), the application of gabazine was accompanied with a spectral shift to lower $\mathrm{Ca}^{2+}$ wave frequencies of higher magnitude (Figure 3.16E-F, Table 3). A mean ratio was calculated as $Q / P$, where $P$ denotes the frequency magnitudes of the oscillatory activity of $\mathrm{M} / \mathrm{T}$ cell pools before gabazine treatment, and $Q$, afterwards (Table 3). In all animals, this ratio was above 1 , which indicates that the magnitude of spontaneous $\mathrm{Ca}^{2+}$ waves rose after the drug was applied to the olfactory bulb. The control experiments consisted of repeated measurements of M/T activities in the absence of gabazine. The $Q / P$ ratio was determined as quotient of the frequency magnitudes acquired in second measurement $(P)$ over the frequency magnitudes of the first measurement. Increased contribution of lower frequencies was not consistently observed in gabazine-free conditions, and the mean ratio of frequency magnitudes mostly remained around or below 1 .

\begin{tabular}{clllll}
\hline Animal & $\mathbf{1}$ & $\mathbf{2}$ & $\mathbf{3}$ & $\mathbf{4}$ & $\mathbf{5}$ \\
\hline Higher magnitude of lower frequencies & yes & yes & yes & yes & yes \\
Magnitude ratio $Q / P($ GBZ/Control) & 1.13 & 1.06 & 1.19 & 1.15 & 1.01 \\
$n$ cells & 39 & 47 & 37 & 35 & 39 \\
\hline Higher magnitude of lower frequencies & no & no & yes & no & no \\
Magnitude ratio $Q / P$ (Control/Control) & 0.97 & 0.94 & 1.03 & 0.89 & 0.98 \\
$n$ cells & 39 & 35 & 37 & 35 & 39 \\
\hline
\end{tabular}

Table 3: Comparison of the frequency distribution of $\mathrm{M} / \mathrm{T}$ cell activities before and after gabazine

The magnitudes of the frequencies of $\mathrm{Ca}^{2+}$ signals were averaged over $n \mathrm{M} / \mathrm{T}$ cells and compared in the presence and absence of the drug. 2 successive measurements of M/T activities were taken in the absence of gabazine for the control, and the average magnitude of the frequencies was also computed.

Altogether, these results show that gabazine application increased the contribution of rhythmic oscillations, and particularly of signals of lower frequencies in the network dynamics of $\mathrm{M} / \mathrm{T}$ cells. The last analysis performed with the pharmacological measurements addressed the general effect of gabazine on $\mathrm{M} / \mathrm{T}$ firing rates revealed by changes of intracellular $\left[\mathrm{Ca}^{2+}\right]$ levels. Past experimental evidence illustrated how the blockade of GABAergic transmission in the frog $O B$ by other $\mathrm{GABA}_{\mathrm{A}}$ receptor antagonists as picrotoxin 
and bicuculline resulted in increased firing frequencies of individual $\mathrm{M} / \mathrm{T}$ cells ${ }^{95}$. Taking advantage of the higher throughput of calcium experiments, the baseline $\left[\mathrm{Ca}^{2+}\right]$ fluctuations reflecting spike rate changes were investigated in these cells with and without gabazine perfusion.

\subsubsection{The influence of gabazine on $\mathrm{M} / \mathrm{T}$ cell baseline $\left[\mathrm{Ca}^{2+}\right]$ levels}

The spontaneous $\left[\mathrm{Ca}^{2+}\right]$ events of $\mathrm{M} / \mathrm{T}$ cell populations loaded with Fluo-4 AM in OB slices were recorded in successive measurements before and after gabazine application. For each $\mathrm{Ca}^{2+}$ trace, a single value (F100) was extracted, as a proxy representing the internal $\left[\mathrm{Ca}^{2+}\right]$ levels of each neuron. F100 was calculated as the average of the $100^{\text {th }}$ lowest values of $F_{t}-F_{0}$, whereby $F_{t}$ is the raw fluoresence signal over time, and $F_{0}$, the camera background measured without excitation light. Figure 3.17 highlights the results the comparison of F100 in $39 \mathrm{M} / \mathrm{T}$ cells before and after drug treatment. In the first measurement taken in control conditions, i.e. with Ringer's solution perfusing over the slice, the mean F100 equalled $36.6 \pm 2.3$ (Figure 3.17B). No significant increase was detected in the second acquisition with a mean F100 value of $37.04 \pm 2.55(\mathrm{p}=0.2733$, paired Student's ttest) (Figure 3.17B). However, when gabazine was applied, F100 drastically rose in most $\mathrm{M} / \mathrm{T}$ cells, and the mean F100 value reached $48.54 \pm 3.85$ ( $<0.001$ ) (Figure 3.17D). 

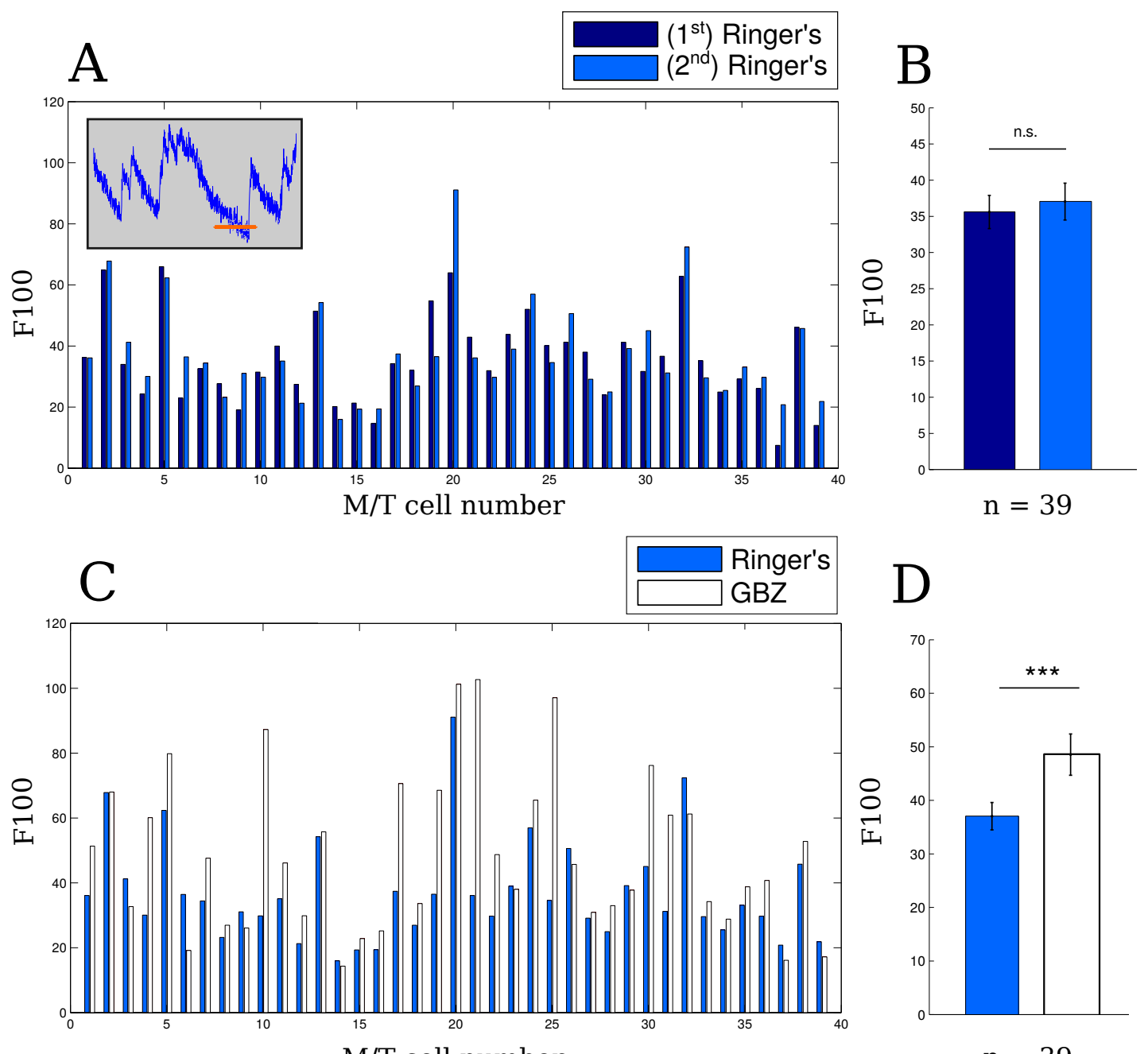

Figure 3.17: Gabazine raises intracellular calcium levels (1).

(A) F100 of $39 \mathrm{M} / \mathrm{T}$ cells of the same slice plotted for two successive measurements in control conditions. F100 is the mean value of $100^{\text {th }}$ lowest values of the raw fluorescence minus the camera background. The inset on the left shows the $\mathrm{Ca}^{2+}$ trace of a neuron, and the yellow bar, the value of F100 in that cell. (B) Mean of F100 values and standard error of the mean (SEM) compared between acquisitions. No significant difference was observed ( $\mathrm{p}=0.2733$, paired Student's t-test). n.s.: non-significant. (C) F100 of $39 \mathrm{M} / \mathrm{T}$ cells of the same slice plotted before and after gabazine application $(100 \mu)$. F100 increases in most $\mathrm{M} / \mathrm{T}$ cells. (D) Mean of F100 values and standard error of the mean (SEM) before and after drug treatment. (***: p $<0.001$, paired Student's t-test).

This trend was corroborated by the analysis of nearly $300 \mathrm{M} / \mathrm{T}$ cells (Figure 3.18). F100 did not significantly rise from one measurement to another ( $31.9 \pm 1.36$ vs $30.81 \pm$ $1.36, n=268, \mathrm{p}=0.2243$ ), whereas upon gabazine application this value soared (31.94 \pm 1.27 vs $44.08 \pm 1.71, n=297, \mathrm{p}<0.001)$. 

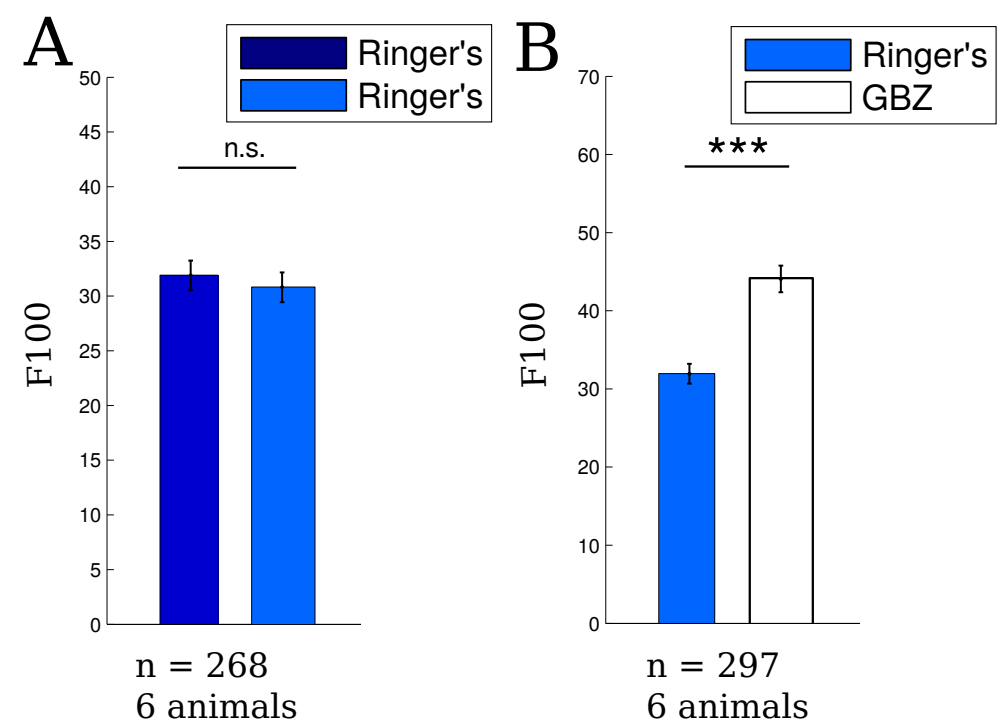

Figure 3.18: Gabazine raises intracellular calcium levels (2).

Comparison of F100 in the absence and presence of gabazine. (A) Mean of F100 values and standard error of the mean (SEM) in control conditions. $n=268, p=0.2243$, paired Student's t-test. n.s.: non-significant. (B) Mean of F100 values and standard error of the mean (SEM) before and after drug treatment. $n=297$, ***: $\mathrm{p}<0.001$, paired Student's t-test.

In summary, the pharmacological experiments with gabazine confirmed that presence of GABA in the olfactory bulb, demonstrated by the immunohistochemistry, serves a functional role in the regulation of $\mathrm{M} / \mathrm{T}$ cell patterns of activity. Blocking GABAergic inhibition resulted in the loss of discrimination of odour responses by M/T cells. Positive responses to stimuli became more redundant, whereas negative responses were suppressed. The enhanced similarity of odour-evoked patterns was accompanied with an modest rise of synchrony of sister M/T cells. In contrast, non-synchronous cells were nearly not affected by the drug, and retained low correlation among themselves. Furthermore, gabazine enhanced the contribution of slower $\mathrm{Ca}^{2+}$ waves in the network, and clearly raised intracellular $\mathrm{Ca}^{2+}$ levels in individual $\mathrm{M} / \mathrm{T}$ cells.

The literature on olfactory research brought evidence that GABA transmission takes place in dendrodendritic synapses within the glomeruli and along M/T cell dendrites. A body of studies described the effect of inhibitory inputs on mitral cell spiking and synchrony in mammals $96,135,165,166$. Recently, Bartel and colleagues were able to reveal the location and density of GABAergic synapses on secondary dendrites of mitral cells in rats using immunohistochemistry ${ }^{167}$. Yet, these sites of recurrent and lateral inhibition by GABAergic 
granule cells have not yet been functionally imaged. The final section reports a battery of experiments carried out to verify the backpropagation of somatic action potentials in $\mathrm{M} / \mathrm{T}$ dendrites of $X$. laevis and to investigate whether Activity Correlation Imaging can reveal dendritic sub-compartments of differential activity.

\subsection{Backpropagating $\mathrm{Ca}^{2+}$ signals and correlation analysis in dendritic sub-compartments}

\subsubsection{Backpropagation of somatically evoked spikes in M/T cell dendrites}

In order to study and visualise the backpropagation of action potentials (AP), and particularly of AP-induced $\mathrm{Ca}^{2+}$ spikes, simultaneous electrophysiological and calcium imaging recordings were combined in $\mathrm{OB}$ acute slices. Single $\mathrm{M} / \mathrm{T}$ cells were current-clamped in whole-cell configuration while Fluo-8 $\mathrm{K}^{+}$salt $(200 \mu \mathrm{M})$ and Alexa Fluor 594 Biocytin $(100 \mu \mathrm{M})$ diffused from the patch pipette to the cellular compartments. Spontaneous action potentials were recorded at the soma and 3D stacks were acquired to image AP-evoked $\mathrm{Ca}^{2+}$ transients along dendrites. Figure 3.19 illustrates the AP pattern and signal propagation from the soma to the glomerulus of a M/T cell. Due to low spiking of M/T cells, $\mathrm{Ca}^{2+}$ events temporally related to the onset of the APs were observed in the proximal dendrite and in the glomerulus.

However, the detection of activity-related $\mathrm{Ca}^{2+}$ signals proved difficult with higher firing rates. A better resolution of AP-induced spiked required a faster acquisition rate of the calcium imaging data, which was achieved at the costs of 3D imaging. Measuring in a single plane, and at times with a reduced field of view clearly improved the quality of the somatic and dendritic $\mathrm{Ca}^{2+}$ spikes (Figure 3.20). Consequently, combined current-clamp and calcium recordings were acquired, AP were somatically by current injections, and the soma/dendrite/glomerulus compartments of the cell imaged at higher speed, plane by plane (Figure 3.21). 6 pulses of $300 \mathrm{nA}$ for $8 \mathrm{msec}$ or $10 \mathrm{msec}$ were injected via the patch pipette at the soma, and the resulting action potentials recorded (Figure 3.21A). The $\mathrm{Ca}^{2+}$ spikes of the dendritic shaft and innervated glomerulus were tightly synchronised with the AP firing (Figure 3.21B-C).

These experiments confirmed that APs generated at the soma of M/T cells backpropagate 
into the dendrites until the glomerular arborisation. The combination of slow firing patterns mimicked by voltage pulses or evoked current injections and 2D fast calcium imaging was optimal to resolve single $\mathrm{Ca}^{2+}$ spikes along the dendrites. 


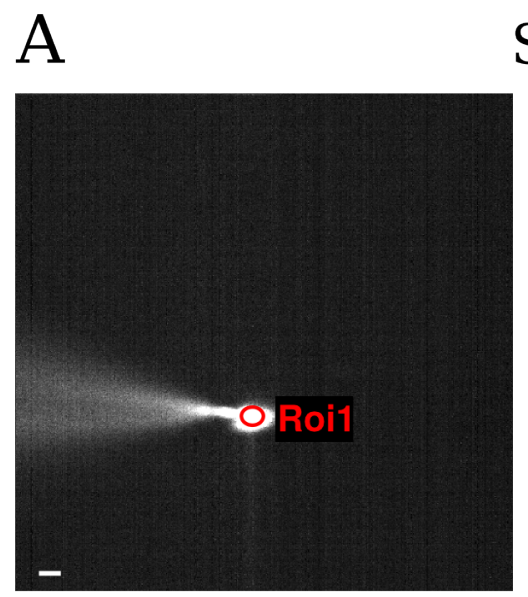

Soma

$\mathrm{B}$
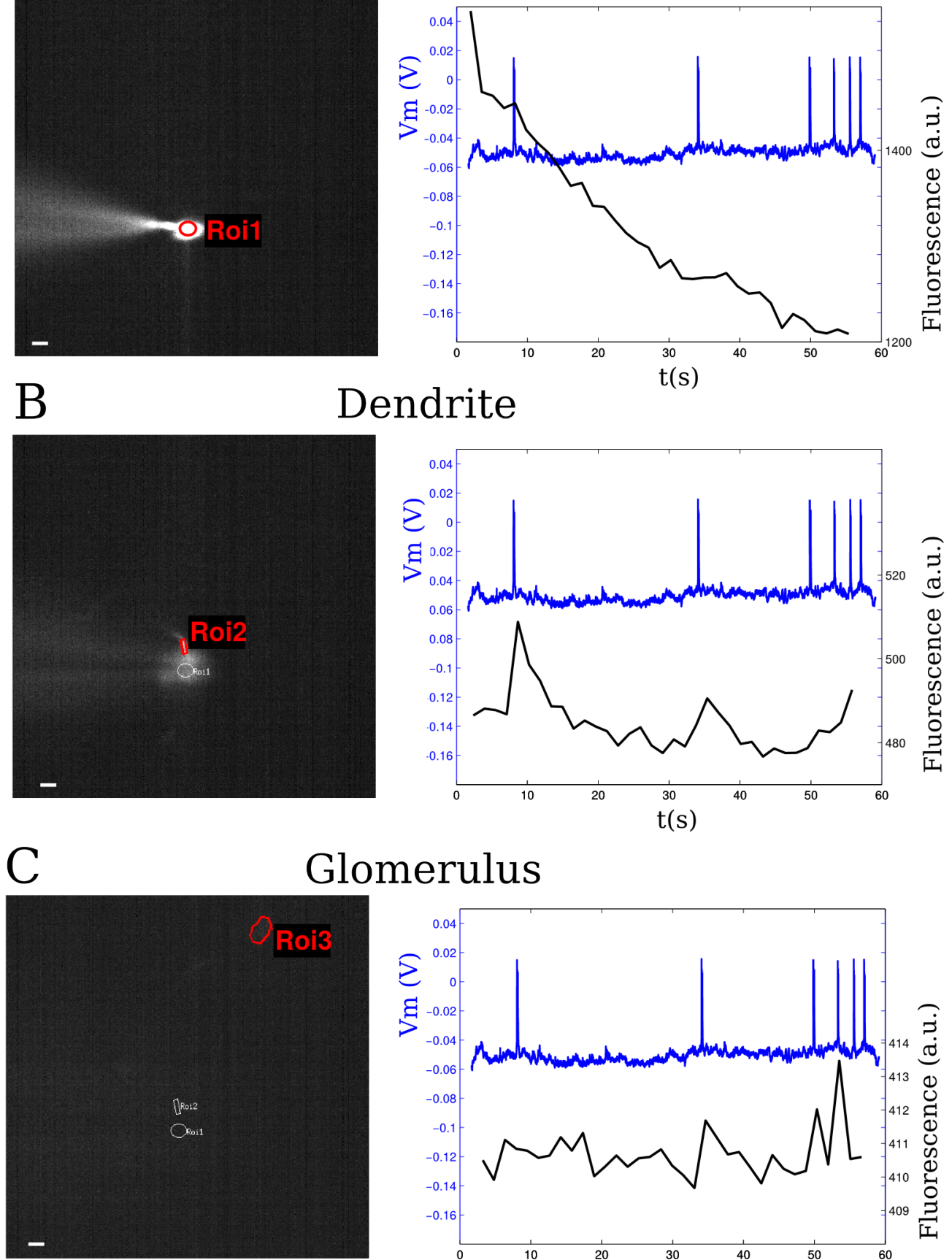

Glomerulus

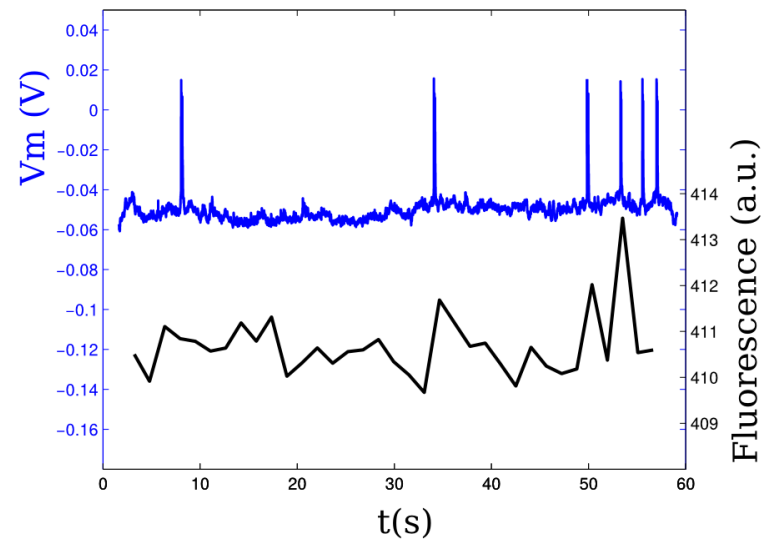

Figure 3.19: Spontaneous AP-induced $\mathrm{Ca}^{2+}$ transients in $\mathrm{M} / \mathrm{T}$ cell dendrites (A) Somatic current clamp recording combined with $3 \mathrm{D}\left[\mathrm{Ca}^{2+}\right]$ imaging of a $\mathrm{M} / \mathrm{T}$ cell. The membrane voltage (blue) and somatic calcium transient (black) of the region of interest (Roi1) are plotted over time. 
Note the slow frequency of APs. Yet, the high concentration of dye concentration and strong buffering at the soma did not permit a clear visualisation of the activity-related calcium signals. (B) A region of interest was drawn on the proximal dendrite. $\mathrm{Ca}^{2+}$ events slowly following the AP patterns were observed. (C) The glomerulus innervated by the $\mathrm{M} / \mathrm{T}$ cell was faintly stained but exhibited $\mathrm{Ca}^{2+}$ events slowly following the AP patterns were observed. Scale bar $=10 \mu \mathrm{m}$.
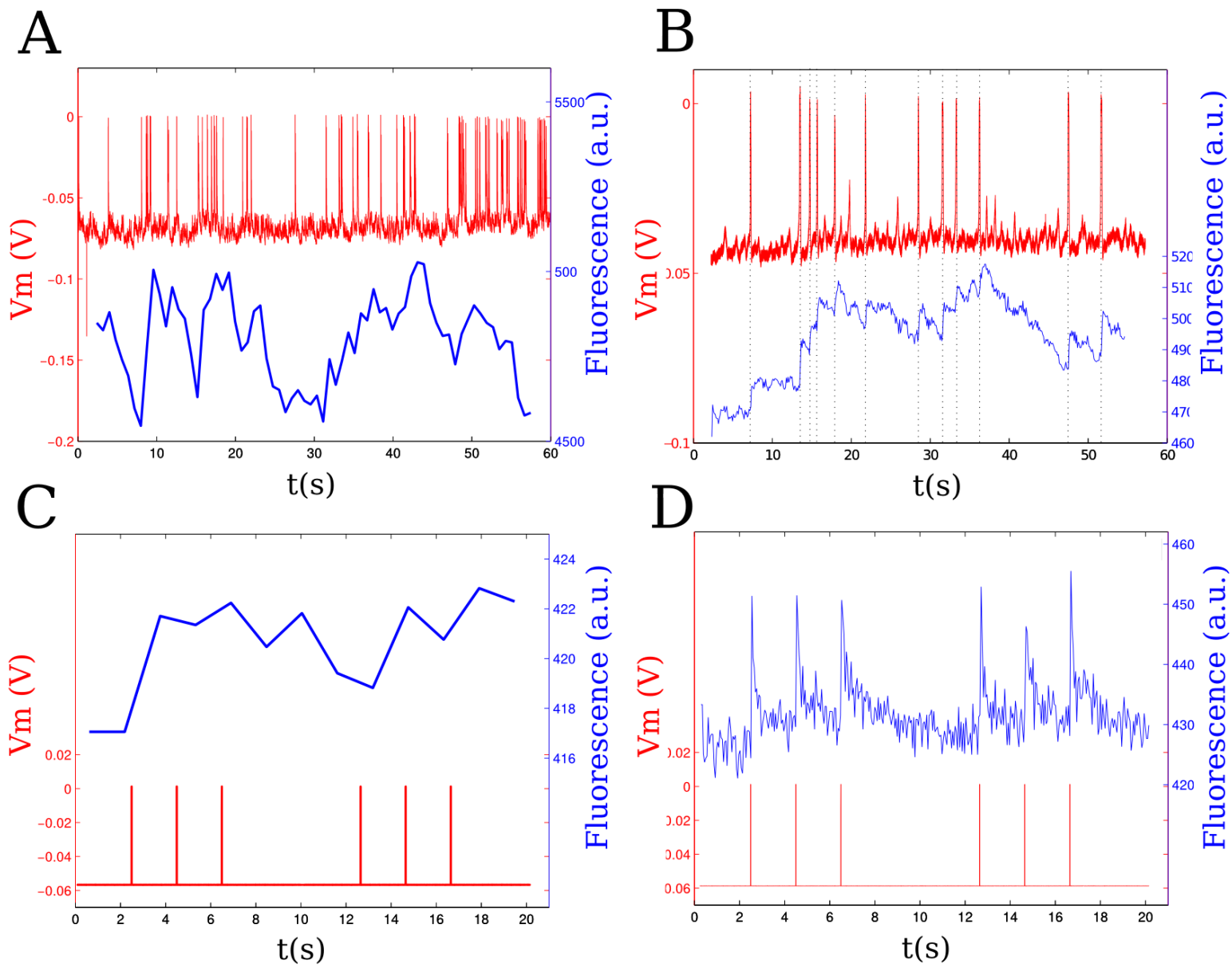

Figure 3.20: Resolution of single $\mathrm{Ca}^{2+}$ spikes

(A) $\mathrm{M} / \mathrm{T}$ cell firing (red) recording in current-clamp mode and related $\mathrm{Ca}^{2+}$ transients (blue) measured at the soma. Frame acquisition rate: ca. $1 \mathrm{~Hz}$. The neuron was imaged in 3D and slow calcium waves, rather than single spikes were detectable. (B) Same as in (A). Frame acquisition rate: ca. $10 \mathrm{~Hz}$. Each action potential triggers a visible increment of $\left[\mathrm{Ca}^{2+}\right]$ levels inside the cell. (C) Depolarisation pulses from -60 to $0 \mathrm{mV}$ and $10 \mathrm{~ms}$ duration were applied in voltage-clamp mode. Dendritic activity-evoked $\mathrm{Ca}^{2+}$ fluctuations (blue) were hardly recognisable due to 3D imaging at low scanning speed. Frame acquisition rate: ca. 1 Hz. (D) Same as in (A). Frame acquisition rate: $19 \mathrm{~Hz}$. The dendritic compartment was imaged in a single plane and the field of view reduced by half. The higher scanning speed allowed an improved $\mathrm{Ca}^{2+}$ spike detection. 

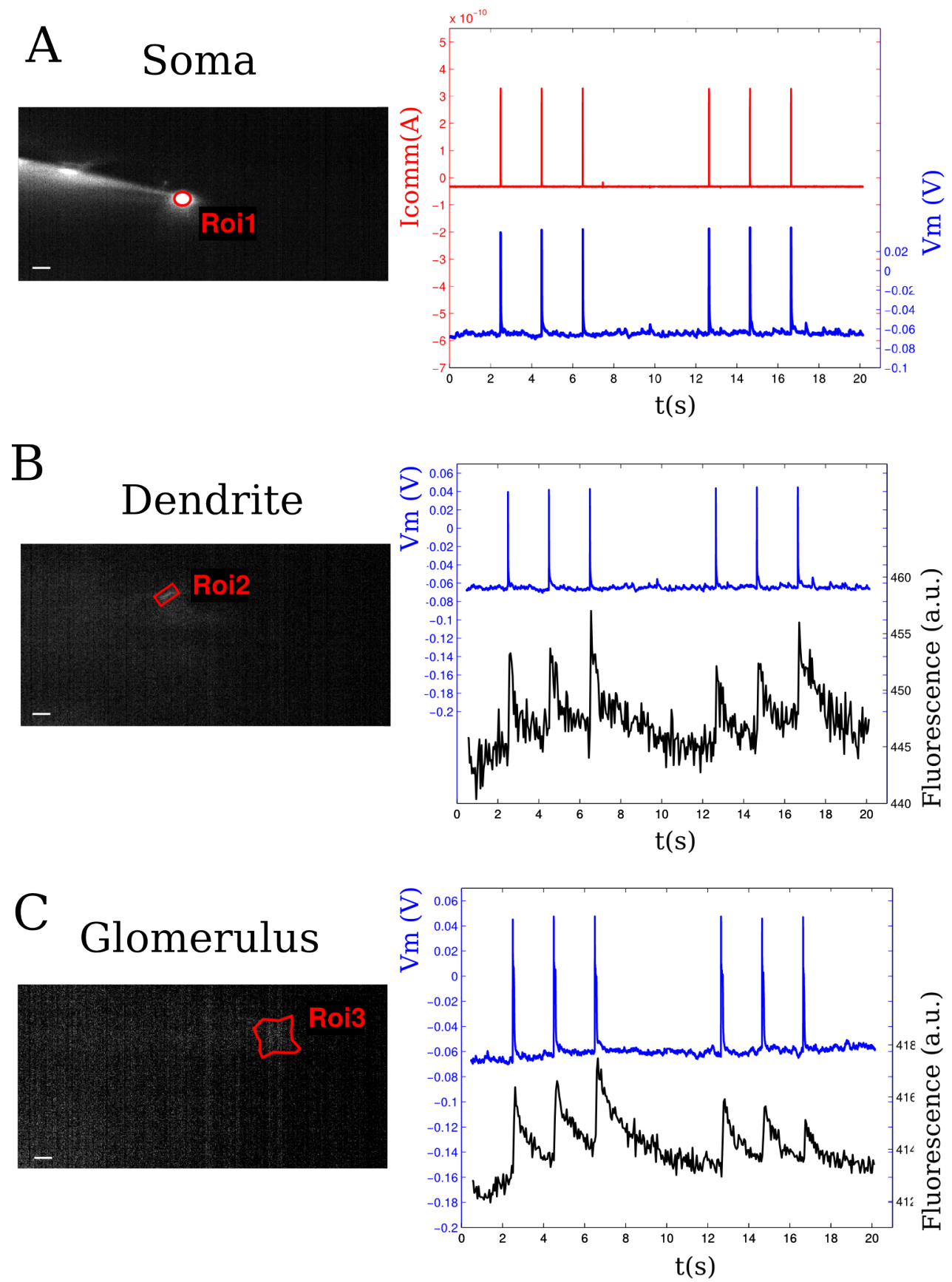

Figure 3.21: Propagation of somatically evoked APs and $\mathrm{Ca}^{2+}$ spikes in a M/T cell dendrite and glomerulus

Current-clamp recording combined with $\mathrm{Ca}^{2+}$ imaging of a $\mathrm{M} / \mathrm{T}$ cell in single planes. Frame acquisition rate: $19 \mathrm{~Hz}$. Single APs were evoked by current injections of $300 \mathrm{nA}$ for $8 \mathrm{msec}$ (B) or $10 \mathrm{msec}(\mathrm{C})$ at the soma. The field of view (512 x 256 pixels) was half the size of that of Figure 3.19, and the single plane recordings were taken instead of 3D timeseries. As a result of the higher imaging speed, the AP-evoked $\mathrm{Ca}^{2+}$ spikes recorded at the dendrite and glomerulus closely followed the stimulation pattern. Scale bar $=10 \mu \mathrm{m}$ 
Next, the uniformity of $\mathrm{Ca}^{2+}$ backpropagating signals along single dendrites was assessed. GABA local uncaging on $\mathrm{M} / \mathrm{T}$ dendrites was reported to attenuate or suppress backpropagating signals in the bulb of rats ${ }^{165,166}$. Thus, the cross-correlation of $\mathrm{Ca}^{2+}$ fluctuations between dendritic sub-compartments a dendrite was computed in the presence and absence of gabazine.

\subsubsection{Correlation analysis of $\mathrm{Ca}^{2+}$ fluctuations along $\mathrm{M} / \mathrm{T}$ cell dendrites}

Initially, the signal correlation along dendrites was studied during spontaneous M/T cell firing. The cells were current-clamped and continuous electrophysiological recordings of $1 \mathrm{~min}$ were acquired. Whenever a longer dendritic segment (above $80 \mu \mathrm{m}$ ) was found in a single plane, $2 \mathrm{D}$ acquisitions of calcium imaging data were preferred. If not the case, 3D timeseries were instead measured with a smaller field of view. Rectangular rois of 2 pixel-width and 3 pixel-length, i.e. $1.5 \mu \mathrm{m} \times 2.2 \mu \mathrm{m}$ were drawn along the shaft using the morphological reconstruction provided by the Alexa Fluor 594 loading. Rois were numbered from a proximal point close to the soma to the more distal compartments. If dendritic branching was noticed, the bifurcations were hallmarked with different rois. The fluorescent signals of each roi on the dendritic segments were extracted and a cross-correlation value to one reference roi was calculated based on the formula earlier described in Equation( 4). In the experiment reported in Figure 3.22, the AP-evoked $\mathrm{Ca}^{2+}$ transients were slow, as the 3D stack comprised 15 planes to achieve sufficient dendritic length. Nevertheless, they were specific enough to the signal of a roi as reference trace and compute the correlation factor between that reference (Roi38, green) and of all others roi signals (Figure 3.22C-D). The observation of the fluctuations within and across the two dendritic branches suggested that the signals were quite similar, and the correlation values were high, i.e. above 0.6 for the most part of both branches. No sudden drop of correlation was detected along the dendritic segments, except for the remote rois of one branch, located in the glomerulus which was imaged by out-of-focus light. 
A
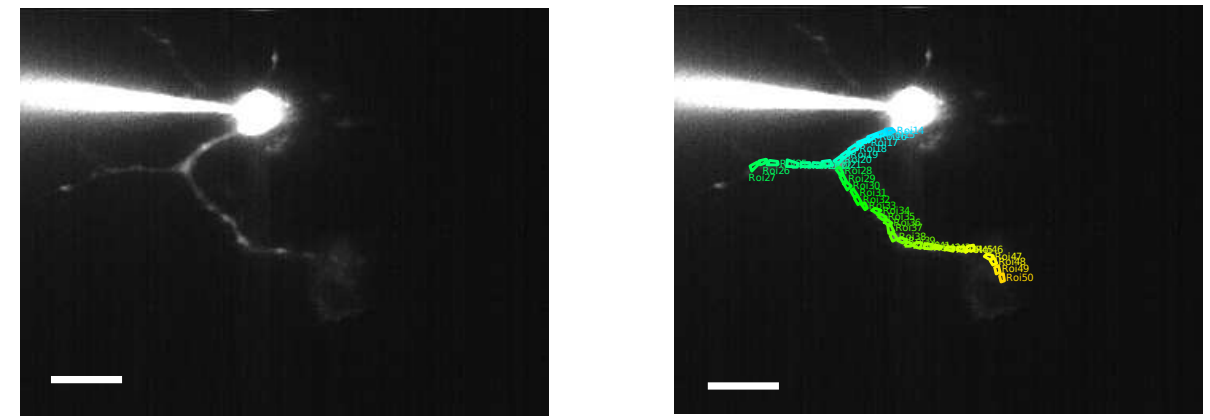

$\mathrm{B}$

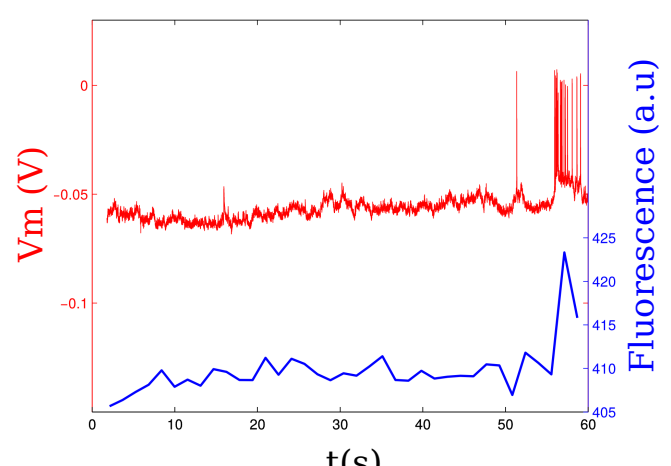

C

$t(s)$

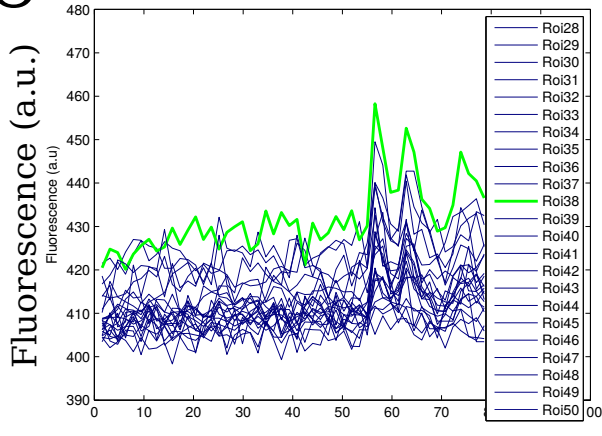

$\mathrm{t}(\mathrm{s})$

$\mathrm{D}$

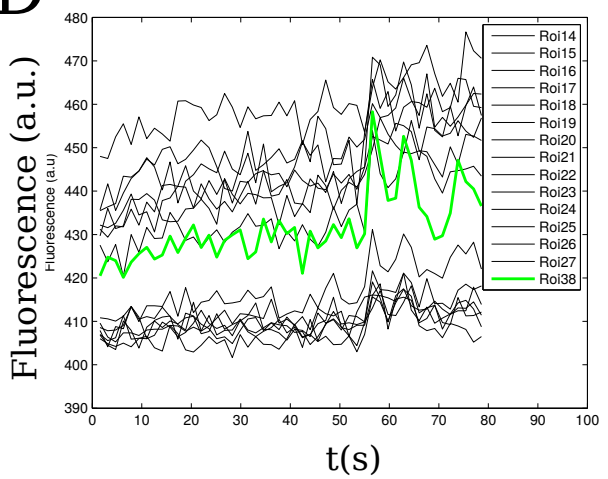

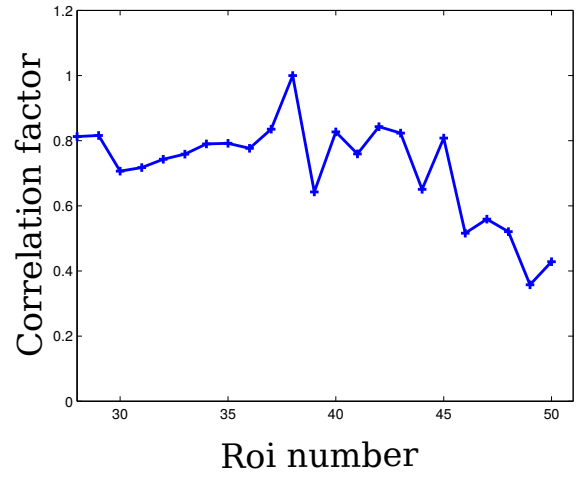

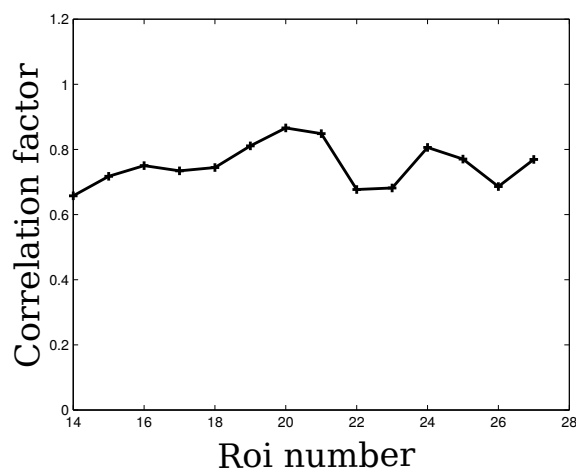

Figure 3.22: High correlation of dendritic sub-compartments during spontaneous firing

(A) M/T cell filled with Fluo-8 (200 $\mu \mathrm{M})$ and Alexa Fluor 594 Biocytin (100 $\mu \mathrm{M})$. Note the dendritic bifurcation and the glomerulus innervated by the right branch. Rois of a 1.5 $\mu \mathrm{m}$-width and $2.2 \mu \mathrm{m}$-length were drawn over the dendritic segments. 
Both images are z-projections of the maximal intensities. Scale bars: $10 \mu \mathrm{m}$ (B) Spontaneous APs recording in current-clamp and simultaneous $\mathrm{Ca}^{2+}$ signal of a dendritic roi. (C) Left: Raw fluorescence signals along the right branch terminating in a glomerulus. Roi38 (green) was used as a reference trace for calculating the cross-correlation between dendritic subcompartments. Right: Correlation factor to Roi38 plotted along the rois of the branch. Rois are numbered from a proximal point to a more distal point. (D) Left Raw fluorescence signals in dendritic sub-compartments of the left branch. Right: Correlation factor to Roi38 plotted along rois of that branch. Note the high cross-correlation values.

The data of Figure 3.22 showed that the signals of the sub-compartments in these dendritic branches were uniformly correlated. Yet, current-clamped M/T cells of Xenopus exhibited alternating active and silent phases, which meant that the nature of the $\mathrm{Ca}^{2+}$ recorded in dendritic compartments varied much from one measurement to the other. The acquisition of repeated measurements of comparable AP and calcium activity necessary for pharmacological experiments proved difficult. As a result, M/T activity was evoked by voltage pulses or current injections as mentioned above to compare the cross-correlation of dendritic sub-compartments over successive sweeps.

Compared to the dendritic correlations induced by spontaneous recordings, the uniformity of the evoked transients was diminished (Figure 3.23B). Stimulation sweeps generating timely matched $\mathrm{Ca}^{2+}$ spikes were repeated, and induced similar signals (Figure 3.23C-D). The fluctuations of correlations between rois observed in the first measurement were maintained in the second recording, although the overall uniformity along the dendrite dropped during the second stimulation (Figure 3.23B). The correlations between individual roi $\mathrm{Ca}^{2+}$ traces were displayed in matrices, which revealed regions of different correlation levels (Figure 3.23E-F).

The correlation fluctuations within single dendrites and the lower uniformity over observed repeated measurements may have been caused by imaging parameters, e.g., some sub-compartments being in- or out-of-focus, and slice shifting or morphing. Thus, in order to evaluate the contribution of GABAergic inhibition, correlation matrices of roi signals were compared before and after the perfusion of gabazine (Figure 3.24). 

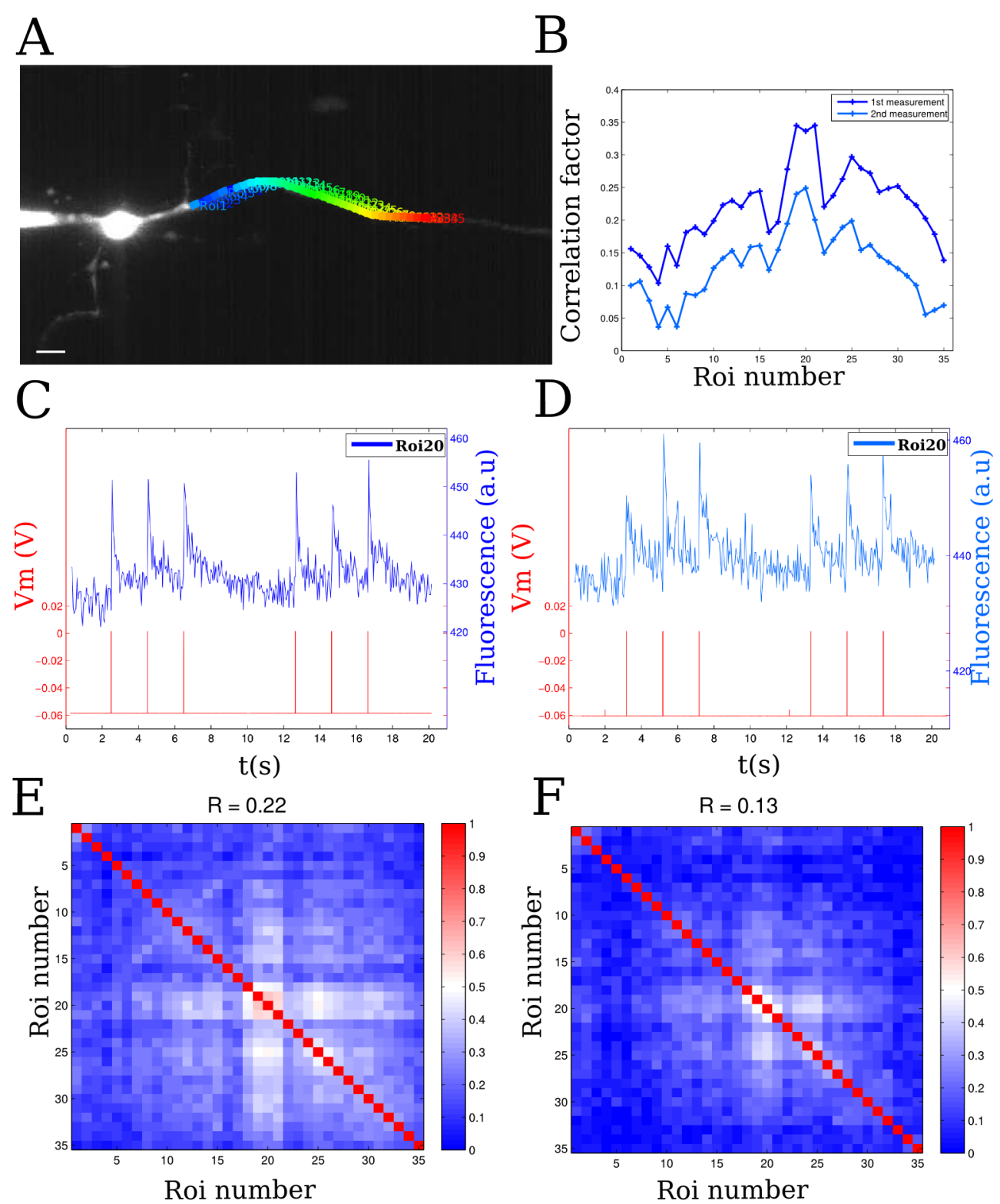

Figure 3.23: Correlation fluctuations of dendritic sub-compartments during evoked activity

(A) M/T cell filled with Fluo-8 $(200 \mu \mathrm{M})$ and Alexa Fluor 594 Biocytin (100 $\mu \mathrm{M})$ with a long dendrite. Scale bar $=10 \mu \mathrm{m}$. Calcium signals were acquired from a single plane at a acquisition speed of $20 \mathrm{~Hz}$. (B) Cross-correlation factors of the 35 roi signals compared over one measurement of evoked activity (dark blue) followed by a second one (light blue). Each point represent the correlation of a single roi trace with all 34 other signals. All correlation values dropped at the second trial, but the fluctuations between rois remained similar. (C-D) $\mathrm{Ca}^{2+}$ pattern of a single roi evoked by the depolarisation pulses ( $-60 \mathrm{mV}$ to 0 $\mathrm{V}$ for $10 \mathrm{~ms}$ ) during the first (C) and second measurement (D). (E-F) Correlation matrices of the signals of 35 rois acquired in the first (E) and in the second (F) measurement. The colour bars indicate the degrees of correlation between rois. $\mathrm{R}$ represents the mean value of correlation, and reflects the uniformity of the dendritic signals. 
Correlation matrices and the mean value of correlation across roi signals of a dendrite and were computed in successive recordings in the absence and presence of the drug. Early observations revealed that gabazine increased the uniformity across dendritic compartments. In the example displayed in Figure 3.24, $\mathrm{Ca}^{2+}$ spikes were evoked by somatic current injections. Correlation matrices were generated to assess the similarity of sub-dendritic signals. The mean value of correlation among rois initially decreased from the first measurement to the second, but doubled when gabazine was perfused over the slice during the third and fourth measurements. Furthermore, the AP-related $\mathrm{Ca}^{2+}$ transients were approximated by double exponential rise/decay functions in each condition. The fit curve was then used as a reference trace to plot the correlations along the dendrite. Interestingly, the correlation of rois to the fit signal was higher than the uniformity among rois (Figure 3.24D). It should be clarified that the increase of correlation reported here were not due to bleaching or to slow $\mathrm{Ca}^{2+}$ fluctuations superimposed over the individual signals of rois. Bleaching of dendritic signals was not observed in short-time measurements (less than $30 \mathrm{~s}$-long) or corrected for in longer recordings prior to data analysis. As to slow $\mathrm{Ca}^{2+}$ oscillations generated by gabazine, as demonstrated earlier, they were fitted by Gaussian curves and subsequently subtracted from the raw fluorescent traces in each individual roi.

The simultaneous electrophysiological and calcium recordings allowed the identification of backpropagating $\mathrm{Ca}^{2+}$ spikes in the dendrites and glomeruli of Xenopus $\mathrm{M} / \mathrm{T}$ cells. The computation of the correlation factors of sub-dendritic signals among rois and to reference traces revealed that $\mathrm{Ca}^{2+}$ signals were not uniform along the dendrites but rather fluctuated over the shaft. Preliminary work suggest that gabazine application may increase the correlation among rois and the efficiency of signal propagation. 

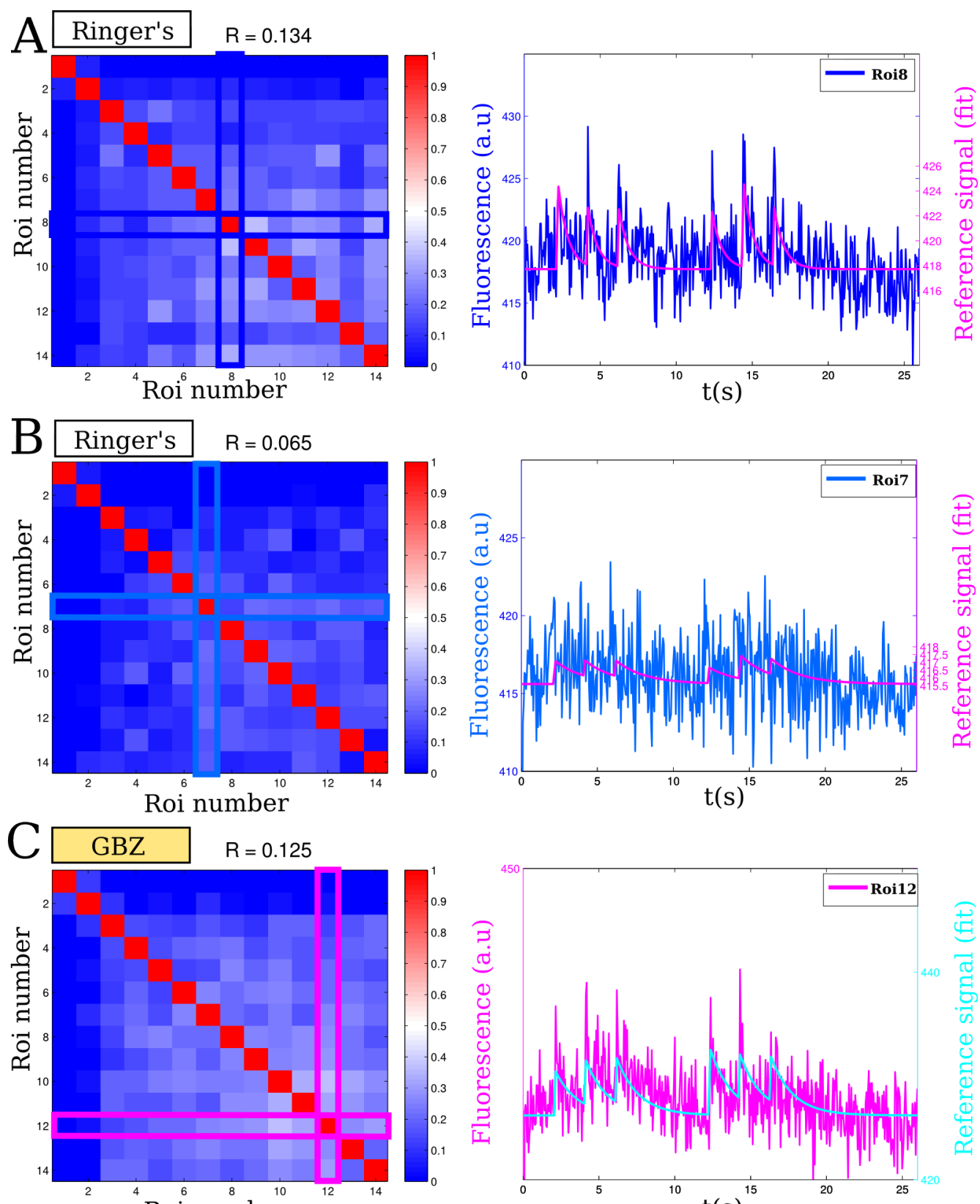

D
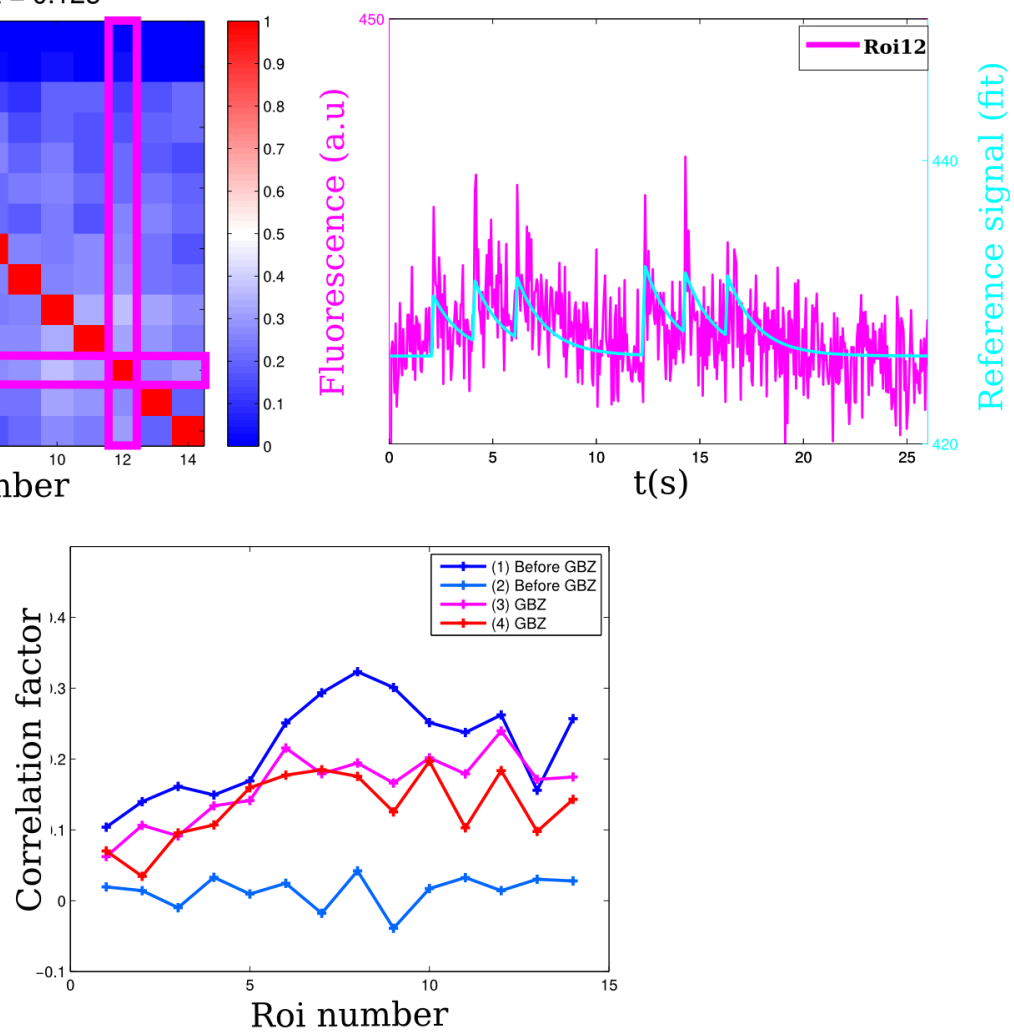

Figure 3.24: Gabazine increases the cross-correlation of $\mathrm{Ca}^{2+}$ signals along dendrites. 
Temporally patterned current injections induced somatic action potentials and backpropagating $\mathrm{Ca}^{2+}$ spikes in the dendrite of a M/T cell. (A) Left: Correlation matrices of the temporal patterns of 14 rois under control conditions. As stated precedently, $\mathrm{R}$ represents the mean value of correlation across the $\mathrm{Ca}^{2+}$ signals of the rois and reflects the uniformity of the dendritic signals. (A) Right: The fluorescence trace of Roi 8 (marked on the left panel) was extracted for approximation by a fit curve of double exponential (rise/decay) functions. (B) Same as in (A) in a second measurement. R strongly decreased, and another fit curve matching the $\mathrm{Ca}^{2+}$ fluctuations better along the dendrite was newly calculated from Roi7's signal. (C) Gabazine application (100 $\mu \mathrm{M})$ resulted in correlation increase among the dendritic sub-compartments as revealed by the correlation matrix and the $\mathrm{R}$ value which more than doubled. The reference trace of Roi 12 was employed to generate the fit curve. (D) The correlation factors of the all 14 roi signals to the fit curves was plotted for all conditions ( 2 measurements before gabazine, and 2 after). The diagram denotes the reliability of the signal propagation over the length of the dendrite. In control conditions, this efficiency diminished over repetitions, but gabazine application rescued the initial correlation-to-fit values. During the $3^{\text {rd }}$ and $4^{\text {th }}$ measurements with current injections, the correlation-to-fit values in the presence of gabazine were higher than those of the $2^{\text {nd }}$ measurement.

Although dendrodendritic synapses on mitral cell dendrites have been studied for more than 3 decades, their functional imaging remains yet a challenge. At last, ACI was applied in a effort to visualise dendritic sub-compartments of differential activity.

\subsubsection{Activity Correlation Imaging of the dendrites of M/T cells}

ACI has been used so far to reconstruct the dendritic morphologies of neurons in 3D volumes. The activity of dendrodendritic synapses was expected to alter or even gate backpropagating signals in Xenopus M/T cells as was reported in rodents ${ }^{165,166}$. Since ACI enhances the contrast of regions of similar activity, it was hypothesised that dendritic segments of correlated activity would be highlighted. Simultaneously, sub-compartments exhibiting signals opposite to the one chosen as reference trace would also be revealed by negative contrast.

ACI was carried out in M/T cells bath-loaded with Fluo-4 AM (18 $\mu \mathrm{M})$ as well as in neurons individually stained via patch pipettes with Fluo- $8 \mathrm{~K}^{+}$salt $(200 \mu \mathrm{M})$. The former recordings were 3D measurements of ca. $1 \mathrm{~min}$, acquired at a rate of $5 \mathrm{~Hz}$ per stack (Figure 3.25). The latter were mostly timeseries of a single plane recorded at $19 \mathrm{~Hz}$ for about $30 \mathrm{~s}$ (Figure 3.26 ). 

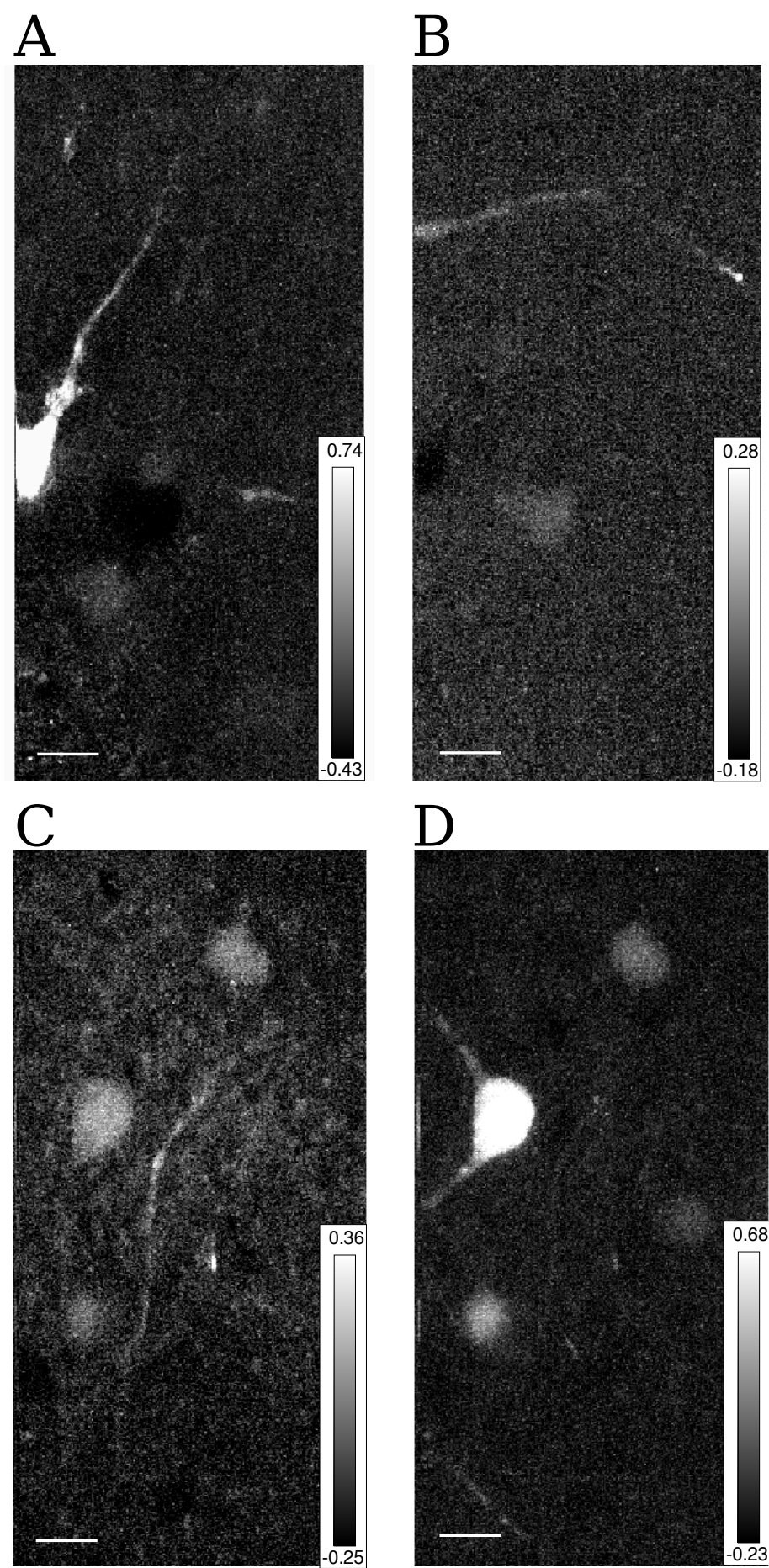

Figure 3.25: ACI of M/T cells loaded with Fluo-4 AM

3D stacks were taken, thereby limiting the speed of acquisition (ca. $5 \mathrm{~Hz}$ ). No sub-dendritic compartments were observed. Each M/T cell appeared as one single unit endowed with the same activity pattern. The colour bars indicate the pixel intensities assigned to the correlation values. All images are z-projections of the maximal intensities. Scale bars: 10 $\mu \mathrm{m}$. 

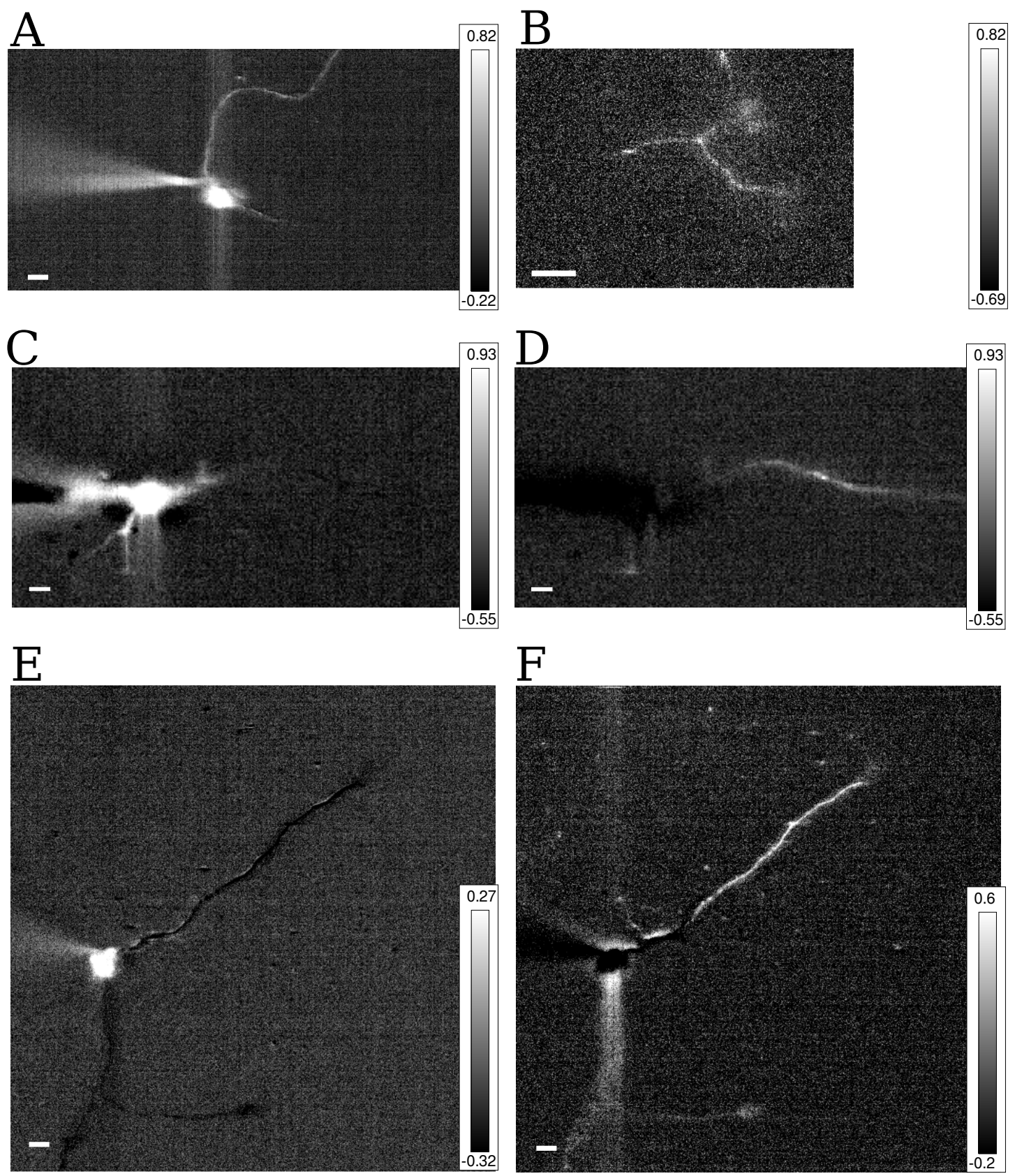

Figure 3.26: ACI of M/T cells loaded with Fluo-8 $\mathrm{K}^{+}$salt

(A-B) The cells were imaged in 3D at a low scanning speed as in Figure 3.25. No correlation drop was observed within the dendrite(s). These images are z-projections of the maximal intensities. Scale bars: $10 \mu \mathrm{m}$. (C-F) Single planes containing the soma and at least one dendritic segment were acquired at a rate of $19 \mathrm{~Hz}$ per frame. ACI revealed differential dynamics of the cell body and sometimes the proximal dendrite than compared to the rest of the dendrite(s).

For M/T cells stained by AM loading and recorded at low frequency, ACI exposed soma and dendritic segments (Figure 3.25). However, so negative correlations were observed 
along the shaft. The segment length usually retained a high correlation over its length until it exited the field of view recorded. Selecting dendritic compartments as reference traces did not change the correlation map obtained. The soma and dendrites still appeared as one single compartment.

$\mathrm{M} / \mathrm{T}$ cells loaded with Fluo- $8 \mathrm{~K}^{+}$and recorded in a similar fashion (in 3D and with low scanning speeds) yielded similar ACI results (Figure 3.26A-B). But when switching to 2D measurements of dendrites in single planes, the cell body - and sometimes the proximal dendritic segment - appeared negatively correlated to the rest of the dendritic shaft. The differential $\mathrm{Ca}^{2+}$ dynamics of the soma vs dendrites were thus detected, but no further sub-compartments of the dendritic shafts were observed. 


\section{Discussion}

\subsection{Integration of thermic and chemosensory inputs}

Several studies have provided evidence that temperature perception is not only a important function of the somatosensory system but is also processed by the verterbate olfactory system. The olfactory system of Xenopus laevis larve is no exception to that dogma, as demonstrated by the presence of thermosensitive first- and second-order neurons. ORNs stimulated by temperature drops were not activated by any other chemical input, and their axons terminate in the $\gamma$-glomerulus ${ }^{24,88}$. M/T cells, however, through their one-to-many glomerular connectivity can receive olfactory inputs from multiple glomeruli. The first section of the thesis reported the existence of two categories of M/T cells: some only responding to temperature changes, and some integrating chemosensory and thermic imputs. Cells of the latter group displayed different degrees of dual-sensitivity. Some were more strongly activated by chemical stimuli than by temperature fluctuations, and vice versa. To our knowledge, Xenopus is the first vertebrate species in which co-processing of chemical and thermic stimuli has been observed in second-order neurons. Bumbalo and colleagues published earlier this year a report suggesting the chemo- and thermosensitivity of Grueneberg Glomeruli of the mouse bulb ${ }^{74}$. The M/T cells connected to these glomeruli may presumably display characteristics similar to Xenopus dual-sensitive cells'.

From a general point of view, temperature perception has a large effect on the physiology and behaviour of amphibians. It influences the development and survival of preand postmetamorphic animals, besides regulating a wide range of behaviours like food localisation and feeding, flight responses, basking, and burrowing ${ }^{168,169}$. It is yet uncertain whether or not the thermosensitivity of the olfactory system contributes to one or more of these functions. An interesting element worth considering for this topic is the unique innervation of each hemispheric $\gamma$-glomerulus from ORNs of both nasal epithelia ${ }^{30,88}$. Chemical stimulation of the contralateral epithelium resulted in the activation of the $\gamma$-glomerulus in the the ipsilateral bulb which had been isolated from ispilateral ON input. This functional connectivity speaks in favour of a close relationship and/or active integration of mechanical (flow-related), thermic and chemical stimuli in the olfactory system of X. laevis ${ }^{170}$. 
At last, the processing of odours along with temperature information may increase odour discrimination when the animal is exposed to cooler environments. Brownian movement of molecules decreases with lower temperatures and so does the diffusion coefficient in a liquid. Besides, the Van't Hoff equation indicates that binding dynamics depends on temperature. Consequently, colder temperatures would slow down the diffusion of odour particles in the mucus, thereby impeding the detection threshold of odourants, and lower the binding properties of molecules to the olfactory receptors. In this case, the added thermic signal may serve to potentiate the bulb's response to a chemical input of weak odour potency or low concentration. A finding consistent with this hypothesis describes that neurons of the Grüneberg ganglion responded to the perfusion of 2,4,5-trimethylthiazole at lower temperatures $\left(13^{\circ} \mathrm{C}\right.$ and $\left.18{ }^{\circ} \mathrm{C}\right)$ with higher calcium fluorescence intensities than when the same molecule was applied at $23{ }^{\circ} \mathrm{C}^{81}$.

\subsection{The role of GABA-mediated inhibition}

As discussed in the introduction, there is piling evidence that lateral and recurrent inhibition of $\mathrm{M} / \mathrm{T}$ cells shape their dynamics and output to further brain targets. In the second part of the thesis, the effect of GABAergic transmission on Xenopus M/T cell populations was assessed with a series of experiments.

\section{GABAergic synapses in the larval Xenopus brain}

Firstly, immunohistochemistry experiments revealed that GABA was abundantly expressed in the OB, particularly in the glomerular and mitral/tufted cell layers. Such a staining was expected because PGCs and GCs make synaptic contacts with M/T cells in both layers, but also since it has been shown that centrifugal GABAergic fibres innervate the bulb in rodents as well as in amphibians ${ }^{146,151,152}$. GABA-immunopositive cell bodies were observed around glomeruli and in the granule cell layer. PGCs usually exhibited a more intense staining than the neurons found in the granule cell layer. A possible explanation might be that some of these cells were immature progenitors of inhibitory neurons, still expressing low levels of GABA. In the brains of anuran frogs, newborn neurons migrate from a layer adjacent to the granule cell layer, the ventricular zone, which is one of the many regions where 
neurogenesis takes place in anuran frogs ${ }^{171}$.

\section{Network activity in M/T cell networks: excitation, inhibition, synchrony}

Secondly, calcium imaging experiments were carried out in the presence and absence of gabazine, a $\mathrm{GABA}_{\mathrm{A}}$ antagonist, in order to investigate the contribution of GABA-mediated inhibition on $\mathrm{M} / \mathrm{T}$ cell activity patterns.

Gabazine suppressed or altered stimulus-induced negative responses. Some of the neurons which were inhibited by the odour input prior to the drug treatment either maintained their activity levels, or strongly responded to the stimulus. Consequently, the negative correlation factor of excited vs inhibited pairs of $\mathrm{M} / \mathrm{T}$ cells was reduced or even reversed to a positive value. Thus, blocking GABAergic inhibition of $\mathrm{M} / \mathrm{T}$ cells decreased the variety odour-evoked responses. Furthermore, gabazine increased the correlation of the M/T cell assemblies activated by an odour mixture. Altogether, these effects speak for a impaired odour discrimination and lower contrast of olfactory coding, which is consistent with reports arguing that the suppression of GABAergic inhibition or of M/T cell hyperpolarisation lowers discrimination of similar chemical odourants ${ }^{172,173}$.

In mammals, sister $\mathrm{M} / \mathrm{T}$ cells show correlated/identical firing rates, although with a different phase shift ${ }^{59}$. In Xenopus, these cells exhibit both correlated AP firing (and $\mathrm{Ca}^{2+}$ ) patterns timely matched ${ }^{58}$. Synchronised temporal patterns of excitatory and/or inhibitory inputs, gap junctions and glutamate spillover at dendritic sites within the glomeruli are all factors potentially driving the similar activities of sister M/T cells ${ }^{56,110,111}$. Here, the correlated $\mathrm{Ca}^{2+}$ signals of sister M/T cells were not abolished by the drug treatment, denoting that the correlation among the cells was not caused by synchronised inhibition. This conclusion corroborates the claim by Chen and colleagues that IPSCs measured in M/T cells are not synchronised and do not account for the synchrony of spontaneous signals ${ }^{58}$. Interestingly, the suppression of the inhibition onto sister M/T cells seemed to further increase the similarity of their patterns. The concept that OB interneurons actively regulate contrast enhancement by decorrelating redundant signals is therefore supported.

Precisely timed inhibitory inputs potentially involved in the generation of the oscillatory activities of $\mathrm{M} / \mathrm{T}$ cells have been observed in the mouse brain ${ }^{132}$. The synchrony and 
phases of the temporal patterns they generate are influenced by respiration and the sniffing behaviour of mammals, which is tightly linked to olfaction ${ }^{48,174,175}$. Sniffing generates an airflow carrying the odour molecules to the mucus layer coating ORN cilia. In premetamorphic $X$. laevis, all nasal cavities are filled with water and the swimming bouts of the larvae together with the movement of the cilia and microvilli in the nose actively generate this flow. As a result, the bulb of $X$. laevis larvae may lack synchronised IPSPs imposed by GABAergic neurons. Thus, GABAergic inhibition of M/T cells drives odour discrimination and contrast enhancement of overlapping odour signals in these neurons, and plays a minor role, if any, in the coupling of $\mathrm{M} / \mathrm{T}$ cells' baseline activities.

The Fourier analysis of the oscillatory activity of M/T populations revealed that gabazine strengthened the contribution of low frequency oscillations. This finding seems conflicting with the conclusions of the rise of spiking activity expected to be induced by the drug, and which was reflected by increased internal $\left[\mathrm{Ca}^{2+}\right]$ levels. Two factors may be at cause: a slow acquisition speed of the $\mathrm{Ca}^{2+}$ signals, and the nature of the calcium indicator. High AP firing rates simultaneously recorded at low acquisition speeds $(1 \mathrm{~Hz})$ generate slow somatic $\mathrm{Ca}^{2+}$ waves, where single APs cannot be resolved. Figure 3.20A illustrates how capturing faster $\mathrm{Ca}^{2+}$ events depends on the frame acquisition rates. The fluorescence measurement of Figure 3.20B was acquired nearly 10 times faster, and allows the detection of single events of shorter timespan, which is also facilitated by the much lower AP frequency. The calcium signals analysed by the Fourier analysis were extracted from measurements taken with an acquisition speed of $5 \mathrm{~Hz}$. The same effect was observed in $\mathrm{Ca}^{2+}$ measurements with odour stimulation. The sudden increase of AP frequency is often visualised in calcium imaging by a long-lasting calcium rise. Yet, for neurons firing as fast as in Figure 3.20A increasing the acquisition speed alone may not suffice to replace the slow waves by timely matched $\mathrm{Ca}^{2+}$ spikes. The combination of rapid calcium imaging with a faster indicator than Fluo-4 of lower binding affinity -to avoid saturation of signals- would be required to resolve high frequency spikes. 


\subsection{Localisation of inhibitory synapses on the dendrites of $\mathrm{M} / \mathrm{T}$ cells}

Simultaneous patch-clamp recordings and $\mathrm{Ca}^{2+}$ imaging demonstrated that APs and related $\mathrm{Ca}^{2+}$ signals backpropagate in the dendrites of Xenopus $\mathrm{M} / \mathrm{T}$ cells until reaching the glomerulus. Both spontaneous and evoked APs triggered $\mathrm{Ca}^{2+}$ spikes timely matched. Thus, dendrites of $\mathrm{M} / \mathrm{T}$ cells contain $\mathrm{Ca}^{2+}$ channels and propagate APs from the soma through the dendritic tree. Voltage steps mimicking APs and depolarising current injections enabled the recording of repeated calcium measurements of comparable signals. Evoked spikes were preferred over spontaneous recordings since it was hypothesised that the open probability of $\mathrm{Ca}^{2+}$ would remain comparable across trials. Besides, signal fitting of the induced dendritic $\mathrm{Ca}^{2+}$ spikes was more easily achieved when the input stimulus to the $\mathrm{M} / \mathrm{T}$ cell was controlled.

Two studies performed in rodents consistently concluded that GABAergic synapses are not uniformly distributed over the dendrites ${ }^{135,167}$. Moreover, earlier work showed that GABA local uncaging on M/T dendrites attenuated or even abolished backpropagating patterns in rats ${ }^{165,166}$. In Xenopus animals, the cross-correlation analysis of $\mathrm{Ca}^{2+}$ fluctuations between dendritic sub-compartments of $2.2 \mu \mathrm{m}$-length exposed differential activities along the dendrites. Gabazine enhances the uniformity of backpropagating spikes along dendrites, thereby suggesting a role of inhibitory synapses in the signal attenuation over the length of the shaft.

Although the correlation analysis hinted at a non-uniform $\mathrm{Ca}^{2+}$ patterns of dendritic sub-compartments, ACI only revealed the differential activity of the cell body as opposed to the dendritic tree. The efficiency of ACI may be improved by using voltage-sensitive dyes, which provide much higher temporal resolution (up to a few milliseconds) ${ }^{176}$, and are better fitted for the detection of subthreshold events. The reduced fluorescent changes yielded by voltage-sensitive dyes may not be as detrimental in single-cell loading experiments, which offer the best signal contrast. 


\section{Bibliography}

\section{References}

1. H. Altner, "Untersuchungen über Leistungen und Bau der Nase des südafrikanischen Krallenfrosches Xenopus laevis (Daudin, 1803)," Zeitschrift für vergleichende Physiologie, vol. 45, no. 3, pp. 272-306, 1962.

2. C. A. Byrd and G. D. Burd, "Development of the olfactory bulb in the clawed frog, Xenopus laevis: a morphological and quantitative analysis.," J Comp Neurol, vol. 314, pp. 79-90, dec 1991.

3. A. Hansen, J. O. Reiss, C. L. Gentry, and G. D. Burd, "Ultrastructure of the olfactory organ in the clawed frog, Xenopus laevis, during larval development and metamorphosis.," The Journal of comparative neurology, vol. 398, pp. 273-88, aug 1998.

4. P. D. Nieuwkoop and J. Faber, "Normal table of Xenopus laevis (Daudin). A systematical and chronological survey of the development from the fertilized egg till the end of metamorphosis.," Normal table of Xenopus laevis (Daudin). A systematical and chronological survey of the development from the fertilized egg till the end of metamorphosis., vol. 22, 1956.

5. P. P. C. Graziadei and J. F. Metcalf, "Autoradiographic and ultrastructural observations on the frog's olfactory mucosa," Zeitschrift $f\{\ddot{u}\} r$ Zellforschung und Mikroskopische Anatomie, vol. 116, no. 3, pp. 305-318, 1971.

6. J. Freitag, J. Krieger, J. Strotmann, and H. Breer, "Two classes of olfactory receptors in Xenopus laevis," Neuron, vol. 15, no. 6, pp. 1383-1392, 1995.

7. Y. Niimura and M. Nei, "Evolutionary dynamics of olfactory receptor genes in Drosophila species," Proc Natl Acad Sci U S A, vol. 104, no. 17, pp. 7122-7127, 2007.

8. K. Hagino-Yamagishi, K. Moriya, H. Kubo, Y. Wakabayashi, N. Isobe, S. Saito, 
M. Ichikawa, and K. Yazaki, "Expression of Vomeronasal Receptor Genes in Xenopus laevis," Journal of Comparative Neurology, vol. 472, no. 2, pp. 246-256, 2004.

9. A. Syed and A. Sansone, "Ancestral amphibian v2rs are expressed in the main olfactory epithelium," Proceedings of the ..., vol. 937216, 2013.

10. A. Sansone, T. Hassenklöver, A. S. Syed, S. I. Korsching, and I. Manzini, "Phospholipase $\mathrm{C}$ and diacylglycerol mediate olfactory responses to amino acids in the main olfactory epithelium of an amphibian.," PloS one, vol. 9, p. e87721, jan 2014.

11. T. V. Getchell, "Functional properties of vertebrate olfactory receptor neurons.," Physiological reviews, vol. 66, no. 3, pp. 772-818, 1986.

12. D. Lancet, "Vertebrate Olfactory Reception," Annual Review of Neuroscience, vol. 9, no. 1, pp. 329-355, 1986.

13. J. G. Hildebrand and G. M. Shepherd, "Mechanisms of Olfactory Discrimination: Converging Evidence for Common Principles Across Phyla," Annual Review of Neuroscience, vol. 20, no. 1, pp. 595-631, 1997.

14. D. Schild and D. Restrepo, "Transduction mechanisms in vertebrate olfactory receptor cells.," Physiological reviews, vol. 78, pp. 429-66, apr 1998.

15. M. Zarzo, "The sense of smell: molecular basis of odorant recognition.," Biological reviews of the Cambridge Philosophical Society, vol. 82, pp. 455-79, aug 2007.

16. U. B. Kaupp, “Olfactory signalling in vertebrates and insects: differences and commonalities.," Nature reviews. Neuroscience, vol. 11, no. 3, pp. 188-200, 2010.

17. S. Gliem, D. Schild, and I. Manzini, "Highly specific responses to amine odorants of individual olfactory receptor neurons in situ.," The European journal of neuroscience, vol. 29, pp. 2315-26, jun 2009.

18. L. P. Nezlin, S. Heermann, D. Schild, and W. Rössler, "Organization of glomeruli in the main olfactory bulb of Xenopus laevis tadpoles.," The Journal of comparative neurology, vol. 464, pp. 257-68, sep 2003. 
19. L. P. Nezlin and D. Schild, "Structure of the olfactory bulb in tadpoles of Xenopus laevis," Cell and Tissue Research, vol. 302, pp. 21-29, sep 2000.

20. M. H. Hofmann and D. L. Meyer, "Subdivisions of the terminal nerve in Xenopus laevis," Journal of Experimental Zoology, vol. 259, no. 3, pp. 324-329, 1991.

21. M. H. Hofmann and D. L. Meyer, "Peripheral origin of olfactory nerve fibers by-passing the olfactory bulb in Xenopus laevis," Brain Research, vol. 589, no. 1, pp. 161-163, 1992.

22. C. Pinelli, B. D’Aniello, G. Polese, and R. K. Rastogi, "Extrabulbar olfactory system and nervus terminalis FMRFamide immunoreactive components in Xenopus laevis ontogenesis.," J Chem Neuroanat, vol. 28, pp. 37-46, sep 2004.

23. A. Gaudin, J. Lardière-Butterfield, and J. Gascuel, "Ontogenesis of the extra-bulbar olfactory pathway in Xenopus laevis," Anatomical Record, vol. 296, no. 9, pp. 14621476, 2013.

24. E. Kludt, Bilateral processing of thermoreception in the olfactory system of larval Xenopus laevis. PhD thesis, 2009.

25. G. M. Shepherd, The synaptic organization of the brain. Oxford University Press, 2003.

26. P. Mombaerts, "Odorant receptor gene choice in olfactory sensory neurons: The one receptor-one neuron hypothesis revisited," Current Opinion in Neurobiology, vol. 14, no. 1, pp. 31-36, 2004.

27. S. Serizawa, K. Miyamichi, and H. Sakano, "One neuron-one receptor rule in the mouse olfactory system," Trends in Genetics, vol. 20, no. 12, pp. 648-653, 2004.

28. T. Hassenklöver and I. Manzini, "Olfactory wiring logic in amphibians challenges the basic assumptions of the unbranched axon concept.," The Journal of neuroscience : the official journal of the Society for Neuroscience, vol. 33, pp. 17247-52, oct 2013.

29. C. Lodovichi and L. Belluscio, "Odorant receptors in the formation of the olfactory bulb circuitry.," Physiology (Bethesda, Md.), vol. 27, no. 4, pp. 200-212, 2012. 
30. A. Brinkmann, C. Okom, E. Kludt, and D. Schild, "Recording Temperature-induced Neuronal Activity through Monitoring Calcium Changes in the Olfactory Bulb of Xenopus laevis," Journal of Visualized Experiments, no. 112, pp. 1-9, 2016.

31. I. Manzini, S. Heermann, D. Czesnik, C. Brase, D. Schild, and W. Rössler, "Presynaptic protein distribution and odour mapping in glomeruli of the olfactory bulb of Xenopus laevis tadpoles," European Journal of Neuroscience, vol. 26, no. 4, pp. 925-934, 2007.

32. A. Gaudin and J. Gascuel, "3D atlas describing the ontogenic evolution of the primary olfactory projections in the olfactory bulb of Xenopus laevis.," The Journal of comparative neurology, vol. 489, pp. 403-24, sep 2005.

33. S. Gliem, A. S. Syed, A. Sansone, E. Kludt, E. Tantalaki, T. Hassenklöver, S. I. Korsching, and I. Manzini, "Bimodal processing of olfactory information in an amphibian nose: odor responses segregate into a medial and a lateral stream.," Cellular and molecular life sciences : CMLS, vol. 70, pp. 1965-84, jun 2013.

34. I. Manzini, C. Brase, T.-W. Chen, and D. Schild, "Response profiles to amino acid odorants of olfactory glomeruli in larval Xenopus laevis.," The Journal of physiology, vol. 581, pp. 567-79, jun 2007.

35. E. R. Soucy, D. F. Albeanu, A. L. Fantana, V. N. Murthy, and M. Meister, "Precision and diversity in an odor map on the olfactory bulb.," Nature neuroscience, vol. 12, pp. 210-20, feb 2009.

36. H. Matsumoto, K. Kobayakawa, R. Kobayakawa, T. Tashiro, K. Mori, H. Sakano, and K. Mori, "Spatial arrangement of glomerular molecular-feature clusters in the odorantreceptor class domains of the mouse olfactory bulb.," Journal of neurophysiology, vol. 103, no. 6, pp. 3490-500, 2010.

37. K. Mori and H. Sakano, "How is the olfactory map formed and interpreted in the mammalian brain?," Annual review of neuroscience, vol. 34, pp. 467-499, jan 2011.

38. L. Ma, Q. Qiu, S. Gradwohl, a. Scott, E. Q. Yu, R. Alexander, W. Wiegraebe, and C. R. $\mathrm{Yu}$, "Distributed representation of chemical features and tunotopic organization of 
glomeruli in the mouse olfactory bulb," Proceedings of the National Academy of Sciences, vol. 109, no. 14, pp. 5481-5486, 2012.

39. S. Nagayama, R. Homma, and F. Imamura, "Neuronal organization of olfactory bulb circuits," Frontiers in Neural Circuits, vol. 8, no. September, pp. 1-19, 2014.

40. J. N. Bourne and N. E. Schoppa, "Three-dimensional synaptic analyses of mitral cell and external tufted cell dendrites in rat olfactory bulb glomeruli," Journal of Comparative Neurology, vol. 00, pp. 1-18, 2016.

41. S. R. y Cajal, Estudios sobre la corteza cerebral humana: IV. Estructura de la corteza cerebral olfativa del hombre y mamiferos, vol. 1. Trab. Lab. Invest. Biol., 1901.

42. G. M. Shepherd, "Synaptic organization of the mammalian olfactory bulb," Physiological Reviews, vol. 52, no. 4, pp. 864-917, 1972.

43. J. H. McLean and M. T. Shipley, Neuroanatomical Substrates of Olfaction, pp. 126-171. New York, NY: Springer New York, 1992.

44. K. Mori, K. Kishi, and H. Ojima, "Distribution of dendrites of mitral, displaced mitral, tufted, and granule cells in the rabbit olfactory bulb," Journal of Comparative Neurology, vol. 219, no. 3, pp. 339-355, 1983.

45. P. I. Ezeh, D. P. Wellis, and J. W. Scott, "Organization of inhibition in the rat olfactory bulb external plexiform layer.," Journal of neurophysiology, vol. 70, no. 1, pp. 263-74, 1993.

46. S. Nagayama, "Mitral and Tufted Cells Differ in the Decoding Manner of Odor Maps in the Rat Olfactory Bulb," Journal of Neurophysiology, vol. 91, no. 6, pp. 2532-2540, 2004.

47. G. Otazu, H. Chae, M. Davis, and D. Albeanu, "Cortical Feedback Decorrelates Olfactory Bulb Output in Awake Mice," Neuron, vol. 86, no. 6, pp. 1461-1477, 2015.

48. I. Fukunaga, M. Berning, M. Kollo, A. Schmaltz, and A. T. Schaefer, "Two Distinct Channels of Olfactory Bulb Output," Neuron, vol. 75, no. 2, pp. 320-329, 2012. 
49. S. Nagayama, "Differential Axonal Projection of Mitral and Tufted Cells in the Mouse Main Olfactory System," Frontiers in Neural Circuits, vol. 4, no. September, pp. 1-8, 2010.

50. K. M. Igarashi, N. Ieki, M. An, Y. Yamaguchi, S. Nagayama, K. Kobayakawa, R. Kobayakawa, M. Tanifuji, H. Sakano, W. R. Chen, and K. Mori, "Parallel Mitral and Tufted Cell Pathways Route Distinct Odor Information to Different Targets in the Olfactory Cortex," 2012.

51. H. L. Eisthen, "Evolution of vertebrate olfactory systems.," Brain, behavior and evolution, vol. 50, no. 4, pp. 222-233, 1997.

52. S. Junek, T.-W. Chen, M. Alevra, and D. Schild, "Activity correlation imaging: visualizing function and structure of neuronal populations.," Biophysical journal, vol. 96, pp. 3801-9, may 2009.

53. N. N. Urban and J. B. Castro, "Tuft Calcium Spikes in Accessory Olfactory Bulb Mitral Cells," Journal of Neuroscience, vol. 25, no. 20, pp. 5024-5028, 2005.

54. J. Ma and G. Lowe, "Action potential backpropagation and multiglomerular signaling in the rat vomeronasal system.," J Neurosci, vol. 24, pp. 9341-9352, oct 2004.

55. J. P. Royet, H. Distel, R. Hudson, and R. Gervais, "A re-estimation of the number of glomeruli and mitral cells in the olfactory bulb of rabbit," Brain Research, vol. 788, no. 1-2, pp. 35-42, 1998.

56. N. E. Schoppa and G. L. Westbrook, "AMPA autoreceptors drive correlated spiking in olfactory bulb glomeruli.," Nature neuroscience, vol. 5, no. 11, pp. 1194-1202, 2002.

57. T.-W. Chen, A Systems Level Analysis of Neuronal Network Function in the Olfactory Bulb : Coding, Connectivity, and Modular organization. PhD thesis, 2008.

58. T.-W. Chen, B.-J. Lin, and D. Schild, "Odor coding by modules of coherent mitral/tufted cells in the vertebrate olfactory bulb.," Proceedings of the National Academy of Sciences of the United States of America, vol. 106, pp. 2401-6, feb 2009. 
59. A. K. Dhawale, A. Hagiwara, U. S. Bhalla, V. N. Murthy, and D. F. Albeanu, "Nonredundant odor coding by sister mitral cells revealed by light addressable glomeruli in the mouse.," Nature neuroscience, vol. 13, no. 11, pp. 1404-12, 2010.

60. M. Migliore, M. Hines, and G. M. Shepherd, "The role of distal dendritic gap junctions in synchronization of mitral cell axonal output," Journal of computational . . , pp. 151161, 2005.

61. S. Junek, E. Kludt, F. Wolf, and D. Schild, "Olfactory coding with patterns of response latencies," Neuron, vol. 67, no. 5, pp. 872-884, 2010.

62. D. Polese, E. Martinelli, S. Marco, C. D. Natale, and A. Gutierrez-Galvez, "Understanding odor information segregation in the olfactory bulb by means of mitral and tufted cells," PLoS ONE, vol. 9, no. 10, pp. 1-9, 2014.

63. M. Yokoi, K. Mori, and S. Nakanishi, "Refinement of odor molecule tuning by dendrodendritic synaptic inhibition in the olfactory bulb.," Proceedings of the National Academy of Sciences of the United States of America, vol. 92, no. 8, pp. 3371-3375, 1995.

64. P. Panzanelli, A.-Z. Perazzini, J.-M. Fritschy, and M. Sassoè-Pognetto, "Heterogeneity of gamma-aminobutyric acid type A receptors in mitral and tufted cells of the rat main olfactory bulb.," The Journal of comparative neurology, vol. 484, no. 1, pp. 121-131, 2005.

65. A. Fritz, D. L. Gorlick, and G. D. Burd, "Neurogenesis in the olfactory bulb of the frog xenopus laevis shows unique patterns during embryonic development and metamorphosis," International Journal of Developmental Neuroscience, vol. 14, no. 7-8, pp. 931-943, 1996.

66. A. Alvarez-Buylla and J. M. García-Verdugo, "Neurogenesis in adult subventricular zone," The Journal of neuroscience, vol. 22, no. 3, pp. 629-634, 2002.

67. L. Petreanu and A. Alvarez-Buylla, "Maturation and death of adult-born olfactory bulb granule neurons: role of olfaction," Journal of Neuroscience, vol. 22, no. 14, pp. 6106-6113, 2002. 
68. A. Mouret, G. Gheusi, M.-M. Gabellec, F. de Chaumont, J.-C. Olivo-Marin, and P.-M. Lledo, "Learning and Survival of Newly Generated Neurons: When Time Matters," Journal of Neuroscience, vol. 28, no. 45, pp. 11511-11516, 2008.

69. F. Martin, J. Riveron, and E. Alcorta, "Environmental temperature modulates olfactory reception in Drosophila melanogaster," Journal of Insect Physiology, vol. 57, no. 12, pp. 1631-1642, 2011.

70. J. Riveron, T. Boto, and E. Alcorta, "Transcriptional basis of the acclimation to high environmental temperature at the olfactory receptor organs of Drosophila melanogaster.," BMC genomics, vol. 14, p. 259, 2013.

71. H. Ay, M. Salihoglu, A. Altundag, H. Tekeli, A. Memis, and M. Cayonu, "The effect of hyperbaric conditions on olfactory functions.," Undersea \& hyperbaric medicine : journal of the Undersea and Hyperbaric Medical Society, Inc, vol. 41, no. 3, pp. 203-207, 2014.

72. M. Kuehn, H. Welsch, T. Zahnert, and T. Hummel, "Changes of pressure and humidity affect olfactory function," European Archives of Oto-Rhino-Laryngology, vol. 265, no. 3, pp. 299-302, 2008.

73. X. Grosmaitre, L. C. Santarelli, J. Tan, M. Luo, and M. Ma, "Dual functions of mammalian olfactory sensory neurons as odor detectors and mechanical sensors.," Nature neuroscience, vol. 10, pp. 348-54, mar 2007.

74. R. Bumbalo, M. Lieber, L. Schroeder, Y. Polat, H. Breer, and J. Fleischer, "Grueneberg Glomeruli in the Olfactory Bulb are Activated by Odorants and Cool Temperature," Cellular and Molecular Neurobiology, 2016.

75. S. D. Munger, T. Leinders-Zufall, and F. Zufall, "Subsystem organization of the mammalian sense of smell.," Annual review of physiology, vol. 71, pp. 115-140, 2009.

76. C. Liu and C. Montell, "Forcing Open TRP channels: mechanical gating as a unifying activation mechanism," Biochem Biophys Res Commun, vol. 33, no. 4, pp. 395-401, 2015. 
77. A. Brinkmann, Processing of different sensory qualities in the olfactory bulb of Xenopus laevis studied by advanced line illumination microscopy. PhD thesis, 2016.

78. M. Gallio, T. a. Ofstad, L. J. Macpherson, J. W. Wang, and C. S. Zuker, "The coding of temperature in the Drosophila brain.," Cell, vol. 144, pp. 614-24, feb 2011.

79. N. Y. Masse, G. C. Turner, and G. S. X. E. Jefferis, "Olfactory Information Processing in Drosophila," Current Biology, vol. 19, no. 16, pp. 700-713, 2009.

80. K. Mamasuew, N. Hofmann, H. Breer, and J. Fleischer, "Grueneberg ganglion neurons are activated by a defined set of odorants.," Chemical senses, vol. 36, pp. 271-82, mar 2011.

81. J. Brechbühl, F. Moine, and M.-C. Broillet, "Mouse Grueneberg ganglion neurons share molecular and functional features with C. elegans amphid neurons.," Frontiers in behavioral neuroscience, vol. 7, p. 193, jan 2013.

82. J. Brechbühl, M. Klaey, and M.-C. Broillet, "Grueneberg Ganglion Cells Mediate Alarm Pheromone Detection in Mice," Science, vol. 321, no. 5892, pp. 1092-1095, 2008.

83. A. Schmid, M. Pyrski, M. Biel, T. Leinders-Zufall, and F. Zufall, "Grueneberg ganglion neurons are finely tuned cold sensors," The Journal of Neuroscience, vol. 30, no. 22, pp. 7563-7568, 2010.

84. S. H. Fuss, M. Omura, and P. Mombaerts, "The Grueneberg ganglion of the mouse projects axons to glomeruli in the olfactory bulb.," Eur J Neurosci, vol. 22, pp. 26492654, nov 2005.

85. D. S. Koos and S. E. Fraser, "The Grueneberg ganglion projects to the olfactory bulb.," Neuroreport, vol. 16, pp. 1929-1932, nov 2005.

86. D. Roppolo, V. Ribaud, V. P. Jungo, C. Lüscher, and I. Rodriguez, "Projection of the Grüneberg ganglion to the mouse olfactory bulb.," Eur J Neurosci, vol. 23, pp. 28872894, jun 2006.

87. M. J. Storan and B. Key, "Septal organ of Grüneberg is part of the olfactory system.," $J$ Comp Neurol, vol. 494, pp. 834-844, feb 2006. 
88. E. Kludt, C. Okom, A. Brinkmann, and D. Schild, "Integrating Temperature with Odor Processing in the Olfactory Bulb," Journal of Neuroscience, vol. 35, no. 20, pp. 7892-7902, 2015.

89. V. N. Murthy, "Olfactory maps in the brain.," Annual review of neuroscience, vol. 34, pp. 233-58, jan 2011.

90. T. A. Cleland and P. Sethupathy, "Non-topographical contrast enhancement in the olfactory bulb.," BMC Neuroscience, vol. 7, p. 7, 2006.

91. T. A. Cleland and C. Linster, "On-Center/Inhibitory-Surround Decorrelation via Intraglomerular Inhibition in the Olfactory Bulb Glomerular Layer.," Frontiers in integrative neuroscience, vol. 6, no. February, p. 5, 2012.

92. J. D. Whitesell, K. A. Sorensen, B. C. Jarvie, S. T. Hentges, and N. E. Schoppa, "Interglomerular lateral inhibition targeted on external tufted cells in the olfactory bulb.," The Journal of neuroscience : the official journal of the Society for Neuroscience, vol. 33, no. 4, pp. 1552-63, 2013.

93. W. Rall, G. M. Shepherd, T. S. Reese, and M. W. Brightman, "Dendrodendritic synaptic pathway for inhibition in the olfactory bulb," Experimental neurology, vol. 14, no. 1, pp. 44-56, 1966.

94. G. M. Shepherd and C. A. Greer, "Olfactory bulb.," 1998.

95. P. Duchamp-Viret and A. Duchamp, "Gabaergic Control of Odor-Induced Activity in the Frog Olfactory-Bulb - Possible Gabaergic Modulation of Granule Cell Inhibitory-Action,” Neuroscience, vol. 56, no. 4, pp. 905-914, 1993.

96. T. W. Margrie, B. Sakmann, and N. N. Urban, "Action potential propagation in mitral cell lateral dendrites is decremental and controls recurrent and lateral inhibition in the mammalian olfactory bulb.," Proc Natl Acad Sci U S A, vol. 98, pp. 319-324, jan 2001.

97. V. Egger, K. Svoboda, and Z. F. Mainen, "Mechanisms of lateral inhibition in the olfactory bulb: efficiency and modulation of spike-evoked calcium influx into granule 
cells.," The Journal of neuroscience : the official journal of the Society for Neuroscience, vol. 23, no. 20, pp. 7551-7558, 2003.

98. R. W. Friedrich, "Dynamics of Olfactory Bulb Input and Output Activity During Odor Stimulation in Zebrafish," Journal of Neurophysiology, vol. 91, no. 6, pp. 2658-2669, 2004.

99. R. Tabor and R. W. Friedrich, "Pharmacological analysis of ionotropic glutamate receptor function in neuronal circuits of the zebrafish olfactory bulb," PLOS ONE, vol. 3, no. 1, 2008.

100. E. A. Barnard, P. Skolnick, R. W. Olsen, H. Mohler, W. Sieghart, G. Biggio, C. Braestrup, A. N. Bateson, and S. Z. Langer, "International Union of Pharmacology. XV. Subtypes of gamma-aminobutyric acidA receptors: classification on the basis of subunit structure and receptor function.," Pharmacological reviews, vol. 50, no. 2, pp. 291-313, 1998.

101. P. J. Whiting, "The GABA-A receptor gene family: New targets for therapeutic intervention," Neurochemistry International, vol. 34, no. 5, pp. 387-390, 1999.

102. W. Sieghart, "Structure and pharmacology of gamma-aminobutyric acidA receptor subtypes.," Pharmacological Reviews, vol. 47, no. 2, pp. 181-234, 1995.

103. J. H. Zhang, M. Sato, K. Noguchi, and M. Tohyama, "The differential expression patterns of the mRNAs encoding beta subunits (beta 1, beta 2 and beta 3 ) of GABAA receptor in the olfactory bulb and its related areas in the rat brain," Neurosci Lett, vol. 119, no. 2, pp. 257-260, 1990.

104. D. J. Laurie, P. H. Seeburg, and W. Wisden, "The distribution of 13 GABAA receptor subunit mRNAs in the rat brain. II. Olfactory bulb and cerebellum.," The Journal of Neuroscience, vol. 12, no. 3, pp. 1063-1076, 1992.

105. Z. Nusser, W. Sieghart, and I. Mody, "Differential regulation of synaptic GABA A receptors by cAMP-dependent protein kinase in mouse cerebellar and olfactory bulb neurones," pp. 421-435, 1999. 
106. G. E. Kaeser, B. A. Rabe, and M. S. Saha, "Cloning and characterization of GABA subunits in Xenopus laevis during development," vol. 240, no. 4, pp. 862-873, 2012.

107. M. Farrant and Z. Nusser, "Variations on an inhibitory theme: phasic and tonic activation of GABA(A) receptors.," Nature reviews. Neuroscience, vol. 6, no. 3, pp. 215229, 2005.

108. D. H. Gire and N. E. Schoppa, "Control of on/off glomerular signaling by a local GABAergic microcircuit in the olfactory bulb.," The Journal of neuroscience : the official journal of the Society for Neuroscience, vol. 29, no. 43, pp. 13454-64, 2009.

109. T. A. Cleland, "Early transformations in odor representation," Trends in Neurosciences, vol. 33, no. 3, pp. 130-139, 2010.

110. J. M. Christie, C. Bark, S. G. Hormuzdi, I. Helbig, H. Monyer, and G. L. Westbrook, "Connexin36 mediates spike synchrony in olfactory bulb glomeruli," Neuron, vol. 46, no. 5, pp. 761-772, 2005.

111. J. S. Isaacson, "Glutamate Spillover Mediates Excitatory Transmission in the Rat Olfactory Bulb ates reciprocal feedback excitation via a different excit," Neuron, vol. 23, pp. 377-384, 1999.

112. N. Buonviso and M. A. Chaput, "Response similarity to odors in olfactory bulb output cells presumed to be connected to the same glomerulus: electrophysiological study using simultaneous single-unit recordings," J Neurophys, vol. 63, no. 3, pp. 447-454, 1990.

113. M. Najac, a. Sanz Diez, a. Kumar, N. Benito, S. Charpak, and D. De Saint Jan, "Intraglomerular Lateral Inhibition Promotes Spike Timing Variability in Principal Neurons of the Olfactory Bulb," Journal of Neuroscience, vol. 35, no. 10, pp. 43194331, 2015.

114. J. P. McGann, N. Pírez, M. A. Gainey, C. Muratore, A. S. Elias, and M. Wachowiak, "Odorant representations are modulated by intra- but not interglomerular presynaptic inhibition of olfactory sensory neurons," Neuron, vol. 48, no. 6, pp. 1039-1053, 2005. 
115. H. Baker and A. I. Farbman, "Olfactory afferent regulation of the dopamine phenotype in the fetal rat olfactory system," Neuroscience, vol. 52, no. 1, pp. 115-134, 1993.

116. J. W. Cave and H. Baker, "Dopamine systems in the forebrain," Adv Exp Med Biol, vol. 29, no. 6, pp. 997-1003, 2009.

117. V. Coronas, L. K. Srivastava, J.-J. Liang, F. Jourdan, and E. Moyse, "Identification and localization of dopamine receptor subtypes in rat olfactory mucosa and bulb: a combined in situ hybridization and ligand binding radioautographic approach," Journal of chemical neuroanatomy, vol. 12, no. 4, pp. 243-257, 1997.

118. N. L. Koster, A. B. Norman, N. M. Richtand, W. T. Nickell, A. C. Puche, S. K. Pixley, and M. T. Shipley, “Olfactory receptor neurons express D2 dopamine receptors," Journal of Comparative Neurology, vol. 411, no. 4, pp. 666-673, 1999.

119. M. Ennis, F.-m. Zhou, K. J. Ciombor, A. Hayar, E. Borrelli, L. a. Zimmer, F. Margolis, M. T. Shipley, and V. Aroniadou-anderjaska, "Dopamine D2 Receptor - Mediated Presynaptic Inhibition of Olfactory Nerve Terminals," Journal of neurophysiology, vol. 86, pp. 2986-2997, 2001.

120. J. Bischofberger and P. Jonas, "Action potential propagation into the presynaptic dendrites of rat mitral cells.," The Journal of physiology, vol. 504 ( Pt 2, pp. 359-65, oct 1997.

121. W. R. Chen, G. Y. Shen, G. M. Shepherd, M. L. Hines, and J. Midtgaard, "Multiple modes of action potential initiation and propagation in mitral cell primary dendrite.," Journal of neurophysiology, vol. 88, pp. 2755-64, nov 2002.

122. V. Egger, K. Svoboda, and Z. F. Mainen, "Dendrodendritic synaptic signals in olfactory bulb granule cells: local spine boost and global low-threshold spike.," The Journal of neuroscience : the official journal of the Society for Neuroscience, vol. 25, pp. 3521-30, apr 2005.

123. A. C. A. Arevian, V. Kapoor, and N. N. N. N. Urban, "Activity-dependent gating of lateral inhibition in the mouse olfactory bulb.," Nature neuroscience, vol. 11, no. 1, pp. 80-7, 2008. 
124. N. N. Urban and A. C. Arevian, "Computing with dendrodendritic synapses in the olfactory bulb," Annals of the New York Academy of Sciences, vol. 1170, pp. 264-269, 2009.

125. G. Lowe, "Olfactory Bulb: Synaptic Organisation,” eLS, pp. 1-10, 2013.

126. F. Cavarretta, A. Marasco, M. L. Hines, G. M. Shepherd, and M. Migliore, "Glomerular and Mitral-Granule Cell Microcircuits Coordinate Temporal and Spatial Information Processing in the Olfactory Bulb.," Frontiers in computational neuroscience, vol. 10, no. July, p. 67, 2016.

127. M. Bazhenov, M. Stopfer, M. Rabinovich, R. Huerta, H. D. I. Abarbanel, T. J. Sejnowski, and G. Laurent, "Model of transient oscillatory synchronization in the locust antennal lobe," Neuron, vol. 30, no. 2, pp. 553-567, 2001.

128. R. W. Friedrich, "Dynamic Optimization of Odor Representations by Slow Temporal Patterning of Mitral Cell Activity," Science, vol. 291, no. 5505, pp. 889-894, 2001.

129. N. Ravel, P. Chabaud, C. Martin, V. Gaveau, E. Hugues, C. Tallon-Baudry, O. Bertrand, and R. Gervais, "Olfactory learning modifies the expression of odour-induced oscillatory responses in the gamma $(60-90 \mathrm{~Hz})$ and beta $(15-40 \mathrm{~Hz})$ bands in the rat olfactory bulb," European Journal of Neuroscience, vol. 17, no. 2, pp. 350-358, 2003.

130. D. Friedman, "Both Electrical and Chemical Synapses Mediate Fast Network Oscillations in the Olfactory Bulb," Journal of Neurophysiology, vol. 89, no. 5, pp. 2601-2610, 2003.

131. K. MacLeod and G. Laurent, "Distinct Mechanisms for Synchronization and Temporal Patterning of Odor-Encoding Neural Assemblies," Science, vol. 274, no. 5289, pp. 976979, 1996.

132. N. E. Schoppa, "Synchronization of olfactory bulb mitral cells by precisely timed inhibitory inputs.," Neuron, vol. 49, pp. 271-83, jan 2006.

133. B. Bathellier, S. Lagier, P. Faure, and P.-M. Lledo, "Circuit Properties Generating 
Gamma Oscillations in a Network Model of the Olfactory Bulb," Journal of Neurophysiology, no. 95, pp. $2678-2691,2006$.

134. S. Marella and B. Ermentrout, "Amplification of asynchronous inhibition-mediated synchronization by feedback in recurrent networks," PLoS Computational Biology, vol. 6, no. 2, 2010.

135. T. S. McTavish, M. Migliore, G. M. Shepherd, and M. L. Hines, "Mitral cell spike synchrony modulated by dendrodendritic synapse location.," Frontiers in computational neuroscience, vol. 6, p. 3, jan 2012.

136. Y. Hayashi, A. Momiyama, T. Takahashi, H. Ohishi, R. Ogawa-Meguro, R. Shigemoto, N. Mizuno, and S. Nakanishi, "Role of a Metabotropic Glutamate Receptor in Synaptic Modulation in the Accessory Olfactory Bulb," Nature, vol. 366, no. 6456, pp. 687-90, 1993.

137. J. Bischofberger and D. Schild, "Glutamate and N-acetylaspartylglutamate block HVA calcium currents in frog olfactory bulb interneurons via an mGluR2/3-like receptor.," Journal of neurophysiology, vol. 76, no. 3, pp. 2089-2092, 1996.

138. J. S. Isaacson and H. Vitten, "GABA(B) receptors inhibit dendrodendritic transmission in the rat olfactory bulb.," The Journal of neuroscience : the official journal of the Society for Neuroscience, vol. 23, no. 6, pp. 2032-2039, 2003.

139. T. Heinbockel, N. Laaris, and M. Ennis, "Metabotropic glutamate receptors in the main olfactory bulb drive granule cell-mediated inhibition.," Journal of neurophysiology, vol. 97, no. 1, pp. 858-870, 2007.

140. P. Duchamp-Viret, V. Coronas, J. C. Delaleu, E. Moyse, and A. Duchamp, "Dopaminergic modulation of mitral cell activity in the frog olfactory bulb: A combined radioligand binding-electrophysiological study," Neuroscience, vol. 79, no. 1, pp. 203-216, 1997.

141. I. G. Davison, J. D. Boyd, and K. R. Delaney, "Dopamine inhibits mitral/tufted-> granule cell synapses in the frog olfactory bulb.," The Journal of neuroscience : the official journal of the Society for Neuroscience, vol. 24, pp. 8057-67, sep 2004. 
142. J. D. Boyd and K. R. Delaney, "Tyrosine hydroxylase-immunoreactive interneurons in the olfactory bulb of the frogs Rana pipiens and Xenopus laevis.," The Journal of comparative neurology, vol. 454, pp. 42-57, dec 2002.

143. P. Panula, A. V. Revuelta, D. L. Cheney, J.-Y. Wu, and E. Costa, "An immunohistochemical study on the location of GABAergic neurons in rat septum," The Journal of comparative neurology, vol. 222, no. 1, pp. 69-80, 1984.

144. L. Záborszky, J. Carlsen, H. R. Brashear, and L. Heimer, "Cholinergic and GABAergic afferents to the olfactory bulb in the rat with special emphasis on the projection neurons in the nucleus of the horizontal limb of the diagonal band.," The Journal of comparative neurology, vol. 243, no. 4, pp. 488-509, 1986.

145. F. J. Gracia-Llanes, C. Crespo, J. M. Blasco-Ibáñez, J. Nacher, E. Varea, L. RoviraEsteban, and F. J. Martínez-Guijarro, "GABAergic basal forebrain afferents innervate selectively GABAergic targets in the main olfactory bulb," Neuroscience, vol. 170, no. 3, pp. 913-922, 2010.

146. I. Kratskin, N. Kenigfest, J. Repérant, J. P. Rio, and N. Vesselkin, "Presumptive GABAergic feedback input to the frog olfactory bulb: a double labelling study with retrograde axonal tracing and GABA immunohistochemistry," Brain Research, vol. 581, no. 1, pp. 171-174, 1992.

147. M. T. Shipley, F. J. Halloran, and J. de la Torre, "Surprisingly rich projection from locus coeruleus to the olfactory bulb in the rat," Brain Research, vol. 329, no. 1-2, pp. 294-299, 1985.

148. J. H. Mclean, M. T. Shipley, W. T. Nickell, G. Aston-Jones, and C. K. Reyher, "Chemoanatomical organization of the noradrenergic input from locus coeruleus to the olfactory bulb of the adult rat.," The Journal of Comparative Neurology, vol. 285, no. 3, pp. 339-349, 1989.

149. D. Czesnik, L. P. Nezlin, J. Rabba, B. Müller, and D. Schild, "Noradrenergic modulation of calcium currents and synaptic transmission in the olfactory bulb of Xenopus laevis tadpoles," European Journal of Neuroscience, vol. 13, no. 6, pp. 1093-1100, 2001. 
150. D. Czesnik, W. Rössler, F. Kirchner, A. Gennerich, and D. Schild, "Neuronal representation of odourants in the olfactory bulb of Xenopus laevis tadpoles," European Journal of Neuroscience, vol. 17, no. 1, pp. 113-118, 2003.

151. L. B. Haberly and J. L. Price, "Association and commissural fiber systems of the olfactory cortex of the rat. II. Systems originating in the olfactory peduncle.," The Journal of comparative neurology, vol. 181, no. 4, pp. 781-807, 1978.

152. M. T. Shipley and G. D. Adamek, "The connections of the mouse olfactory bulb: a study using orthograde and retrograde transport of wheat germ agglutinin conjugated to horseradish peroxidase," Brain research bulletin, vol. 12, no. 6, pp. 669-688, 1984.

153. A. M. Boyd, J. F. Sturgill, C. Poo, and J. S. Isaacson, "Cortical Feedback Control of Olfactory Bulb Circuits," Neuron, vol. 76, no. 6, pp. 1161-1174, 2012.

154. A. Nunez-Parra, Regulation of the inhibitory drive in the olfactory bulb. PhD thesis, 2013.

155. C. Mazo, G. Lepousez, A. Nissant, M. T. Valley, and P.-M. Lledo, "GABAB Receptors Tune Cortical Feedback to the Olfactory Bulb," The Journal of Neuroscience, vol. 36, no. 32, pp. 8289-8304, 2016.

156. D. Arruda, R. Publio, and A. C. Roque, "The periglomerular cell of the olfactory bulb and its role in controlling mitral cell spiking: a computational model.," PloS one, vol. 8, p. e56148, jan 2013.

157. B.-J. Lin, T.-W. Chen, and D. Schild, "Cell type-specific relationships between spiking and $[\mathrm{Ca} 2+] \mathrm{i}$ in neurons of the Xenopus tadpole olfactory bulb.," The Journal of physiology, vol. 582, pp. 163-75, jul 2007.

158. U. Scheidweiler, L. P. Nezlin, J. Rabba, B. Müller, and D. Schild, "Slice culture of the olfactory bulb of Xenopus laevis tadpoles.," Chemical senses, vol. 26, pp. 399-407, may 2001.

159. I. Manzini, T.-S. Schweer, and D. Schild, "Improved fluorescent (calcium indicator) 
dye uptake in brain slices by blocking multidrug resistance transporters.," Journal of neuroscience methods, vol. 167, pp. 140-7, jan 2008.

160. T. Hassenklöver, L. P. Pallesen, D. Schild, and I. Manzini, "Amino acid- vs. peptideodorants: responses of individual olfactory receptor neurons in an aquatic species.," PloS one, vol. 7, p. e53097, jan 2012.

161. D. Schild, "A computer-controlled device for the application of odours to aquatic animals.," J Electrophysiol Techn., vol. 12, pp. 71-79, 1985.

162. J. Eilers and A. Konnerth, "Dye loading with patch pipettes," Cold Spring Harbor Protocols, 2009.

163. D. R. Myatt, T. Hadlington, G. A. Ascoli, and S. J. Nasuto, "Neuromantic - from semi-manual to semi-automatic reconstruction of neuron morphology.," Frontiers in neuroinformatics, vol. 6, no. March, p. 4, 2012.

164. G. Bao and D. Schild, "Fast and accurate fitting and filtering of noisy exponentials in Legendre space," PLoS ONE, vol. 9, no. 3, pp. 1-11, 2014.

165. W. Xiong and W. R. Chen, "Dynamic gating of spike propagation in the mitral cell lateral dendrites," Neuron, vol. 34, no. 1, pp. 115-126, 2002.

166. G. Lowe, "Inhibition of backpropagating action potentials in mitral cell secondary dendrites.," Journal of neurophysiology, vol. 88, no. 1, pp. 64-85, 2002.

167. D. L. Bartel, L. Rela, L. Hsieh, and C. A. Greer, "Dendrodendritic synapses in the mouse olfactory bulb external plexiform layer," Journal of Comparative Neurology, vol. 523, no. 8, pp. 1145-1161, 2015.

168. M. E. Feder and W. W. Burggren, Environmental physiology of the amphibians. University of Chicago Press, 1992.

169. K. D. Wells, The ecology and behavior of amphibians. University of Chicago Press, 2010.

170. A. Brinkmann and D. Schild, "One Special Glomerulus in the Olfactory Bulb of Xenopus laevis Tadpoles Integrates a Broad Range of Amino Acids and Mechanical Stimuli," Journal of Neuroscience, vol. 36, no. 43, pp. 10978-10989, 2016. 
171. L. Almli and W. Wilczynski, "Regional distribution and migration of proliferating cell populations in the adult brain of Hyla cinerea (Anura, Amphibia)," Brain Research, vol. 1159, no. 1, pp. 112-118, 2012.

172. O. Gschwend, N. M. Abraham, S. Lagier, F. Begnaud, I. Rodriguez, and A. Carleton, "Neuronal pattern separation in the olfactory bulb improves odor discrimination learning," Nature Neuroscience, no. August, 2015.

173. K. Gödde, O. Gschwend, D. Puchkov, C. K. Pfeffer, A. Carleton, and T. J. Jentsch, "Disruption of Kcc2-dependent inhibition of olfactory bulb output neurons suggests its importance in odour discrimination," Nature Communications, vol. 7, no. May, p. 12043, 2016.

174. D. W. Wesson, J. V. Verhagen, and M. Wachowiak, "Why sniff fast? The relationship between sniff frequency, odor discrimination, and receptor neuron activation in the rat.," Journal of neurophysiology, vol. 101, no. 2, pp. 1089-1102, 2009.

175. R. M. Carey and M. Wachowiak, "Effect of sniffing on the temporal structure of mitral/tufted cell output from the olfactory bulb," vol. 31, no. 29, pp. 10615-10626, 2011.

176. M. Popovic, X. Gao, and D. Zecevic, "Voltage-sensitive dye recording from axons, dendrites and dendritic spines of individual neurons in brain slices.," Journal of visualized experiments : JoVE, no. 69, p. e4261, 2012. 


\section{Acknowledgements}

I am forever indebted to You, Father, for without Your unfailing love, support and constant guidance, none of this work would have been possible.

I wish to express my sincere thanks to my supervisor Prof. Dr. Dr. Detlev Schild for letting me join his interdisciplinary lab combining research across the fields of Neuroscience, (Bio)physics, and Molecular Biology. Though initially feeling a stranded (neuro)biologist in this new environment, I came to appreciate the fruitful working atmosphere. Thank you for the opportunity to practice working independently and explore new ideas with an open and curious, yet critical mind.

I would like to thank Prof. Dr. André Fiala and Prof. Dr. Nils Brose for their smooth co-supervision over the past 4 years and for their readiness to accommodate their busy schedules for our meetings. At the same time, I would like to acknowledge Prof. Dr. Michael Hörner, Prof. Dr. Swen Hülsmann, and Prof. Dr. Stefan Schütz for setting apart some of their precious time to assess and evaluate this thesis.

My gratitude also goes to the European Neuroscience Campus-Network led by Prof. Dr. Arjen Brussaard, with the help of the Maaike Leusden. Thank you for your eagerness to foster, support and challenge young neuroscientists in their scientific endeavours and help them broaden their horizons. I absolutely loved being part of this network of lovely and brilliant people, and felt privileged to travel all over Europe to "rack my brains" at inspiring conferences and meetings, thanks to the scholarship granted by Erasmus Mundus.

I am very grateful for the support the CMPB programme coordinated by Prof. Dr. Michael Hörner. Michael, thank you for the amazing framework provided to all of us, CMPB students, as for your readiness to help us with any issue and guide us along this great $\mathrm{PhD}$ journey.

I will not forget to thank the GGNB Office for supporting me financially with their Bridging Fund during the final stretch of my $\mathrm{PhD}$.

Furthermore, I also would like to address a word of thanks to Prof. Dr. Huib Mansvelder and Dr. Rhiannon Meredith for allowing me to visit their lab, for the opportunity to discuss my work with them, and their encouragement to focus on my research.

Swen, my deepest thanks for giving me complete freedom to work in your lab over the 
last year. I truly enjoyed it.

My heartfelt thanks go to the core group of my colleagues with whom I had to pleasure to work alongside these past 4 years. Mihai, you are the wisest and the calmest of us all. Thank you for patiently solving my MATLAB issues and for proof-reading my thesis in an unprecedented record time. Bao, thank you for your readiness to help at all levels possible, whether it meant being our Ringer's Hero or fixing a broken setup. Jakob, thanks for rounding us up almost every day and for making us smile during lunch breaks. Alexander and Daniëlle, we started as colleagues...and became friends. Thank you for you always lending listening ears, and for advising and encouraging me throughout this $\mathrm{PhD}$. Alex, you know how much I appreciated our collaboration. Things turned out quite well for these young moles, eventually. Thanks for boosting me during the writing phase! Lieve Daan, dankjewel voor je vriendschap en liefde. We were meant to meet, and I am so thankful for that.

To all my beloved brothers and sisters who supported me with their love and prayers, a thousands thanks. To the Doctors among us, Betty, Helge, Filip, Kevin, Raphael, Tino, Yiling, thank you for showing me the way with and without words. Christina, I don't even know how to thank you for delivering a warm dinner at my lab every day during the writing phase. I will dearly miss you and your tasty Indian cooking.

Clélia, ma tendre amie d'enfance, merci de m'avoir toujours soutenue ces dix dernières années. Comme il se dit en anglais, "10 years and counting!"

Mr \& Mme Tchouateu (Muti!), merci pour tout. Je bénis le SEIGNEUR d'avoir permis que nous nous rencontrions.

Jihane, bien-aimée, tu fus, et restes envers moi une Epaphras. Merci jumelle. NZAMBE a pambola yo.

Jean, merci de m'avoir acceptée et d'avoir été un père pour moi durant mon adolescence. Tu as contribué à mon développement, et tu restes dans mon coeur.

Mam, merci pour tous les sacrifices que tu as acceptés afin que DIEU m'amène si loin. Cette thèse de doctorat est aussi ta réussite. Je t'aime. 


\title{
Curriculum Vitae
}

\author{
Camille Inès Alexandra OKOM \\ Place of birth: Strasbourg, France \\ Date of birth: 4 May 1990 \\ camille.okom@gmail.com
}

\section{EDUCATION}

- 2012-present: Doctoral thesis at the Institute of Neurophysiology and Cellular Biophysics (Department head and supervisor: Prof. Dr. Detlev Schild) GEORG-AUGUST UNIVERSITY OF GOETTINGEN, Goettingen, Germany

Göttingen Graduate School for Neurosciences, Biophysics, and Molecular Biosciences Major track: Molecular Physiology of the Brain

- 2010-2012: Research M.Sc Neuroscience \& Cognition UTRECHT UNIVERSITY, Utrecht, The Netherlands Graduate School of Life Sciences Major track: Experimental and Clinical Neuroscience Final GPA: 4.0

- 2007-2010: B.Sc Life Sciences \& Biology (with Honours) UNIVERSITE PIERRE ET MARIE CURIE, Paris, France Faculty of Life Sciences

- 2003-2006: GCE A-Levels "Baccalauréat Scientifique" (with Honours) LYCEE MARCELIN BERTHELOT, Saint-Maur, France

\section{GRANTS \& SCHOLARSHIPS}

- 2016: GGNB Bridging Stipend (October-December)

- 2012-2015: Scholarship awarded by the European Neuroscience Campus Network (an Erasmus Mundus Joint Doctoral programme)

- 2011: Neuroscience \& Cognition Utrecht (NCU) Scholarship

- 2010: EOLE Grant, awarded by the Réseau Franco-Néerlandais (Franse-Nederlandse Academie)

\section{ACADEMIC ACTIVITIES}

- Student representative

- Member of the Board of Fellows of the European Neuroscience Campus Network (2013-present) 


\section{- Invited speaker}

- Invited talk entitled "Olfactory coding in Xenopus laevis larvae" for XLAB visiting students from Granada and Valladolid (July 2014)

- Invited talk entitled "Studying at Utrecht University" at the Orientation Day for international students (Feb. 2011)

\section{- Intern supervisor}

- Supervision of a laboratory rotation project (M.Sc student: Sarah Wibbeke) Project title: "Do mitral cells in the olfactory bulb of larval Xenopus laevis project to more than one glomeruli? Preliminary experiments to a combined morphological and functional approach." (Feb.-May 2014)

- Supervision of a laboratory rotation project (M.Sc student: Michael Feyerabend) Project title: "Mitral cell connectivity in the olfactory bulb of Xenopus laevis" (Jan.-Feb. 2014)

- Tutorial for M.Sc/Ph.D Neuroscience students: Introduction to fluorescence microscopy and (non-)confocal imaging (Oct. 2013, Oct. 2015)

\section{- Conference organiser}

- Member of the organising committee of the "Game of Brains" Ph.D Symposium 2013

Task: Contact person for the speakers (June-Oct. 2013)

- Member of the organising committee of the "Mind The Brain" Symposium 2011

Task: Public Relations \& Sponsorship (Nov. 2010-Apr. 2011)

\section{PEER-REVIEWED PUBLICATIONS}

Brinkmann, A., Okom, C. , Kludt, E., Schild, D. Recording Temperature-induced Neuronal Activity through Monitoring Calcium Changes in the Olfactory Bulb of Xenopus laevis. J. Vis. Exp. (112), e54108, doi:10.3791/54108 (2016).

Open access link: http://www. jove.com/video/54108/

Kludt, E., Okom, C., Brinkmann, A., Schild, D. Integrating Temperature with Odor Processing in the Olfactory Bulb. The Journal of Neuroscience, 35(20), 7892-7902. (2015).

\section{CONFERENCE ABSTRACTS}

Kludt, E., Okom, C., Brinkmann, A., Schild, D. (Poster)

Integrating temperature with odor processing in the olfactory bulb

$10^{\text {th }}$ FENS Forum 2016, July 2016, Copenhagen, Denmark

Camille Okom, Detlev Schild (Talk)

Imaging the granule cell-mediated inhibition of mitral cells

Talk title: "Network activity in the olfactory bulb: excitation, inhibition and synchrony"

ENCODS 2016, July 2016, Elsinore, Denmark

S. Junek, T-W. Chen, C. Okom, M. Alevra, D. Schild (Poster)

Visualising activity and structure of neural networks with Activity Correlation Imaging

ENCODS 2013, April 2013, Bordeaux, France

C.I.A. Okom, M. Trejo, E. Masliah, H.W. Kessels (Poster)

The role of mitochondria in GluR1 trafficking and synthesis

$10^{\text {th }}$ Dutch Endo-Neuro-Psycho Meeting, May 2012, Lunteren, The Netherlands 
C.I.A. Okom, E.R.E. Schmidt, R.J. Pasterkamp (Talk)

Molecular mechanisms driving the organisation of mesodiencephalic dopaminergic fibers in the fasciculus retroflexus

Talk title: "Molecular mechanisms regulating the organisation of the mesohabenular dopamine circuitry"

$9^{\text {th }}$ Dutch Endo-Neuro-Psycho Meeting, May 2011, Lunteren, The Netherlands

MISCELLEANOUS

Languages:

- French (native)

- English (fluent)

- German (proficient)

- Dutch (basic) 